Article

\title{
Modification of Aquifer Pore-Water by Static Diffusion Using Nano-Zero-Valent Metals
}

\author{
David D. J. Antia
}

DCA Consultants Ltd., Haughend, Bridge of Earn Road Dunning, Perthshire, PH2 9BX, Scotland, UK; E-Mail: dcacl@btconnect.com; Tel.: +44-1764-64664

Received: 5 December 2010; in revised form: 24 December 2010 / Accepted: 6 January 2011 / Published: 11 January 2011

\begin{abstract}
Sixteen static diffusion reactors containing n-ZVM $\left(\mathrm{Fe}^{0}, \mathrm{Cu}^{0}, \mathrm{Al}^{0}\right)$ establish a common equilibrium redox (Eh-pH) trajectory which is directly linked to the aquifer pore volume, volume of injected n-ZVM, throughflow rate within the aquifer and time. The effect of $\mathrm{NaCl}$ and $\mathrm{Ca}$-montmorillonite on the trajectory is considered. The trajectory can be directly linked to TDS (EC) and to the equilibrium removal of contaminants. In each example, the progressive oscillation between reduction and oxidation reactions (including Fenton reactions) creates the catalytic nuclei (and redox environment) required for the decomposition of organic pollutants and their reconstruction as simple alkanes and oxygenates.
\end{abstract}

Keywords: zero valent iron; ZVI; zero valent metal; ZVM; TCE; DCE; desalination; decontamination; aquifer

\section{Introduction}

Modification of the aquifer/reservoir redox ( $\mathrm{Eh}, \mathrm{pH}$ ) environment and the formation of Fe ions (as active catalytic sites) are essential prerequisites [1] for in situ reservoir (i) decontamination/remediation, (ii) dechlorination of organic contaminants [1-9], (iii) desalination, and (iv) catalytic oil restructuring (e.g., as part of an enhanced oil recovery scheme).

A number of pilot projects have used (i) $n-\mathrm{Fe}^{0}$ injection (IZVM) [1,10-16] and (ii) the placement of permeable reactive barriers (PRB) containing $n-\mathrm{Fe}^{0}$ within flow paths located in an aquifer to modify 
the pore-water redox by static diffusion [1,17-23]. Remediation is a direct result of the change in redox environment. The equilibrium concentration of each contaminant varies with $\mathrm{Eh} / \mathrm{pH}$.

Flow through permeable, or semi-permeable, barriers is not homogenous (e.g., PRB). Flow is characterized by the development of mesopores, macropores and natural pipes [1,24-27] where only a small part of the throughflow has direct contact with the matrix/particles of the barrier [25-27]. The principal mechanism for redox modification of the throughflow is static diffusion within the macropores.

ZVM research has focused on determining n-ZVM kinetic reaction rates [28] over a period of minutes or hours [29,30] or months [28]. Reaction kinetics are important in a simple closed system reactor design, but are largely irrelevant in the design of IZVM (injected ZVM program) or a ZVM PRB in a more complex open or semi-open aquifer buffer environment.

ZVM aquifer geoengineering requires [1] an understanding of the inter-relationship between $\mathrm{pH}, \mathrm{Eh}$, and space velocity (SV) during the design of a $n-Z V M$ permeable reactive barrier (PRB) or injected ZVM (IZVM) program. This is to allow quantitative modelling of the expected changes in aquifer redox environment as a function of time, injection/infiltration rates, and aquifer flow rates.

The impact of changing water salinity, or the presence of clays, on the inter-relationship between $\mathrm{pH}$, Eh, and space velocity is poorly understood. Following n-ZVM injection, the aquifer Eh, $\mathrm{pH}$ varies with time and SV [12,14]. Static diffusion studies [1] using m-ZVM have established a redox trajectory which can be directly linked to time and SV. The linkage to SV allows continuous flow reactors to target a constant product water $\mathrm{Eh}, \mathrm{pH}$, with a consistent level of water treatment. The same strategy cannot be applied to fixed bed reactors containing n-ZVM (due to loss of permeability with time) but may be applicable to fluidised bed reactors or slurry reactors containing n-ZVM. These reactors can contain clays (e.g., montmorillonite). The large pore size and particle size associated with $\mathrm{m}-\mathrm{ZVM}$ results in a relatively high degree of variance associated with the redox trajectory (with time and SV) [1]. n-ZVM has a smaller particle size and pore size. In a continuous flow fixed bed reactor, this results (when compared with $\mathrm{m}-\mathrm{ZVM}$ ) in a higher Eh and $\mathrm{pH}$ associated with a specific flow rate and SV. This, in turn, reduces both the level of water treatment control and the types of contaminant which may be removed using a continuous flow fixed bed water treatment reactor.

This study seeks to address these issues by investigating the change in pore-water redox (with $\mathrm{n}-\mathrm{ZVM}$, salinity and clay presence) associated with static diffusion using sixteen static diffusion micro-reactors, SDR, (MR1-MR16). The observed relationships between SV (Equations 1 and 2), and $\mathrm{Eh}, \mathrm{pH}, \mathrm{EC}$ and water salinity + clay presence can be used to design a geoengineered redox transformation of an aquifer. They can also be used to predict the expected behavior of pore-water modification programs associated with injected n-ZVM and n-ZVM permeable reactive barriers. Similar relationships for $\mathrm{m}-\mathrm{ZVM}$ have been presented elsewhere [1] together with a detailed methodology for their application in designing ZVM aquifer treatment.

$$
\mathrm{SV}\left(\mathrm{m}^{3} \mathrm{H}_{2} \mathrm{O} \mathrm{h}^{-1} \mathrm{~m}^{-3} \mathrm{n}-\mathrm{ZVM}\right)=\left(\mathrm{V}_{\mathrm{w}} / \mathrm{V}_{\mathrm{c}}\right) / \mathrm{R}_{\mathrm{t}}
$$

$\mathrm{V}_{\mathrm{w}}=$ Water volume, $\mathrm{m}^{3} ; \mathrm{V}_{\mathrm{c}}=$ nano-metal volume, $\mathrm{m}^{3} ; \mathrm{R}_{\mathrm{t}}=$ Average time spent by each $\mathrm{m}^{3}$ of water in the reactor, $h$. For a static water body $\mathrm{R}_{\mathrm{t}}=$ time; For a flowing water body within a aquifer, $\mathrm{SV}\left(\mathrm{m}^{3} \mathrm{H}_{2} \mathrm{O} \mathrm{h}^{-1} \mathrm{~m}^{-3} \mathrm{n}-\mathrm{ZVM}\right)$ can be calculated as 


$$
\mathrm{SV}\left(\mathrm{m}^{3} \mathrm{H}_{2} \mathrm{O} \mathrm{h}^{-1} \mathrm{~m}^{-3} \mathrm{n}-\mathrm{ZVM}\right)=\left(\mathrm{V}_{\mathrm{wf}} / \mathrm{V}_{\mathrm{c}}\right)
$$

where $\mathrm{V}_{\mathrm{wf}}=$ Flowing water volume, $\mathrm{m}^{3} \mathrm{~h}^{-1}$.

\section{Materials and Methods}

Measurements were made of $E C, E h, p H$, and temperature using Hanna HI-98120 (ORP/Temperature, Hanna Calibration Number = 24230), Hanna HI-98129 (pH, EC, TDS, Temperature; Hanna Calibration Number $=33999)$. Hi-98120 is factory calibrated. HI-98129 was calibrated using Hanna test reagents ( $p H$ buffer solutions 4.01, 7.01, 10.01 (HI-7004, HI-7007,

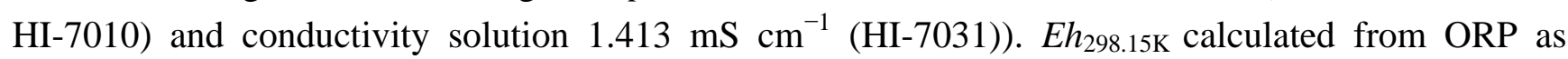
$E h=$ ORP $\left(298.15 / \mathrm{T}_{\mathrm{o}}\right) . \mathrm{T}_{\mathrm{o}}=$ measured temperature, K. TDS (Total dissolved solids, ppm) $=E C$ $\left(\mathrm{mS} \mathrm{cm} \mathrm{cm}^{-1}\right) \times F \times 10^{3} . F=$ a factor (e.g., 0.5). The untreated test water $(p H=6.2-7.1$, $E h=0.034-0.185 \mathrm{~V})$ was extracted from an unconfined infiltration reservoir in fractured Devonian (Old Red Sandstone Volcanic Series, Ochil Hills, UK) basalts.

\subsection{Experimental Micro-SDR}

Static diffusion was examined in four different environments:

1. Fresh water containing n-ZVM (MR1-MR6)—Figures A1-A6 in Appendix.

2. Saline water containing n-ZVM (MR7, MR8)_Figures A7 and A8 in Appendix.

3. Fresh water containing n-ZVM + Ca-montmorillonite (MR9-MR11) Figures A9-A11 in Appendix.

4. Saline water containing n-ZVM + Ca-montmorillonite (MR12-MR16)Figures A12-A16 in Appendix.

Each micro-SDR (0.07 m internal diameter) contained $0.0032 \mathrm{~m}^{3} \mathrm{H}_{2} \mathrm{O}$ [(MR1-5); $0.002 \mathrm{~m}^{3} \mathrm{H}_{2} \mathrm{O}$ (MR6-16)] with nano-zero valent metal (n-ZVM) placed at the base of the reactor. The n-ZVM occupied between 1.2\% (MR1, MR2, MR6) and 4.4\% (MR16) of the stored water volume. The standard ZVM quantities used in each $\mathrm{SDR}$ are $\mathrm{Fe}^{0}=18 \mathrm{gms} ; \mathrm{Cu}^{0}=2.8 \mathrm{gms} ; \mathrm{Al}^{0}=4.6 \mathrm{gms}$; Ca-montmorillonite $=12.5 \mathrm{gms}$. The $\mathrm{n}-\mathrm{ZVM}$ is constructed as ground high purity metal $(<66,000 \mathrm{~nm})$. The Ca-montmorillonite was added as anhydrous granules $(1-5 \mathrm{~mm})$. This clay swells and flocculates in the presence of water to create a clay containing $\mathrm{n}-\mathrm{ZMV}$. The static diffusion test results are placed in Appendix, Figures A1-A16. The water used in MR6 (Figure A6 in Appendix) contains dissolved organic matter (DOM) derived from chicken manure fertiliser.

\subsection{Characterization of $n-Z V M$}

The n-ZVM powders used are illustrated elsewhere [1] and have a particle size of 44,000-66,000 $\mathrm{nm}$ (mesh size: $\mathrm{BSS}=240-350$; Tyler $=250-325$; US $=230-325)$. The surface area of the $\mathrm{n}-\mathrm{ZVM}$ used in this study varies from $0.00289-0.01732 \mathrm{~m}^{2} \mathrm{~g}^{-1}$ (Table 1). This type of powder is produced by grinding metal. Most n-ZVM used in water treatment is produced by precipitating $n-Z V M$ onto a skeleton in order to maximize n-ZVM surface area. 
Consequently the surface areas of the n-ZVM used in this study are substantially lower than the typical BET surface area of $35 \mathrm{~m}^{2} \mathrm{~g}^{-1}$ precipitated $\mathrm{n}-\mathrm{Pd} / \mathrm{Fe}($ median particle size $=60 \mathrm{~nm})[31,32]$ and commercially available $\mathrm{n}-\mathrm{Fe}$ powder $(<10 \mathrm{~nm})$, surface area of $0.9 \mathrm{~m}^{2} \mathrm{~g}^{-1}$ [32]. Most precipitated $\mathrm{n}-\mathrm{Fe}^{0}$ powders and powders derived from the reduction of ferrous iron used in water treatment have a BET surface area of about $30 \mathrm{~m}^{2} \mathrm{~g}^{-1}$ [33]. Larger grain size powders (e.g., 800-2800 nm) may have surface areas of $6-15 \mathrm{~m}^{2} \mathrm{~g}^{-1}$ [34]. Surface areas of $50-600 \mathrm{~m}^{2} \mathrm{~g}^{-1}$ are associated with $\mathrm{n}-\mathrm{Fe}^{0}$ produced by reduction of iron oxide nanoparticles $(<30 \mathrm{~nm})[35]$.

Table 1. Relationship between $\mathrm{Fe}^{0}$ particle size and surface area $\left(\mathrm{m}^{2} \mathrm{~g} \mathrm{Fe}^{0}\right)$, where the $\mathrm{n}-\mathrm{Fe}^{0}$ is produced by grinding $\mathrm{Fe}^{0} .1 \mathrm{~nm}=10^{-9} \mathrm{~m}$. The nano-particles examined in this study have a grain size of $0.044-0.066 \mathrm{~mm}$.

\begin{tabular}{|c|c|c|c|c|c|c|c|}
\hline \multirow[b]{2}{*}{$\begin{array}{r}\text { Size } \\
\mathrm{m}\end{array}$} & \multirow[b]{2}{*}{$\begin{array}{l}\text { Size } \\
\mathrm{mm} \\
\end{array}$} & \multicolumn{3}{|c|}{ Spherical Form } & \multicolumn{3}{|l|}{ Cube Form } \\
\hline & & $\begin{array}{r}\text { Grain Area } \\
\mathrm{m}^{2}\end{array}$ & $\begin{array}{r}\text { Grain Weight } \\
\text { g }\end{array}$ & $\begin{array}{l}\text { Surface area } \\
\mathrm{m}^{2} \mathrm{~g} \mathrm{Fe}^{0}\end{array}$ & $\begin{array}{r}\text { Grain Area } \\
\mathrm{m}^{2}\end{array}$ & $\begin{array}{r}\text { Grain Weight } \\
\text { g }\end{array}$ & $\begin{array}{l}\text { Surface area } \\
\mathrm{m}^{2} \mathrm{~g} \mathrm{Fe}^{0}\end{array}$ \\
\hline $2.0010^{-03}$ & 2 & $1.2610^{-05}$ & $3.3010^{-02}$ & 0.00038 & $6.0010^{-06}$ & $6.3010^{-02}$ & 0.00010 \\
\hline $1.0010^{-03}$ & 1 & $3.1410^{-06}$ & $4.1210^{-03}$ & 0.00076 & $1.5010^{-06}$ & $7.8710^{-03}$ & 0.00019 \\
\hline $5.0010^{-04}$ & 0.5 & $7.8510^{-07}$ & $5.1510^{-04}$ & 0.00152 & $3.7510^{-07}$ & $9.8410^{-04}$ & 0.00038 \\
\hline $1.0010^{-04}$ & 0.1 & $3.1410^{-08}$ & $4.1210^{-06}$ & 0.00762 & $1.5010^{-08}$ & $7.8710^{-06}$ & 0.00191 \\
\hline $6.6010^{-05}$ & 0.066 & $1.3710^{-08}$ & $1.1910^{-06}$ & 0.01155 & $6.5310^{-09}$ & $2.2610^{-06}$ & 0.00289 \\
\hline $4.4010^{-05}$ & 0.044 & $6.0810^{-09}$ & $3.5110^{-07}$ & 0.01732 & $2.9010^{-09}$ & $6.7110^{-07}$ & 0.00433 \\
\hline $1.0010^{-06}$ & 0.001 & $3.1410^{-12}$ & $4.1210^{-12}$ & 0.76200 & $1.5010^{-12}$ & $7.8710^{-12}$ & 0.19050 \\
\hline $1.0010^{-07}$ & 0.0001 & $3.1410^{-14}$ & $4.1210^{-15}$ & 7.62002 & $1.5010^{-14}$ & $7.8710^{-15}$ & 1.90500 \\
\hline $1.0010^{-08}$ & 0.00001 & $3.1410^{-16}$ & $4.1210^{-18}$ & 76.20015 & $1.5010^{-16}$ & $7.8710^{-18}$ & 19.05004 \\
\hline
\end{tabular}

\subsubsection{Negative activation energies}

Historically $\mathrm{n}-\mathrm{ZVM}$ is treated as a catalyst whereby the effectiveness of the $\mathrm{n}-\mathrm{ZVM}$ is assumed to be a function of the $\mathrm{n}-\mathrm{ZVM}$ surface area $\left(\mathrm{m}^{2} \mathrm{~g} \mathrm{Fe}^{0}\right)$. The assumption made (in accordance with standard catalyst theory) is that increasing surface area will increase the availability of active sites and the ability for adsorption/desorption reactions to occur on/in the catalyst. These reactions are typically characterized by positive activation energies. It has been demonstrated [1] that n-ZVM associated reactions are essentially fluid phase electrochemical reactions (or contact surface reactions) where the principal controls on remediation are the $\mathrm{H}^{+}: \mathrm{OH}^{-}$ratio $(\mathrm{pH})$ and the $\mathrm{HO}_{2}{ }^{-}: \mathrm{OH}^{-}$ratio (Eh) in the fluid. Eh and $\mathrm{pH}$ alteration of pore water chemistry is electrochemical [1] and not purely catalytic.

The low surface area of the n-ZVM used in this study (Table 1) will result in a domination of fluid, electrochemical (and surface) reactions. The principal control on remediation is switched from catalytic adsorption/desorption reactions over the n-ZVM surface area to the impact of the electrochemical environment in the fluid created by the presence of the $n-Z V M$. This forces reaction selectivity towards reactions which have negative activation energies (e.g., reaction rate increases with decreasing temperature) and fluid/surface reactions which involve $\mathrm{OH}, \mathrm{O}$, methylene and halogen species (i.e., reactions which are directly controlled by $p H$ and $E h$ ). Negative activation energies are also associated with the interaction of methylene (e.g., $\mathrm{ZVM}^{-\mathrm{CH}_{3}}$ ) and halogen species (e.g., $\mathrm{HCl}, \mathrm{HBr}$, etc.) to produce methane + halogen [36] and the breakdown of n-alkanes [37]. 
The addition of $\mathrm{OH}$ or $\mathrm{O}_{2}\left(\right.$ as $\mathrm{H}_{2} \mathrm{O}_{2}$ or $\left.\mathrm{HO}_{2}{ }^{-}\right)$to an organic double bond results [38] in the virtually instantaneous breakdown of alkenes [38,39]. Similar observations have been made [39] for the break down (by $\mathrm{OH}$ addition) of carbonyls (e.g., aldehydes), haloethanes, and aromatic hydrocarbons [39] and reconstruction of $\mathrm{CO}$ to $\mathrm{CO}_{2}\left(\mathrm{n}-\mathrm{ZVM}-\mathrm{OH}+\mathrm{CO}=\mathrm{n}-\mathrm{ZVM}+\mathrm{H}+\mathrm{CO}_{2}\right)$ [40]. The latter reaction has a negative activation energy in the presence of water, but may have a positive activation energy when water is absent [40]. This remediation is accelerated by:

1. Increasing the availability of $\mathrm{OH}^{-}$(i.e., increasing $\mathrm{pH}$ as the concentration of $\mathrm{OH}^{-}\left(\mathrm{Mol} \mathrm{L}^{-1}\right)$ $\left.=10^{(14-p H)}\right)$.

2. Increasing the rate of degradation of $\mathrm{HO}_{2}^{-}$to $\mathrm{H}_{2} \mathrm{O}+0.5 \mathrm{O}_{2}$ (i.e., decreasing Eh, as Eh is a direct measure of the ratio $\left[\mathrm{HO}_{2}{ }^{-}\right]:\left[\mathrm{OH}^{-}+\mathrm{HO}_{2}{ }^{-}\right]$).

Studies using m-ZVM [1] have demonstrated that $\mathrm{Fe}^{0}$ can adjust the fluid $\mathrm{pH}$ from $<7$ to $>11$, and that bi or tri metal combinations of $\mathrm{m}-\mathrm{ZVM}$ will maximize the rate of Eh reduction (and $\mathrm{O}_{2}$ evolution). Eh reductions may fall in the range 0.3 to $0.8 \mathrm{~V}$. The fluid phase reaction routes which result may (for a specific $\mathrm{pH}$ ) be dependent on Eh. For example where the water contains $\mathrm{CO}_{2}$ and $\mathrm{H}^{+}$ions, then for $\mathrm{pH}=7$, the relationships provided in Equation 3 may apply [41]:

$$
\begin{array}{ll}
\mathrm{CO}_{2}+2 \mathrm{H}^{+}+2 \mathrm{e}^{-}=\mathrm{HCOOH} & \mathrm{Eh}=-0.61 \mathrm{~V} \\
\mathrm{CO}_{2}+2 \mathrm{H}^{+}+2 \mathrm{e}^{-}=\mathrm{CO}+\mathrm{H}_{2} \mathrm{O} & \mathrm{Eh}=-0.53 \mathrm{~V} \\
\mathrm{CO}_{2}+6 \mathrm{H}^{+}+6 \mathrm{e}^{-}=\mathrm{CH}_{3} \mathrm{OH}+\mathrm{H}_{2} \mathrm{O} & \mathrm{Eh}=-0.38 \mathrm{~V}
\end{array}
$$

The reaction product is a function of $\mathrm{Eh} . \mathrm{CO}_{2}$ in the water will be reduced to $\mathrm{CO}$ or hydrocarbons in the remediation zone (Equation 3). The CO product will maintain the ZVM in a reduced state [40].

\subsection{Dissolved Organic Matter (DOM)}

Pore-water redox modification by static diffusion using $\mathrm{n}-\mathrm{Fe}^{0}$ was analyzed (MR1, Figure A1 in Appendix) using fresh water (Figure 1). The experiment was repeated (MR6, Figure A6 in Appendix) using water containing dissolved organic matter (DOM). The water for MR6 was prepared using a commercial dried (sterilized) granulated chicken manure fertilizer. The fertilizer was dissolved in the water and the solute was added to the ZVM. The solute was diluted to ensure an initial EC of $<2000 \mu \mathrm{S} \mathrm{cm}^{-1}$ (Figure A6 in Appendix).

The fertilizer contained $4.5 \% \mathrm{~N}$ (as ammonium salts and nitrates), 3.5\% $\mathrm{P}$ (as phosphates and phosphenes), $2.5 \% \mathrm{~K}, 1 \% \mathrm{Mg}, 0.5 \% \mathrm{~S}$ (as $\mathrm{SO}_{4}$ ), $9 \% \mathrm{Ca}+$ traces of $\mathrm{Fe}, \mathrm{Mn}, \mathrm{Mo}, \mathrm{Cu}, \mathrm{Zn}$. The residue is organic matter. The mineral composition of this chicken manure is typical [42]. It is established that chicken manure increases $p H$ [43,44] (by up to about 5 units [44]) and increases EC substantially [43].

Similar observations have been made with raw cow manure, where $\mathrm{pH}$ increases to 7-9 units and Eh decreases to between -0.07 and $-0.37 \mathrm{~V}[45,46]$. Anaerobic digestion within the manure can result in acidification (i.e., $\mathrm{pH}<7$ ) and a decrease in Eh (i.e., <-0.5 V) [47]. 
Figure 1. Eh-pH relationship for feed water. (a) natural variation in groundwater mound (March-July 2010). Redox fences for Fe from [1]; (b) Eh vs. Temperature; (c) pH vs. Temperature; (d) EC $\left(\mu \mathrm{S} \mathrm{cm}^{-1}\right) v s$. temperature; (e). EC $\left(\mu \mathrm{S} \mathrm{cm}^{-1}\right) v s . \mathrm{pH}$; (f) EC $\left(\mu \mathrm{S} \mathrm{cm}^{-1}\right)$ vs. Eh. Temperatures are the sampled temperature of water abstracted from the groundwater mound.

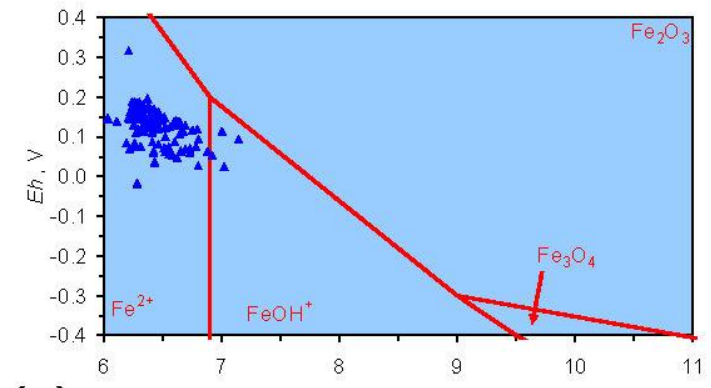

(a)
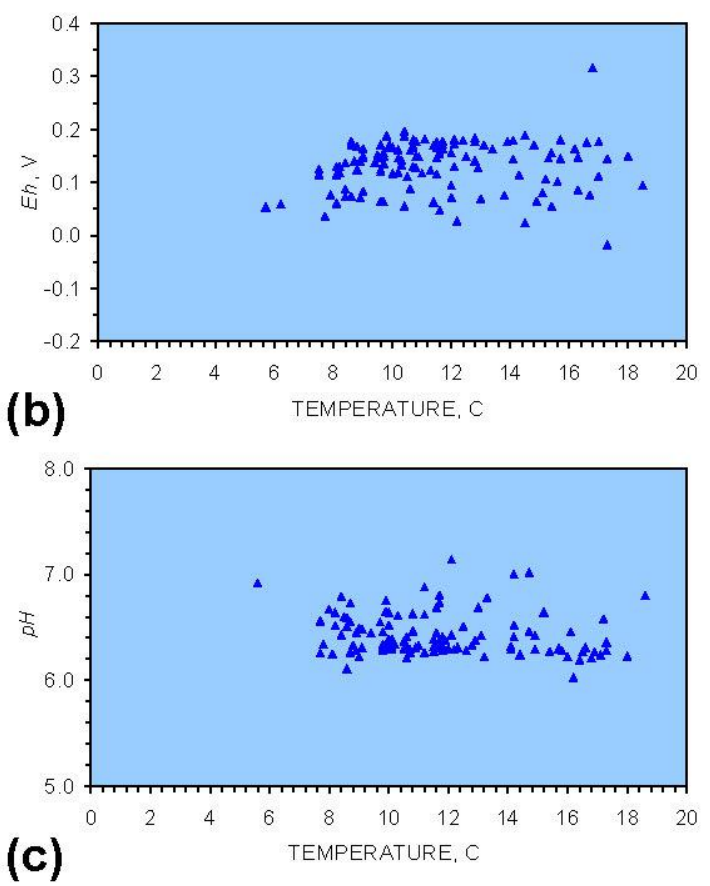
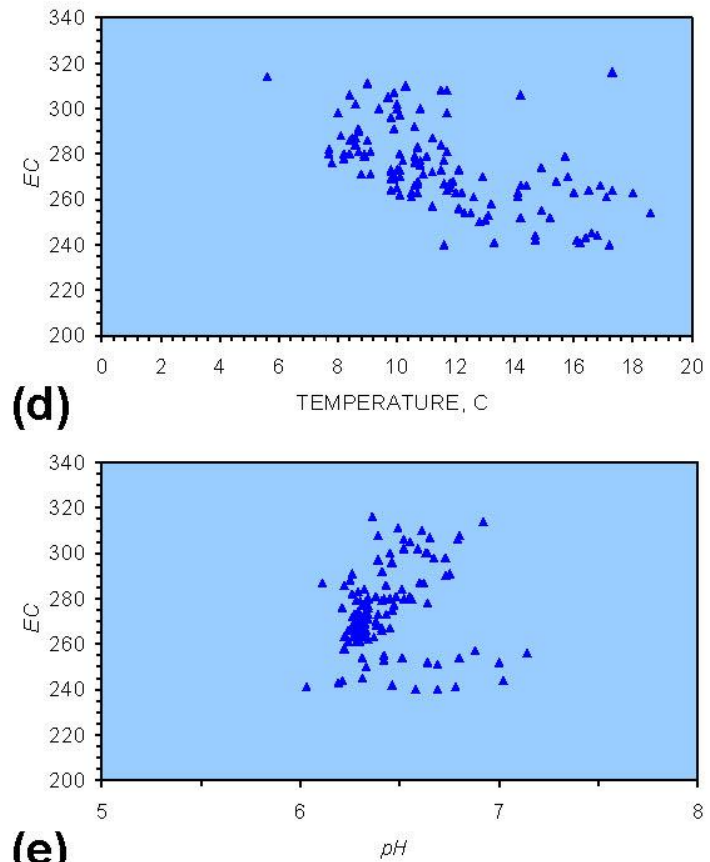

(e)

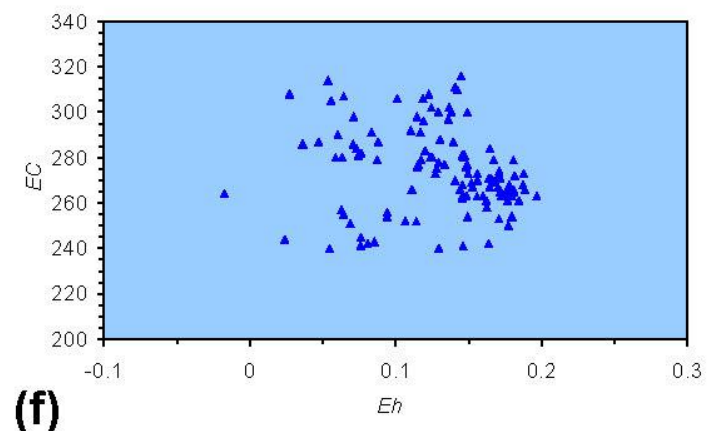

\section{Experimental Results: n-ZVM + Water}

\subsection{Source Water}

The source infiltration groundwater mound has an Eh-pH relationship, which varies over the course of a year (Figure 1a, 1b, 1c). The EC (i.e., TDS) decreases with increasing temperature (Figure 1d). EC is not related to $\mathrm{pH}$ or Eh (Figure 1e, 1f).

The experiments were designed to determine if:

1. Addition of $\mathrm{n}-\mathrm{ZVM}$ resulted in a significant change in $\mathrm{EC}, \mathrm{pH}$ or Eh.

2. The change in Eh, EC, $\mathrm{pH}$ followed a specific (and predictable) pattern as a function of contact time with the ZVM (e.g., SV). 


\subsection{Experimental Results}

The experimental results are presented in Figures A1-A16 (Appendix) as a series of relationships vs. time (or space velocity) and a series of crossplots. These establish that Eh, $\mathrm{pH}$ and EC change with time in the presence of ZVM or Ca-montmorillonite, and that the presence of $\mathrm{NaCl}$ impacts on the Eh, $\mathrm{pH}$ and EC. These changes can be related to a series of regression relationships $v$ s. time (or space velocity). They can therefore provide an indication of the modified redox environment and its changes with time. The methodology required to translate the graphical data into modeled aquifer performance results (for an aquifer remediation program) for the design of permeable reactive barriers and aquifer remediation programs is provided elsewhere [1].

In each example containing $\mathrm{n}-\mathrm{Fe}^{0}$ the same general pattern is replicated (e.g., Figure A1g in Appendix):

(i) An initial rapid increase in $\mathrm{pH}$ (to around $\mathrm{pH}=10$ ) is accompanied by a decrease in Eh.

(ii) This is followed by a stabilization in $\mathrm{pH}$ (at around $\mathrm{pH}=10$ ) and a rise in Eh.

(iii) This is then followed by a stabilization of Eh (e.g., Eh $=0.05 \mathrm{~V})$ and a decrease in $\mathrm{pH}$ to a base level (e.g., $\mathrm{pH}=8-9$ ).

The $\mathrm{pH}$ then remains constant at the base level (e.g., $\mathrm{pH}=8-9$ ) and the Eh then starts to decline to a base level, (e.g., Eh $\leq-0.1 \mathrm{~V}$ ) to form a stabilized redox environment (SRE).

This general pattern is illustrated in Figure $\mathrm{A} 1 \mathrm{~g}$, and is present in all the test samples containing $\mathrm{n}-\mathrm{Fe}^{0}$. The test sample containing only $\mathrm{n}-\mathrm{Al}^{0}$ (Figure A2g in Appendix) shows a similar pattern. However, the cycle continues with an increase in $\mathrm{pH}$ (from about 7.5 to about 8.5, Figure A2g in Appendix), followed by $\mathrm{pH}$ stabilization and a rise in Eh.

The general patterns associated with $\mathrm{n}-\mathrm{Al}^{0}$ (Figure A2 in Appendix) can be compared directly with the Ca-montmorillonite patterns (Figures A9 and A12 in Appendix). In freshwater these show an initial decrease in Eh (or stable Eh) accompanied by an increase in $\mathrm{pH}$. This is then followed by an increase in Eh and decrease in $\mathrm{pH}$. Ca-montmorillonite contains $\mathrm{Al}$ cations. In saline water, the $\mathrm{pH}$ increase is accompanied by a stable Eh (Figure A13 in Appendix).

Figures A1 to A5 demonstrate that the impact of adding different $n-Z V M$ to $n-F^{0}$ is to reduce the maximum $\mathrm{pH}$ achieved in the redox cycle and adjust the stabilized $\mathrm{pH}$ and Eh (SRE) over the longer term (compare Figure A1g, A3g-A5g in Appendix). The presence of dissolved organic matter (DOM), while affecting the initial starting $\mathrm{pH}$, Eh and EC, does not appear to affect the overall redox cycle (Figure A6g in Appendix). The SRE and redox trajectory (associated with $\mathrm{n}-\mathrm{Fe}^{0}$ ) is unaffected by the presence of DOM in the initial feed water (compare Figure A1g and A6g in Appendix).

The addition of $\mathrm{NaCl}$ to the water appears to leave the Eh:pH location of the SRE unchanged (compare Figures A1g and A7g in Appendix) When $n-\mathrm{Fe}^{0}+\mathrm{n}-\mathrm{Cu}^{0}+\mathrm{n}-\mathrm{Al}^{0}$ is present, the presence of $\mathrm{NaCl}$ initially results in the development of a common SRE at the end of the redox cycle (compare Figures A5g and A8g in Appendix). However, in a saline environment, the Eh subsequently increases. This Eh increase is accompanied by a decrease in $\mathrm{pH}$ (Figure A8g in Appendix). This can result (Figure A8 in Appendix) in a similar starting and final Eh and $\mathrm{pH}$. 
When Ca-montmorillonite is present, the major decrease in Eh does not occur until the $\mathrm{pH}$ has reduced to its SRE level (Figures A10g, A11g, A13g, A14g-A16g in Appendix).

\section{Interpretation}

The test results (Figures A1-A16 in Appendix) have established that static diffusion associated with $\mathrm{n}-\mathrm{ZVM}$ results in an $\mathrm{Eh}, \mathrm{pH}, \mathrm{EC}$ trajectory which can be related directly to time/space velocity. This trajectory is oscillatory, and its exact route varies with ZVM combinations and salinity.

\subsection{Equilibrium Oscillation}

Figures A1-A16 in Appendix demonstrate that $\mathrm{Eh}$ and $\mathrm{pH}$ is in a state of a perpetual equilibrium oscillation between reduction and oxidation reactions. For example, the reduction of $\mathrm{Fe}-\mathrm{OH}(\mathrm{s})$ or $\mathrm{Fe}-\mathrm{OH}$ (aq) (Equation 4)

$$
\mathrm{zFeOH}+\mathrm{nH}^{+}+\mathrm{mO}_{\mathrm{q}} \mathrm{H}^{-}+\mathrm{kH}_{2} \mathrm{O}+\mathrm{cFe}_{\mathrm{d}} \mathrm{Ob}=\mathrm{pFe}^{0}+\mathrm{gFe}-\mathrm{H}^{+}+\mathrm{xH}_{2} \mathrm{O}+\mathrm{yO}_{2}(\mathrm{~g})+\mathrm{jO}_{\mathrm{q}} \mathrm{H}^{-}
$$

$\left[\mathrm{O}_{2}\right.$ degassing, Eh reduction, and $\mathrm{pH}$ increase or decrease $]$

oscillates with the oxidation of $\mathrm{Fe}^{0}$ or $\mathrm{Fe}-\mathrm{H}^{+}$(Equation 5)

$$
\mathrm{pFe}^{0}+\mathrm{gFe}-\mathrm{H}^{+}+\mathrm{xH}_{2} \mathrm{O}+\mathrm{rO}_{\mathrm{q}} \mathrm{H}^{-}=\mathrm{cFe}_{\mathrm{d}} \mathrm{O}_{\mathrm{b}}+\mathrm{zFeOH}+\mathrm{nH}^{+}+\mathrm{mO}_{\mathrm{q}} \mathrm{H}^{-}+\mathrm{hFe}-\mathrm{H}^{+}+\mathrm{jH}_{2}(\mathrm{~g})
$$

[ $\mathrm{H}^{+}$ion or $\mathrm{H}_{2}(\mathrm{~g})$ formation, Eh and $\mathrm{pH}$ increase or decrease]

$\mathrm{yO}_{2}(\mathrm{~g})$ can be present as $\mathrm{H}_{2} \mathrm{O}_{2}$ or as $\left[\mathrm{H}_{2} \mathrm{O}\right]_{\mathrm{m}}\left(\mathrm{O}_{2}\right)_{\mathrm{n}}$. $\mathrm{yH}_{2}(\mathrm{~g})$ can be present as $\mathrm{H}_{3} \mathrm{O}^{+}$or as $\left[\mathrm{H}_{2} \mathrm{O}_{\mathrm{m}}\left(\mathrm{H}_{2}\right)_{\mathrm{n}}\right.$. Increases in $\mathrm{Eh}$ are associated with an increase in the $\mathrm{HO}_{2}^{-}$(i.e., $\mathrm{OH}^{-}[\mathrm{O}]$ ): $\mathrm{OH}^{-}$ratio [1]. Increases in $\mathrm{pH}$ result from a decrease in the $\mathrm{H}^{+}: \mathrm{H}_{2} \mathrm{O}$ ratio. The observed redox changes (Figures A1 to A16 in Appendix) can be linked directly to changes in these ion concentrations, and therefore to the redox reactions (Equations 3-8). Increases in EC are associated with aqueous ion formation (e.g., $\mathrm{Fe}^{2+}$, $\mathrm{FeOH}^{-}$) while the removal of aqueous ions is associated with a decrease in EC. Decreases in Eh, associated with increases in $\mathrm{pH}$ may be associated with the release of $\mathrm{H}_{2}(\mathrm{~g})$, but are commonly associated with the release of $\mathrm{O}_{2}$ resulting from the decomposition of $\mathrm{H}_{2} \mathrm{O}_{2}$.

The continual Eh:pH oscillation (Figures A1 to A16 in Appendix) interacts with ZVM to form nuclei of the generic form ZVM- $\left(\mathrm{H}^{+}\right)_{\mathrm{n}}, \mathrm{ZVM}-(\mathrm{O}-\mathrm{H})_{\mathrm{n}}, \mathrm{ZVM}-\left((\mathrm{CH})_{2}\right)_{\mathrm{n}}, \mathrm{ZVM} \mathrm{CH}_{\mathrm{n}}, \mathrm{ZVM}-\mathrm{CHCl}_{2}$, $\mathrm{ZVM}-\mathrm{CHCl}_{3}, \mathrm{ZVM}-\mathrm{CHCl}$, and $\mathrm{ZVM}-\mathrm{CH}_{2} \mathrm{Cl}[28-30,48]$. These nuclei act as loci for organic matter remediation. Examples of ZVM nuclei formation are provided in Equation 6:

$$
\begin{aligned}
& \mathrm{ZVM}+\mathrm{H}^{+}=\mathrm{ZVM}-\mathrm{H}^{+} \\
& \mathrm{ZVM}-\mathrm{H}^{+}+\mathrm{CO}_{2}=\mathrm{ZVM}-\mathrm{COOH}^{+} \\
& \mathrm{ZVM}-\mathrm{H}^{+}+\mathrm{CO}_{2}+\mathrm{xH}^{+}=\mathrm{ZVM}-\mathrm{CH}_{\mathrm{n}}+2 \mathrm{H}_{2} \mathrm{O} \\
& \mathrm{ZVM}-\mathrm{H}^{+}+\mathrm{CH}_{4}=\mathrm{ZVM}-\mathrm{CH}_{3}+2 \mathrm{H}^{+} \\
& \mathrm{ZVM}-\mathrm{H}^{+}+\mathrm{CO}_{2}+6 \mathrm{H}^{+}=\mathrm{ZVM}-\mathrm{CH}_{3}+2 \mathrm{H}_{2} \mathrm{O} \\
& \mathrm{ZVM}-\mathrm{H}^{+}+\mathrm{C}_{\mathrm{x}} \mathrm{H}_{(2 \mathrm{x}+2)}=\mathrm{ZVM}-\left(\mathrm{CH}_{2}\right)_{(\mathrm{x}-1)} \mathrm{CH}_{3}+2 \mathrm{H}^{+}
\end{aligned}
$$




$$
\mathrm{ZVM}-\mathrm{H}^{+}+\mathrm{C}_{\mathrm{x}} \mathrm{H}_{\mathrm{y}} \mathrm{O}_{\mathrm{z}}+\mathrm{mH}^{+}=\mathrm{ZVM}-\mathrm{C}_{\mathrm{p}} \mathrm{H}_{\mathrm{q}}+\mathrm{nH}_{2} \mathrm{O}
$$

\subsection{Impact of $\mathrm{CO}_{2}$}

Organic matter within an aquifer is degraded to form $\mathrm{CO}_{2}$ (aq) by biogenic activity [48]. $\mathrm{Fe}^{0}$ catalyses the formation of simple organic chains from the aqueous $\mathrm{CO}_{2}[1,49,50]$. These form simple alkanes (methane, ethane, etc.) and simple oxygenates (e.g., acetone, butanone, methanal, ethanal, methanoic acid, ethanoic acid, etc.) [1,48]. These ZVM products replace the TCE's, humic acids, dissolved organic matter, pesticides over a period of time $[1,12,49,50]$. The concentration of these products increases with time and may be directly linked to decreases in EC (e.g., Figure A6e in Appendix). These products may form a primary food source for the microbiota [48]. The general process of $\mathrm{CO}_{2}$ and halogen-alkane/alkene reutilisation to form, grow and release simple alkanes and alkenes is summarized in Equation 7 [1,48] as:

$$
\begin{gathered}
\mathrm{Fe}^{0}+\mathrm{H}_{2} \mathrm{O}=\mathrm{OH}^{-}+\mathrm{Fe}-\mathrm{H}^{+}-\text {catalytic nuclei formation } \\
\mathrm{Fe}^{0}+\mathrm{H}_{3} \mathrm{O}^{+}=\mathrm{Fe}-\mathrm{H}^{+}+\mathrm{H}_{2} \mathrm{O}-\text { catalytic nuclei formation } \\
\mathrm{Fe}-\mathrm{H}^{+}+\mathrm{CO}_{2}+6 \mathrm{H}_{3} \mathrm{O}^{+}=\mathrm{Fe}-\mathrm{CH}_{3}+8 \mathrm{H}_{2} \mathrm{O}-\text { chain formation } \\
\mathrm{Fe}-\mathrm{CH}_{3}+\mathrm{CO}_{2}+6 \mathrm{H}_{3} \mathrm{O}^{+}=\mathrm{Fe}-\mathrm{CH}_{2} \mathrm{CH}_{3}+8 \mathrm{H}_{2} \mathrm{O}-\text { chain growth } \\
\mathrm{Fe}-\mathrm{CH}_{3}{ }^{+} \mathrm{CO}_{2}+6 \mathrm{H}_{3} \mathrm{O}^{+}=\mathrm{Fe}-\left(\mathrm{CH}_{2}\right)_{2} \mathrm{CH}_{3}+8 \mathrm{H}_{2} \mathrm{O}-\text { chain growth }
\end{gathered}
$$

$\mathrm{Fe}-\left(\mathrm{CH}_{2}\right)_{2} \mathrm{CH}_{3}+2 \mathrm{H}_{3} \mathrm{O}^{+}=\mathrm{Fe}-\mathrm{H}^{+}+2 \mathrm{H}_{2} \mathrm{O}+\mathrm{CH}_{3} \mathrm{CH}_{2} \mathrm{CH}_{3}-$ chain termination

$\mathrm{ZVM}+\mathrm{C}_{\mathrm{x}} \mathrm{H}_{\mathrm{y}} \mathrm{Cl}_{\mathrm{Z}}=\mathrm{ZVM}-\mathrm{C}_{\mathrm{a}} \mathrm{H}_{\mathrm{b}} \mathrm{Cl}_{\mathrm{c}}+\ldots-$ catalytic nuclei formation

$\mathrm{ZVM}-\mathrm{CCl}_{3}+\mathrm{CH}_{4}=\mathrm{ZVM}-\mathrm{CCl}_{2} \mathrm{CH}_{3}+\mathrm{Cl}^{-}+\mathrm{H}^{+}-$chain growth

$\mathrm{ZVM}-\mathrm{CHCl}_{2}+\mathrm{CH}_{4}=\mathrm{ZVM}-\mathrm{CH}_{2} \mathrm{CH}_{3}+2 \mathrm{Cl}^{-}-$chain growth

$\mathrm{ZVM}-\mathrm{CH}_{2} \mathrm{CH}_{3}+\mathrm{CH}_{4}=\mathrm{ZVM}-\mathrm{CH}_{2} \mathrm{CH}_{2} \mathrm{CH}_{3}+2 \mathrm{H}^{+}-$chain growth

$\mathrm{ZVM}-\mathrm{CHCl}_{2}+4 \mathrm{H}^{+}=\mathrm{ZVM}-\mathrm{H}^{+}+\mathrm{CH}_{4}+2 \mathrm{Cl}^{-}-$chain termination

$\mathrm{ZVM}-\mathrm{CH}_{2} \mathrm{CH}_{2} \mathrm{CH}_{3}+2 \mathrm{H}^{+}=\mathrm{ZVM}-\mathrm{H}^{+}+\mathrm{CH}_{3} \mathrm{CH}_{2} \mathrm{CH}_{3}-$ chain termination

$\mathrm{ZVM}-\mathrm{CH}_{2} \mathrm{CH}_{2} \mathrm{CH}_{3}+\mathrm{H}^{+}=\mathrm{ZVM}+\mathrm{CH}_{3} \mathrm{CH}_{2} \mathrm{CH}_{3}-$ chain termination

$\mathrm{ZVM}-\mathrm{CH}_{2} \mathrm{CH}_{3}+\mathrm{ZVM}-\mathrm{CH}_{2} \mathrm{CH}_{3}+2 \mathrm{H}^{+}=2 \mathrm{ZVM}-\mathrm{H}^{+}+\mathrm{CH}_{3} \mathrm{CH}_{2} \mathrm{CH}_{2} \mathrm{CH}_{3}-$ chain termination

$\mathrm{ZVM}-\mathrm{CH}_{2} \mathrm{CH}_{3}+\mathrm{ZVM}-\mathrm{CH}_{2} \mathrm{CH}_{3}=2 \mathrm{ZVM}+\mathrm{CH}_{3} \mathrm{CH}_{2} \mathrm{CH}_{2} \mathrm{CH}_{3}-$ chain termination

$\mathrm{CH}_{4}$ can be replaced by $\mathrm{C}_{\mathrm{x}} \mathrm{H}_{\mathrm{y}}$ or $\mathrm{C}_{\mathrm{x}} \mathrm{H}_{\mathrm{y}} \mathrm{Cl}_{\mathrm{z}}$ or $\mathrm{C}_{\mathrm{x}} \mathrm{H}_{\mathrm{y}} \mathrm{O}_{\mathrm{z}}$ [1]. The presence of $\mathrm{CO}_{2}$ in the water (from any source) results in a spontaneous interaction with $\mathrm{Fe}^{0}$ which can result (Equation 8 ) in the release of $\mathrm{H}_{2}[1,50,51]$.

$$
\begin{gathered}
\mathrm{CO}_{2}(\mathrm{~g})=\mathrm{CO}_{2}(\mathrm{aq})-\Delta \mathrm{G}^{\mathrm{o}}=+8.335 \mathrm{~kJ} \mathrm{~mol}^{-1} \\
\mathrm{CO}_{2}(\mathrm{aq})+\mathrm{H}_{2} \mathrm{O}(\mathrm{l})=\mathrm{HCO}_{3}{ }^{-}(\mathrm{aq})+\mathrm{H}^{+}(\mathrm{aq})-\Delta \mathrm{G}^{\mathrm{o}}=+36.305 \mathrm{~kJ} \mathrm{~mol}^{-1} \\
\mathrm{Fe}^{0}+2 \mathrm{H}^{+}(\mathrm{aq})=\mathrm{Fe}_{2}{ }^{+}(\mathrm{aq})+\mathrm{H}_{2}(\mathrm{~g})-\Delta \mathrm{G}^{\mathrm{o}}=-91.525 \mathrm{~kJ} \mathrm{~mol}^{-1}
\end{gathered}
$$




$$
\mathrm{Fe}^{0}+2 \mathrm{CO}_{2}(\mathrm{~g})=2 \mathrm{HCO}_{3}{ }^{-}(\mathrm{aq})+\mathrm{Fe}_{2}{ }^{+}(\mathrm{aq})+\mathrm{H}_{2}(\mathrm{~g})-\Delta \mathrm{G}^{\mathrm{o}}=-2.245 \mathrm{~kJ} \mathrm{~mol}^{-1}
$$

\subsection{Fenton Reactions}

Most aquifers are oxygenated to some extent, and most contain organic matter (OM). When $\mathrm{Fe}^{0}$ is added to water contaminated with organic matter (or containing $\mathrm{Al}$ cations or $\mathrm{Al}^{0}$ ) the first stage of the redox trajectory is a reduction in $\mathrm{pH}$ and Eh (Figures A1-A16 in Appendix) which is associated with $\mathrm{O}_{2}$ degassing (Figures A4-A6 in Appendix). This initial change is associated with Fenton reactions (Equation 9) [1,52,43]

$$
\begin{gathered}
\mathrm{O}_{2}+\mathrm{Fe}^{0}+2 \mathrm{H}^{+}=\mathrm{H}_{2} \mathrm{O}_{2}(\mathrm{aq})+\mathrm{Fe}^{2+} \\
\mathrm{OM}_{\text {oxidized } 1}+\mathrm{Fe}^{0}=\mathrm{OM}_{\text {reduced }}+\mathrm{Fe}^{2+} \\
\mathrm{OM}_{\text {reduced }}+\mathrm{O}_{2}+2 \mathrm{H}^{+}=\mathrm{H}_{2} \mathrm{O}_{2}(\mathrm{aq})+\mathrm{OM}_{\text {oxidized } 2} \\
2 \mathrm{H}_{2} \mathrm{O}_{2}(\mathrm{aq})=2 \mathrm{H}_{2} \mathrm{O}(\mathrm{l})+\mathrm{O}_{2}(\mathrm{~g}) \\
2 \mathrm{Fe}^{0}+2 \mathrm{H}_{2} \mathrm{O}=2 \mathrm{Fe}-\mathrm{H}^{+}+2 \mathrm{OH}^{-} \\
2 \mathrm{Fe}^{0}+\mathrm{O}_{2}+2 \mathrm{H}_{2} \mathrm{O}=2 \mathrm{Fe}^{2+}+4 \mathrm{OH}^{-} \\
2 \mathrm{Fe}^{0}+2 \mathrm{H}_{2} \mathrm{O}[\mathrm{O}]=2 \mathrm{Fe}^{2+}+4 \mathrm{OH}^{-} \\
2 \mathrm{OH}^{-}=\mathrm{H}_{2} \mathrm{O}_{2} \\
\mathrm{Fe}^{2+}+\mathrm{H}_{2} \mathrm{O}_{2}=\mathrm{Fe}^{3+}+2 \mathrm{OH}^{-}
\end{gathered}
$$

$\mathrm{O}_{2}$ includes $2 \mathrm{HO}_{2}^{-}=2 \mathrm{OH}^{-}+\mathrm{O}_{2}$. The ion concentrations $\left(\mathrm{HCO}_{3}{ }^{-}, \mathrm{HO}_{2}^{-}, \mathrm{OH}^{-}, \mathrm{Fe}^{\mathrm{n}+}, \mathrm{FeOH}^{-}\right)$ resulting from the interaction of $\mathrm{Fe}^{0}$ with $\mathrm{CO}_{2}$ (aq) and $\mathrm{H}_{2} \mathrm{O}$ vary as function of pore-water velocity and distance from the ZVM [53]. The primary reduction in DOM occurs after the $\mathrm{pH}$ has increased to a maximum value (Figure A6 in Appendix). This increase in $\mathrm{pH}$ is associated with a decrease in Eh (i.e., release of $\mathrm{H}^{+}$(aq), removal of $\mathrm{HO}_{2}^{-}$(aq).) and the formation of $\mathrm{FeO}(\mathrm{OH}) \cdot \mathrm{nH}_{2} \mathrm{O}$ at the $\mathrm{ZVM}-$ water interface, i.e., $\mathrm{Fe}^{0}+\mathrm{HO}_{2}^{-}+\mathrm{nH}_{2} \mathrm{O}=\mathrm{FeO}(\mathrm{OH}) \cdot \mathrm{nH}_{2} \mathrm{O}$.

\subsection{Sulphur and Oxylate Removal}

ZVM interacts with sulphur to form active sites [54] which can be used to remediate organic pollutants. These active sites take the form (Equation 10):

$$
\begin{gathered}
\mathrm{ZVM}-\mathrm{H}^{+}+\mathrm{aH}_{2} \mathrm{~S}\left(\text { aq or g) }=\mathrm{ZVM}^{-\mathrm{S}_{\mathrm{a}}}+(\mathrm{a}+0.5) \mathrm{H}_{2}\right. \\
\mathrm{ZVM}-\mathrm{CH}_{3}+\mathrm{H}_{2} \mathrm{~S}=\mathrm{CH}_{3}-\mathrm{ZVM}_{-} \mathrm{SH}^{+}+0.5 \mathrm{H}_{2}
\end{gathered}
$$

Sulphur, like oxygen can be inserted into any $\mathrm{C}-\mathrm{C}$ or $\mathrm{C}-\mathrm{H}$ bond. Consequently, in sulphurous waters (or water containing sulphate fertilizer), ZVM treatment will result in the formation of ZVM-S, ZVM- $\mathrm{O}_{\mathrm{x}} \mathrm{S}$ sites and associated $\mathrm{C}_{\mathrm{x}} \mathrm{H}_{\mathrm{y}} \mathrm{S}_{\mathrm{n}}$ and $\mathrm{C}_{\mathrm{x}} \mathrm{H}_{\mathrm{y}} \mathrm{N}_{\mathrm{v}} \mathrm{S}_{\mathrm{n}}$ compounds [54]. While the addition of $\mathrm{H}_{2} \mathrm{~S}$ was not examined, it is a common biogenic product in many anoxic (low Eh) aquifers. The test results (Figures A1 to A16 in Appendix) establish that when $\mathrm{Fe}^{0}$ is present, the SRE, is anoxic (Eh $<-0.1 \mathrm{~V}$ ) with an intermediate $\mathrm{pH}(8-10)$. In this environment biogenic activity will degrade sulphur compounds 
(e.g., $\mathrm{SO}_{4}{ }^{2-}$ ) to $\mathrm{H}_{2} \mathrm{~S}$ and will produce oxylates. The $\mathrm{ZVM}$ will reduce this $\mathrm{H}_{2} \mathrm{~S}$ to form active sites with the associated formation of $\mathrm{H}^{+}, \mathrm{H}_{2}(\mathrm{~g}), \mathrm{H}_{3} \mathrm{O}^{+}, \mathrm{H}_{2} \mathrm{O}\left[\mathrm{H}_{2}\right]_{\mathrm{n}}$, and $\mathrm{ZVM}-\mathrm{H}^{+}$. The $\mathrm{FeS}-\mathrm{H}_{2} \mathrm{~S} / \mathrm{FeS}$ redox couple can be linked to $\mathrm{CO}_{2}$ reduction [55], where $2 \mathrm{FeS}+2 \mathrm{CO}_{2}$ [or $\left.+\mathrm{H}_{2} \mathrm{C}_{2} \mathrm{O}_{4}\right]+2 \mathrm{H}_{2} \mathrm{O}=\mathrm{FeS}_{2}+$ $\mathrm{Fe}-\mathrm{C}_{2} \mathrm{O}_{4} \cdot 2 \mathrm{H}_{2} \mathrm{O}$ [or $\mathrm{Fe}-\mathrm{C}_{2} \mathrm{O}_{4} \cdot 2 \mathrm{H}_{2} \mathrm{O}+\mathrm{H}_{2}$ ] [56]. These observations indicate that $\mathrm{ZVM}$ treatment of sulphur rich waters (with a low throughflow) containing organic contaminants, will result in organic decontamination, $\mathrm{CO}_{2}$ removal, and removal of sulphur from the aquifer. Electrochemical ZVMoxylate formation is induced by reducing Eh [57]. Reductions of $>-0.03 \mathrm{~V}$ are required [57]. Figures A1-A16 in Appendix demonstrate Eh reductions of -0.2 to $>-0.5$. This indicates that ZVM-oxylate formation will occur in the SRE and along the redox trajectory when the porewater contains one or more of $\mathrm{H}_{2} \mathrm{C}_{2} \mathrm{O}_{4}, \mathrm{HC}_{2} \mathrm{O}_{4}{ }^{-}$, and $\mathrm{C}_{2} \mathrm{O}_{4}{ }^{2-}$. The principal $\mathrm{Fe}$ sites formed by this process include $\mathrm{FeC}_{2} \mathrm{O}_{4}{ }_{4}$, $\mathrm{Fe}\left(\mathrm{C}_{2} \mathrm{O}_{4}\right)_{2}{ }^{-}, \mathrm{Fe}\left(\mathrm{C}_{2} \mathrm{O}_{4}\right)_{3}{ }^{3-}$ and $\mathrm{FeHC}_{2} \mathrm{O}_{4}{ }^{2+}{ }^{2}[58]$.

\subsection{General Patterns}

The interaction between reductive and oxidative reactions results in the development of a SRE (e.g., Figure A1g in Appendix). The interaction is complex and involves all organic and metal species contained within the water and associated matrix (e.g., clays). Consequently, within aquifers involving a large number of species there will be a high variance on Eh, $\mathrm{pH}$ with time or SV. This will be associated with sequential oscillations between progressive reductive and oxidative states. However, Figures A5, A6, A11 and A16 in Appendix demonstrate that as the number of active ZVM site types increase, the $\mathrm{Eh}, \mathrm{pH}$ and EC variance associated with a specific SV decreases. Figure A6 demonstrates that these active sites can be organic and can be in solution (e.g., DOM). Specific observations in a simple ZVM-water system are:

(i) Increases in $\mathrm{FeOH}^{-}$(aq) ions are associated with a general increase in Eh (Figure A1 in Appendix), i.e., $\mathrm{Fe}^{0}+\mathrm{nHO}_{2}^{-}+\mathrm{yOH}^{-}=\mathrm{FeOH}^{-}(\mathrm{aq})+\mathrm{nHO}_{2}^{-}+[\mathrm{y}-1] \mathrm{OH}^{-}$. Subsequent removal of the $\mathrm{FeOH}^{-}$(aq) is associated with both a decrease in Eh and $\mathrm{pH}$ (Figure A1 in Appendix).

(ii) The formation of $\mathrm{Al}^{3+}$ (aq) ions, resulting in a substantial increase in EC (Figure A2 in Appendix) is linked directly to a decrease in $\mathrm{Eh}$ and an increase in $\mathrm{pH}$, e.g., $\mathrm{H}^{+}+\mathrm{HO}_{2}^{-}=2 \mathrm{OH}^{-}$(or $\mathrm{H}_{2} \mathrm{O}_{2}$ ).

In both examples, the major formation of metal ions (aq) can be avoided by maintaining a high space velocity through the aquifer. The addition of a second zero valent metal (Figures A3-A5) or organic material (Figure A6 in Appendix) or $\mathrm{NaCl}$ (Figures A7, A8, A13-A16 in Appendix) prevents the formation of substantial quantities of $\mathrm{FeOH}^{-}$(aq) (Figures $\mathrm{A} 1$ and $\mathrm{A} 10$ in Appendix) and accelerates the reduction in EC (i.e., removal of dissolved material). In this instance the major removal of pollutants occurs 10-200 days after the ZVM is placed in the aquifer (Figures A3-A5 in Appendix).

In aquifers containing Ca-montmorillonite the change in redox environment associated with the SRE is associated with a net desalination of the aquifer [1]. The degree of desalination increases with decreasing SV. The desalination is associated with substitution of Ca cations with Na cations in the montmorillonite. At low SV in Figures A13-A16 in Appendix, the SRE is associated with an Eh within the range -0.1 to $-0.5 \mathrm{~V}$. This indicates that cation exchange is also associated with the removal 
of $\mathrm{HO}_{2}^{-}$, or an increase in $\mathrm{OH}^{-}$. The latter may result from the removal of Ca hydration shells within the clay, as part of the cation substitution process.

\subsection{Removal of Dissolved Organic Matter}

Humic acids (HA) are complex structures containing phenolic and carboxylic groups. They have the ability to form complexes (including chelates) with $\mathrm{Fe}, \mathrm{Ca}, \mathrm{Mg}, \mathrm{K}$ and other aqueous metal ions. Dissolved organic matter (e.g., Humic acids) have been demonstrated to shorten the effective operating life of $\mathrm{n}-\mathrm{Fe}^{0}$ for the removal of dissolved $\mathrm{Zn}$ and $\mathrm{Ni}$ species, but not $\mathrm{Cr}$ species [59]. The removal of $\mathrm{Zn}$ (aq) species (by oxide formation) increases with increasing $\mathrm{pH}$ [60], while the removal of $\mathrm{Ni}(\mathrm{aq})$ species decreases with increasing Eh [60]. Cr removal occurs when the $\mathrm{pH}$ increases above 3 when Eh is between 0.9 and -0.5 [60]. This study has demonstrated that DOM is removed by ZVM (Figure A6 in Appendix) and that initial increases in $\mathrm{pH}$ and decreases in Eh are followed by a cycle of increasing Eh, decreasing $\mathrm{pH}$ and decreasing Eh. It has also been demonstrated that as m-ZVM loses its ability (due to oxide formation) to remediate water its $\mathrm{pH}$ decreases and Eh increases [1].

While this study has demonstrated removal from low surface area n-ZVM (Table 1), most academic studies focus on high surface area (e.g., 24-32 $\mathrm{m}^{2} \mathrm{~g}^{-1}$ ) $\mathrm{n}-\mathrm{Fe}^{0}$ [61]. These studies have demonstrated that

a) the rate $\mathrm{HA}$ removal increases with increasing $\mathrm{n}-\mathrm{Fe}^{0}$ concentration (though $\mathrm{k}$ remains constant) [61], indicating that the removal may be linked to surface area.

b) HA removal is associated with a significant decrease in $\mathrm{pH}$ [61].

c) HA removal is associated over time with a change in $\mathrm{n}-\mathrm{Fe}^{0}$ elemental ratio (Fe:O:C) from 85:13.5:0 (at onset) to 31:52:17 (after 90 days) [61].

This study has demonstrated (Figure A6) that significant DOM removal only occurs when the Eh starts to decrease as the water redox environment moves into the SRE. The $\mathrm{Fe}^{0}$ was oxidized at the water ZVM interface (to form iron hydroxides), but remained as reduced $n-\mathrm{Fe}^{0}$ below the interface zone. Dechlorination studies of tetrachloroethylene using palladized $n-\mathrm{Fe}^{0}$ have demonstrated that the rate of dechlorination to ethane and ethylene is increased by increasing the concentration of HA [62]. This indicates that HA may act as electron shuttles [62]. However, different types of DOM/HA may interact differently with nanoparticles and electrolytes [63].

The experimental results (Figure A6 in Appendix) suggest that $\mathrm{Fe}^{0}$ may act as an electron shuttle (catalyst) whereby organic acids mediate electron transfer to $\mathrm{O}_{2}\left[\mathrm{HO}_{2}^{-}, \mathrm{H}_{2} \mathrm{O}_{2}\right]$ resulting in the formation of $\mathrm{OH}$ radical-mediated oxidation of organic compounds through the Fenton Reaction [1,51]. The electron shuttle reaction can be simplified [1] (Equation 11) to:

$$
\mathrm{Fe}^{0}+2 \mathrm{H}_{2} \mathrm{O}=2 \mathrm{OH}^{-}+\mathrm{Fe}-\mathrm{H}_{2}=\mathrm{Fe}_{2}^{+}+4 \mathrm{H}^{+}+\mathrm{O}_{2}(\mathrm{~g})
$$

This electron shuttle process decreases $E h$ (by production of $\mathrm{OH}^{-}$) and subsequent decreases in $p H$ (associated with the co-release of $\mathrm{H}^{+}$and $\mathrm{O}_{2}$ ) are prevented by capture of $\mathrm{H}^{+}$in organic chain formation/breaking reactions. $\mathrm{O}_{2}$ release is associated with the formation of negative $\mathrm{Eh}$ and $\mathrm{Eh}$ declines are associated with the release of Fe ions [1].

Organic matter (e.g., pyridinium) can act as an electron shuttle to catalyse the reduction of $\mathrm{CO}_{2}$ to carboxylic acids, aldehydes and alcohols [64]. DOM (HA) can enhance Fe(II) and Fe(III) oxide 
reduction by both electron shuttling and Fe(II) complexation [65,66]. Reduced HA will reductively transform chlorinated solvents and nitroaromatic [66].

The presence of organic matter (and microbial activity) in an aquifer can therefore be expected to complicate the overall remediation process, particularly when the n-ZVM has a high surface area [66]. In this environment, the DOM/HA may foul the n-ZVM [61]. This study has established (compare Figures A1 and A6 in Appendix) that when the $n-Z V M$ has a low surface area (Table 1), the primary control on remediation shifts from n-ZVM surface area dependent interactions (e.g., adsorption/desorption reactions) to electrochemical reactions associated with $\mathrm{H}^{+}, \mathrm{OH}^{-}$and $\mathrm{HO}_{2}{ }^{-}$ ion concentrations in the aquifer. Many of these reactions have negative activation energies and high rate constants at the aquifer temperature [38,39]. This results in a direct relationship between the level of remediation (EC reduction), Eh, $\mathrm{pH}$ and $\mathrm{n}-\mathrm{ZVM}$ concentration.

These observations suggest that switching n-ZVM remedial programs from the use of high cost, high surface area $\mathrm{n}-\mathrm{ZVM}$ (derived from Fe ion precipitation) to the substantially lower cost, low surface area $\mathrm{n}-\mathrm{ZVM}$ (derived from ground metals) may have significant benefits for a IZVM or PRB remediation program. These benefits include:

a) Reduced cost. n-ZVM (n-ZVMA) derived from a ground metal is typically about $10 \%$ of the cost of $n-Z V M(n-Z V M B)$ produced by precipitation from a nitrate, chloride or sulphate.

b) Increased active life. n-ZVMA is less prone to fouling by DOM/HA than n-ZVMB [61].

c) Increased activity. n-ZVMA produces larger shifts in both $\mathrm{pH}$ and Eh than n-ZVMB (Figures A1-A16) or m-ZVM [1].

d) Increased control on product selectivity. Figures A1 to A16 in Appendix demonstrate that changing the concentrations of ZVM components can alter the redox trajectory, Eh, $\mathrm{pH}$ and consequently the degree and level of remediation. The use of ground metal particles, rather than bi-metal or tri-metal precipitated complexes, allows the relative ratios of $\mathrm{Fe}: \mathrm{Cu}: \mathrm{Al}$ to be rapidly adjusted during the course of the remediation program in order to compensate for redox changes/interactions associated with the aquifer microbiota, aquifer chemistry, interactions with the host rock minerals and changes in the aquifer flow rate.

\section{Conclusions}

This study has established that there is a common Eh-pH trajectory with time and space velocity for $\mathrm{Fe}^{0}$, when added to water. This trajectory is modified by the presence of $\mathrm{Cu}^{0}$, or $\mathrm{Al}^{0}$, or $\mathrm{NaCl}$, or clay, but is unaffected by the presence of dissolved organic matter. The Eh-pH environment in the aquifer can be predicted from the regression relationships encapsulated by the graphs of Eh and $\mathrm{pH} v s$. SV in the Appendix. In these relationships SV is directly related to a target aquifers pore volume, the amount of ZVM injected, the throughflow rate in the aquifer, changing aquifer permeability and time.

Aquifer remediation is a function of individual equilibrium redox reactions, the product of the constant oscillation between reduction and oxidation and the catalytic reformation $\mathrm{C}_{\mathrm{x}} \mathrm{H}_{\mathrm{y}}, \mathrm{C}_{\mathrm{x}} \mathrm{H}_{\mathrm{y}} \mathrm{O}_{\mathrm{z}}$ and $\mathrm{CO}_{\mathrm{x}}$ to simple organic compounds which can be removed by the microbiota. The establishment of a redox trajectory which is linked directly to $\mathrm{SV}$, allows ZVM aquifer remediation programs to be designed to target a specific redox environment with a specific timeframe. This remediation approach 
has already been shown to be effective for m-ZVM [1]. This study demonstrates that a similar approach could be applied to n-ZVM associated with IZVM and PRB programs.

Static diffusion affects water flowing through IZVM and PRB's, and provides a halo of remediation around the n-ZVM zone. This study has demonstrated (i) that n-ZVM can be used to provide similar levels of treatment for both saline and freshwater, (ii) that the presence of clays can be used to reinforce treatment trajectories. In a previous study [1], it was observed that placement of $\mathrm{m}-\mathrm{ZVM}$ in a PRB provided a less effective aquifer treatment than recirculation through a continuous flow reactor. The redox trajectories (Figures A1-A16) associated with n-ZVM have a lower variance than the similar trajectories associated with $\mathrm{m}-\mathrm{ZVM}$. This difference has significant implications for PRB design, particularly in impermeable or low permeability sediments. Static groundwater mounds are common in low permeability sediments [24-27]. When surface water runoff is directed to infiltration devices in impermeable/low permeability sediments, the infiltration devices will frequently contain static (standing) water between recharge events [24-27]. The air-water contact represents the upper surface of a perched (self-sealing) ground water mound which extends spatially into the surrounding sediment [24-27]. Consequently, placement of n-ZVM in the infiltration devices below the air-water contact will allow modification of the $E h$ and $p H$ of the static ground water mound by static diffusion. This allows placement of PRB's in infiltration devices to provide targeted pollutant removal from overland flow (associated with sustainable urban drainage schemes (SUDS)), and a targeted reconstruction of the redox environment of the associated perched groundwater mounds [25-27].

\section{Acknowledgements}

The two reviewers are thanked for their helpful and constructive comments on an earlier draft.

\section{References}

1. Antia, D.D.J. Sustainable zero-valent metal (ZVM) water treatment associated with diffusion, infiltration, abstraction and recirculation. Sustainability 2010, 2, 2988-3073.

2. Chuang, F-W.;Larson, R.A.; Wessman, M.S. Zero-valent iron-promoted dechlorination of polychlorinated biphenyls. Environ. Sci. Technol. 1995, 29, 2460-2463.

3. Orth, R.; Daudo, T.; McKenzie, D.E. Reductive dechlorination of DNAPL Trichloroethylene by zero-valent iron. Prac. Period. Hazard. Toxic. Radioact. Waste Manag. 1998, 2, 123-128

4. Chen, J.L.; Al-Abed, S.R.; Ryan, J.A.; Li, Z. Effects of pH on dechlorination of trichloroethylene by zero-valent iron. J. Hazard Mater. 2001, 83, 243-254.

5. Lowry, G.V.; Johnson, K.M. Congener-specific dechlorination of dissolved PCBs by microscale and nanoscale zerovalent iron in water/methanol solution. Environ. Sci. Technol. 2004, 38, 5208-5216.

6. Shin, M-C.; Choi, H-D.; Kim, D-H.; Baek, K.; Effect of surfactant on reductive dechlorination of trichloroethylene by zero-valent iron. Desalination 2008, 223, 299-307.

7. Kim, G.; Jeong, W.; Choe, S. Dechlorination of atrazine using zero-valent iron $\left(\mathrm{Fe}^{0}\right)$ under neutral pH conditions. J. Hazard. Mater. 2008, 155, 502-506.

8. Ghazali, M.; McBean, E.; Shen, H.; Dastous, P-A. Impact of iron concentration and ph on zero-valent iron dechlorination of DDT for brownfields. Remediat. J. 2010, 20, 97-107. 
9. Thompson, J.M.; Chisholm, B.J.; Bezbaruah, A.N. Reductive dechlorination of Chloroactetanilide herbicide (Alachlor) using zero-valent iron nanoparticles. Environ. Engrg. Sci. 2010, 27, 227-232.

10. McElroy, B.; Keith, A.; Glasgow, J.; Dasappa, S. The use of zero-valent iron injection to remediate groundwater: Results of a pilot test at Marshall space flight center. Remediation 2003, $13,145-153$.

11. Demonstration of in situ Dehalogenation of DNAPL through Injection of Emulsified Zero-Valent Iron at Launch Complex 34 in Cape Canaveral Air Force Station, Florida; Innovative Technology Evaluation Report, EPA/540/R-07/006; U.S. Environmental Protection Agency: Cincinnati, OH, USA, September, 2004.

12. Gavaskar, A.; Tatar, L.; Condit, W. Cost and Performance Report: Nanoscale Zero-Valent Iron Technologies for Source Remediation; Contract Report CR-05-007-ENV; Naval Facilities Engineering Command/Engineering Service Center (NAVFAC ESC): Port Hueneme, CA, USA, 2005; p. 44.

13. Pupeza, M.; Cernik, M.; Greco, M. Dechlorination of chlorinated hydrocarbons by zero-valent iron nano-particles. NATO Sci. Ser. 2007, 75, 111-118.

14. Gavaskar, A.; Bhargava, M.; Condit, W. Cost and Performance Report for a Zero-Valent Iron (ZVI) Treatability Study at Naval Air Station North Island; Technical Report TR-2307-ENV; Naval Facilities Engineering Command/Engineering Service Center (NAVFAC ESC): Port Hueneme, CA, USA, 2008.

15. Alvarado, J.S.; Rose, C.; LaFreniere, L. Degradation of carbon tetrachloride in the presence of zero-valent iron. J. Environ. Monit. 2010, 12, 1524-1530.

16. Sunkara, B.; Zhan, J.; He, J.; McPherson, G.L.; Piringer, G.; John, V.T. Nanoscale zerovalent iron supported on uniform carbon microspheres for the in situ remediation of chlorinated hydrocarbons. ACS Appl. Mater. Interfaces, 2010, 2, 285-2862.

17. Sorel, D.; Warner, S.D.; Longino, B.L.; Honniball, J.H.; Hamilton, L.A. Performance monitoring and dissolved hydrogen measurements at a permeable zero valent iron reactive barrier. ACS Symp. Ser. 2002, 837, 278-285.

18. Choi, J-H.; Kim, Y-H.; Choi, S.J. Reductive dechlorination and bidegradation of 2,4,6-trichlorophenol using sequential permeable reactive barriers: laboratory studies. Chemosphere 2007, 67, 1551-1557.

19. Nurmi, J.T.; Tratnyek, P.G.; Johnson, R.L.; Thoms, R.B.; Johnson, R.O.B. Reduction of TNT and RDX by core material from an iron permeable reactive barrier. Paper M-009. In Proceedings of the 6th International Conference on Remediation of Chlorinated and Recalcitrant Compounds, Monterey, CA, USA, May 2008; Sass, B.M., Ed.; Battelle: Columbus, OH, USA, 2008.

20. Higgins, M.R.; Olson, T.M. Life-cycle case study comparison of permeable reactive barrier versus pump-and-treat remediation. Environ. Sci. Technol. 2009, 43, 9432-9438.

21. Phillips, D.H.; Van Nooten, T.; Bastiaens, L.; Russell, M.I.; Dickson, K.; Plant, S.; Ahad, J.M.; Newton, T.; Elliot, T.; Kalin, R.M. Ten year performance evaluation of a field-scale zero-valent iron permeable reactive barrier installed to remediate trichloroethene contaminated groundwater. Environ. Sci. Technol. 2010, 15, 3861-3869. 
22. Gilbert, O.; de Pablo, J.; Cortina, J.-L.; Ayora, C. In situ removal of arsenic from groundwater by using permeable reactive barriers of organic matter/limestone/zero-valent iron mixtures. Environ. Geochem. Health 2010, 32, 373-378.

23. Luo, H.; Jin, S.; Fallgren, P.H.; Colberg, P.J.S.; Johnson, P.A. Prevention of iron passivation and enhancement of nitrate reduction by electron supplementation. Chem. Eng. J. 2010, 160, 185-189.

24. Antia, D.D.J. Prediction of overland flow and seepage zones associated with the interaction of multiple Infiltration Devices (Cascading Infiltration Devices). Hydrol. Proc. 2008, 22, 2595-2614.

25. Antia, D.D.J. Formation and control of self-sealing high permeability groundwater mounds implications for SUDS and sustainable pressure mound management. Sustainability 2009, 1, 855-923.

26. Antia, D.D.J. Interacting Infiltration Devices (Field Analysis, Experimental Observation and Numerical Modeling): Prediction of Seepage (Overland Flow) Locations, Mechanisms and Volumes-Implications for SUDS, Groundwater Raising Projects and Carbon Sequestration Projects. In Hydraulic Engineering: Structural Applications, Numerical Modeling and Environmental Impacts, 1st ed.; Hirsch, G., Kappel, B., Eds.; Nova Science Publishers: Hauppauge, NY, USA, 2010; pp. 85-156.

27. Antia, D.D.J. Interpretation of Overland Flow Associated with Infiltration Devices Placed in Boulder Clay and Construction Fill. In Overland Flow and Surface Runoff, 1st ed.; Wong, T.S.W., Ed.; Nova Science Publishers: Hauppauge, NY, USA, 2011 (In Press).

28. Fiore, S.; Zanetti, M.C. Preliminary tests concerning zero-valent iron efficiency in organic pollutants removal. Am. J. Environ. Sci. 2009, 5, 555-560.

29. Hao, Z.W.; Xu, X.H.; Wang, D.H. Reductive denitrification of nitrate by scrap iron filings. J. Zhejang Univ. Sci. B. 2005, 6, 182-186.

30. Hao, Z.W.; Xu, X.H.; Jin, J.; He, P.; Liu, Y.; Wang, D.H. Simultaneous removal of nitrate and heavy metals by iron metal. J. Zhejang Univ. Sci. B. 2005, 6, 307-310.

31. Zhang, W-X. Nanoscale iron particles for environmental remediation: An overview. J. Nanoparticle Res. 2003, 5, 323-332.

32. Wang, C-B.; Zhang, W-X. Synthesising nano-scale iron particles for rapid and complete dechlorination of TCE and PCBs. Environ. Sci. Technol. 1997, 31, 2154-2156.

33. Liu, Y.; Majetich, S.A.; Tilton, R.D.; Sholl, D.S.; Lowry, G.V. TCE dechlorination rtaes, pathways and efficiency of nanoscale particles with different properties. Environ. Sci. Technol. 2005, 39, 1338-1345.

34. Tokoro, H.; Nakabayashi, T.; Fujii, S.; Zhao, H.; Hafeli, U.O. Magnetic iron particles with high magnetization useful for immunoassay. J. Magnetism Magnetic Mat. 2009, 321, 1676-1678.

35. Antony, J.; Nutting, J.; Baer, D.R.; Meyer, D.; Sharma, A.; Qiang, Y. Size-dependent specific surface area of nanoporous film assembled by core-shell iron nanoclusters. J. Nanomat. 2006, 1, $1-4$.

36. Krasnoperov, L.N.; Peng, J.; Marshall, P. Modified transition state theory and negative apparent activation energies of simple metathesis reactions: Application to the reaction $\mathrm{CH}_{3}+\mathrm{HBr}=\mathrm{CH}_{4}+\mathrm{Br}$. J. Phys. Chem. A 2006, 110, 3110-3120.

37. Wei, J. Adsorption and cracking of n-alkanes over ZSM-5: negative activation energy of reaction. Chem. Engrg. Sci. 1996, 51, 2995-2999. 
38. Alvarez-Idaboy, J.R.; Mora-Diez, N.; Vivier-Bunge, A. A quantum chemical and classical transition state theory explanation of negative activation energies in $\mathrm{OH}$ addition to substituted ethenes. J. Am. Chem. Soc. 2000, 122, 3715-3720.

39. Alvarez-Idaboy, J.R.; Mora-Diez, N.; Boyd, R.J.; Vivier-Bunge, A. On the importance of prereactive complexes in molecule-radical reactions: hydrogen abstraction from aldehydes by $\mathrm{OH}$. J. Am. Chem. Soc. 2001, 123, 2018-2024.

40. Cunningham, D.A.H.; Vogel, W.; Haruta, M. Negative activation energies in CO oxidation over an icosahedral $\mathrm{Au} / \mathrm{Mg}(\mathrm{OH})_{2}$ catalyst. Cat. Let. 1999, 63, 43-47.

41. Brookhaven National Laboratory Carbon Dioxide (Reduction); Report BNL-67077(Produced for the U.S.. Department of Energy), Contract DE-AC02-98CH10886; Brookhaven National Laboratory: Long Island, NY, USA, 1998; p. 10.

42. Perkins, H.F.; Parker, M.B.; Walker, M.L. Chicken Manure-Its Production, Composition and Use as a Fertilizer; Georgia Agricultural Experiment Stations, University of Georgia College of Agriculture: Athens, GA, USA, 1964.

43. Dikinya, O.; Mufwanzala, N. Chicken manure - enhanced soil fertility and productivity: Effects of application rates. J. Soil Sci. Environ. Manag. 2010, 1, 46-54.

44. Materechera, S.A.; Mkhabela, T.S. The effectiveness of lime, chicken manure and leaf litter ash in ameliorating acidity in a soil previously under black wattle (Acacia mearnsii) plantation. Biores. Technol. 2002, 85, 9-16.

45. Himathongkham, S.; Bahari, S.; Riemann, H.; Cliver, D. Survivial of Escherichia coli O157:H7 and Salmonella typhimurium in cow manure and cow slurry. FEMS Mircobiol. Let. 1999, 178, 251-257.

46. Kunz, A.; Steinmetz, R.L.R; Ramme, M.A.A.; Coldebella, A. Effect of storage time on swine manure solid separation by screening. Biores. Technol. 2009, 100, 1815-1818.

47. Xing, Y.; Li, Z.; Fan, Y.; Hou, H. Biohydrogen production from dairy manures with acidification pretreatment by anaerobic fermentation. Environ. Sci. Pollut. Res. Int. 2010, 17, 392-399.

48. Antia, D.D.J. Oil polymerisation and fluid expulsion from low temperature, low maturity, over pressured sediments. J. Petrol. Geol. 2008, 31, 263-282.

49. Elek, J. Homogenous Catalytic Reduction of $\mathrm{CO}_{2}$ in Aqueous Medium; PhD Thesis; University of Debrecen: Debrecen, Hajdu-Bihar, Hungary, 2003.

50. Guan, G.; Kida, T.; Ma, T.; Kimura, K.; Abe, E.; Yoshida, A. Reduction of aqueous $\mathrm{CO}_{2}$ at ambient temperature using zero-valent iron-based composites. Green Chemistry 2003, 5, 630-634.

51. Kang, S.H.; Choi, W. Oxidative degradation of organic compounds using zero-valent iron in the presence of natural organic matter serving as an electron shuttle. Environ. Sci. Technol. 2009, 43, 878-883.

52. Rahmani, A.R.; Zarrabi, M.; Samarghandi, M.R.; Afkhami, A.; Ghaffari, H.R. Degradation of Azo Dye Reactive Black 5 and Acid Orange 7 by Fenton like mechanim. Iranian J. Chem. Eng. 2010, 7, 87-94.

53. Wang, F. Modelling of Aqueous Carbon Dioxide Corrosion in Turbulent Pipe Flow; PhD Thesis; University of Saskatchewan: Saskatoon, Canada, 1999. 
54. Schmitt-Kopplin, P.; Gabelica, Z.; Gougeon, R.D.; Fekete, A.; Kanawati, B.; Harir, M.; Gebefugi, I.; Eckel, G.; Hertkorn, N. High molecular diversity of extraterrestrial organic matter in Murchison meteorite revealed 40 years after its fall. PNAS 2010, 107, 2763-2768.

55. Drobner, E.; Huber, H.; Wachterhauser, G.; Rose, D.; Stetter, K.O. Pyrite formation linked with hydrogen evolution under anaerobic conditions. Nature 1990, 346, 742-744.

56. Chai, L.; Navrotsky, A. Enthalpy of formation of siderite and its application in phase equilibria calculation. Am. Mineral. 1994, 79, 921-929.

57. Angamuthi, R.; Byers, P.; Lutz, M.; Spek, A.L.; Bouwman, E. Electrocatalytic $\mathrm{CO}_{2}$ conversion to oxylate by a copper complex. Science 2010, 327, 313-315.

58. Baur, R.F.; Smith, W.M. The mono-oxalato complexes of iron (III). Can. J. Chem. 1965, 43, 2755-2762.

59. Dries, J.; Bastiaens, L.; Springael, D.; Kuypers, S.; Agathos, S.N.; Diels, L. Effect of humic acids on heavy metal removal by zero-valent iron in batch and continuous flow column systems. Water Res. 2005, 39, 3531-3540.

60. Geological Survey Japan. Atlas of Eh-pH Diagrams; Open File Report No. 419; National Institute of Advanced Industrial Science and Technology: Naoto, Japan, 2005.

61. Giasuddin, A.B.M.; Kanel, S.R.; Choi, H. Adsorption of humic acid onto nanoscale zerovalent iron and its effect on arsenic removal. Environ. Sci. Technol. 2007, 41, 2022-2027.

62. Doong, R-A.; Lai, Y-J. Dechlorination of tetrachloroethylene by palladized iron in the presence of humic acid. Water Res. 2005, 39, 2309-2318.

63. Liu, X.; Wazne, M.; Han, Y.; Christodoulatos, C.; Jasinkiewicz, K.L. Effects of natural organic matter on aggregation kinetics of boron nanoparticles in monovalent and divalent electrolytes. J. Colloid. Interface Sci. 2010, 348, 101-107.

64. Cole, E.B.; Lakkaraju, P.S.; Rampulla, D.M.; Morris, A.J.; Abelev, E; Bocarsly, A.B. Using a one-electron shuttle for the multielectron reduction of $\mathrm{CO}_{2}$ to methanol: Kinetic, mechanistic and structural insights. J. Am. Chem. Soc. 2010, 132, 11539-11551.

65. Royer, R.A.; Burgos, W.D.; Fischer, A.S.; Unz, R.F.; Dempsey, B.A. Enhancement of biological reduction of hematite by electron shuttling and Fe(II) complexation. Environ. Sci. Technol. 2002, 36, 1939-1946.

66. Kappler, A.; Benz, M.; Schink, B.; Brune, A. Electron shuttling via humic acids in microbial iron (III) reduction in a freshwater sediment. FEMS Microbiol. Ecol. 2004, 47, 85-92. 


\section{Appendix}

The experimental results for $\mathrm{n}-\mathrm{ZVM}$ are provided in Figures $\mathrm{A} 1$ to $\mathrm{A} 16 . \mathrm{EC}=\mu \mathrm{S} \mathrm{cm}{ }^{-1} . \mathrm{Eh}=\mathrm{V}$.

Figure A1. MR1: n-Fe ${ }^{0}$, fresh water. (a) $p H$ vs. Time; (b) $p H$ vs. SV; (c) Eh vs. time; (d) Eh vs. SV; (e) EC/EC Initial vs. time; (f) EC/EC Initial vs. SV; (g) Eh vs. pH (SRE ringed); (h) $\mathrm{pH}$ vs. EC/EC Initial; (i) Eh vs. EC/EC Initial; (j) $\mathrm{pH} v s . \mathrm{E}(\mathrm{C})$ Arrows indicate decreasing SV and increasing tim(e).

(a)
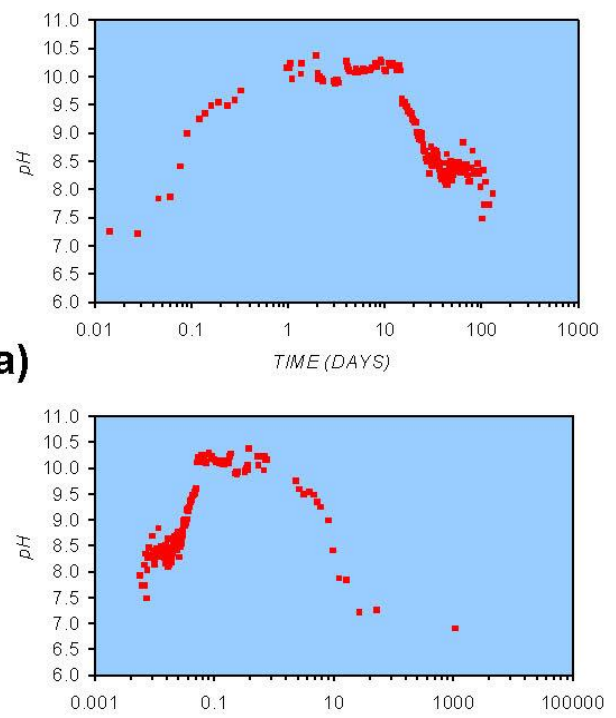

(b)

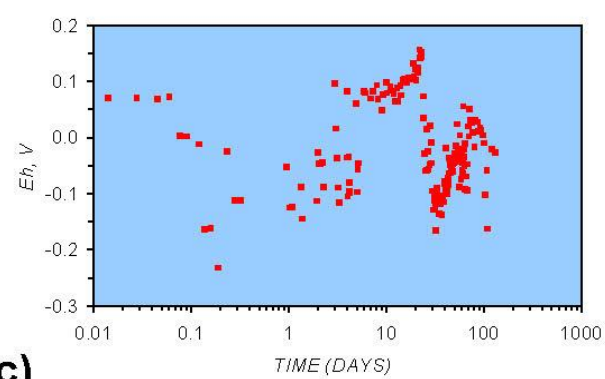

(c)

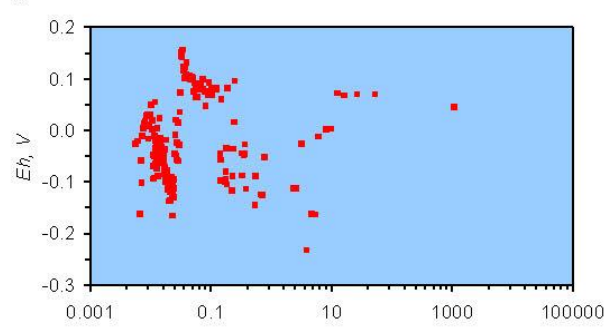

(d)

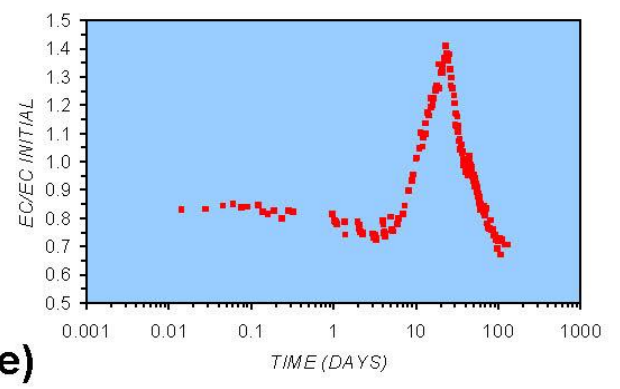

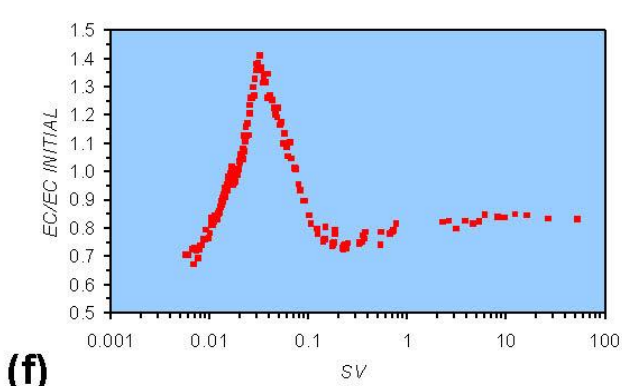

(f)
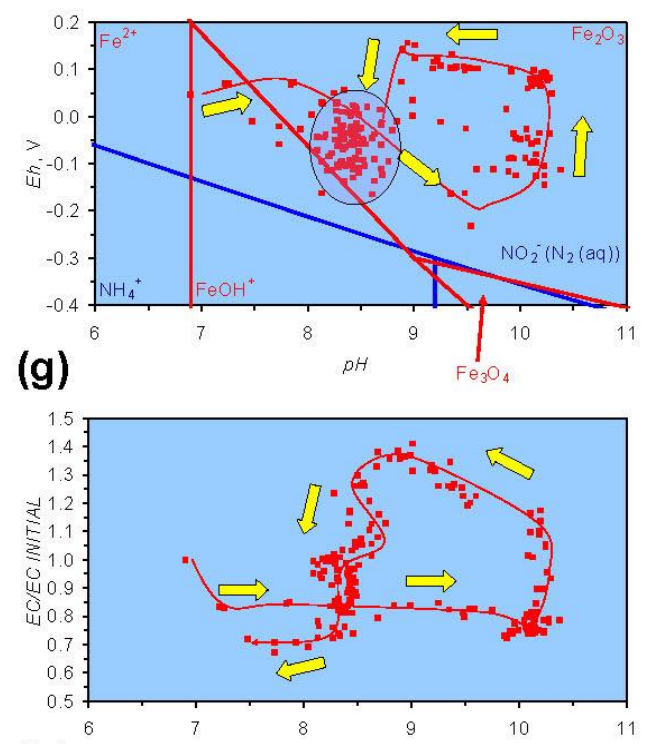

(h)

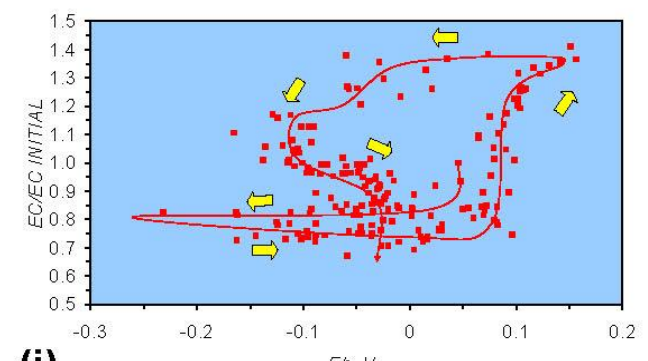

(i)

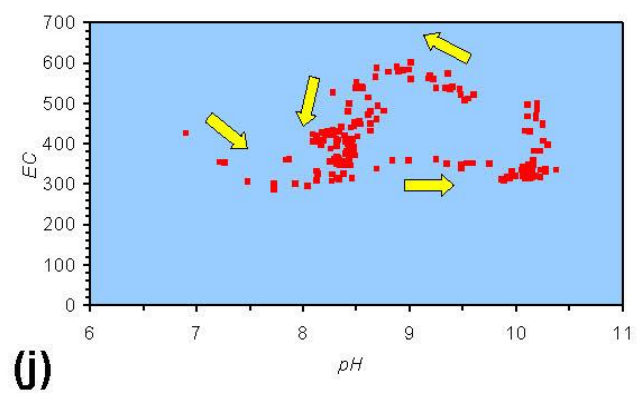


Figure A2. MR2: $\mathrm{n}-\mathrm{Al}^{0}$, fresh water. (a) $p H$ vs. Time; (b) $p H$ vs. SV; (c) $E h$ vs. time; (d) Eh $v s . \mathrm{SV}$; (e) EC/EC Initial vs. time; (f) EC/EC Initial vs. SV; (g) Eh vs. pH (SRE ringed); (h) $\mathrm{pH}$ vs. EC/EC Initial; (i) Eh vs. EC/EC Initial; (j) $\mathrm{pH} v s$. E(C) Arrows indicate decreasing SV and increasing tim(e).

(a)
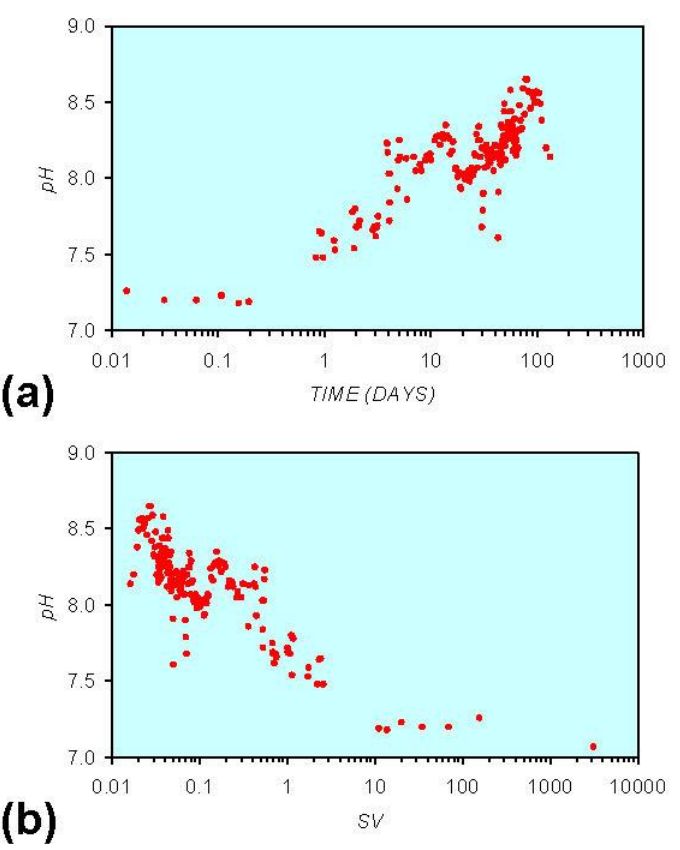

(c)

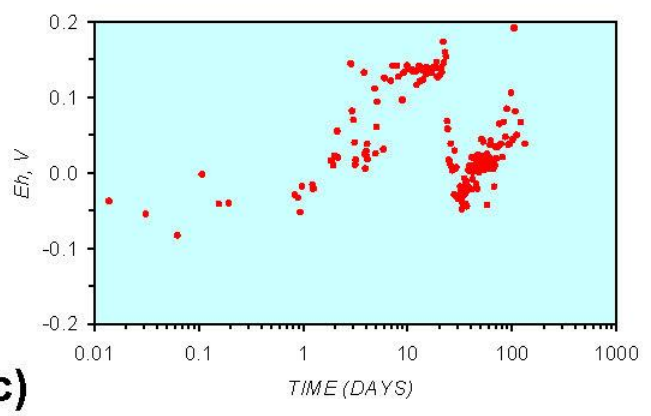

(d)
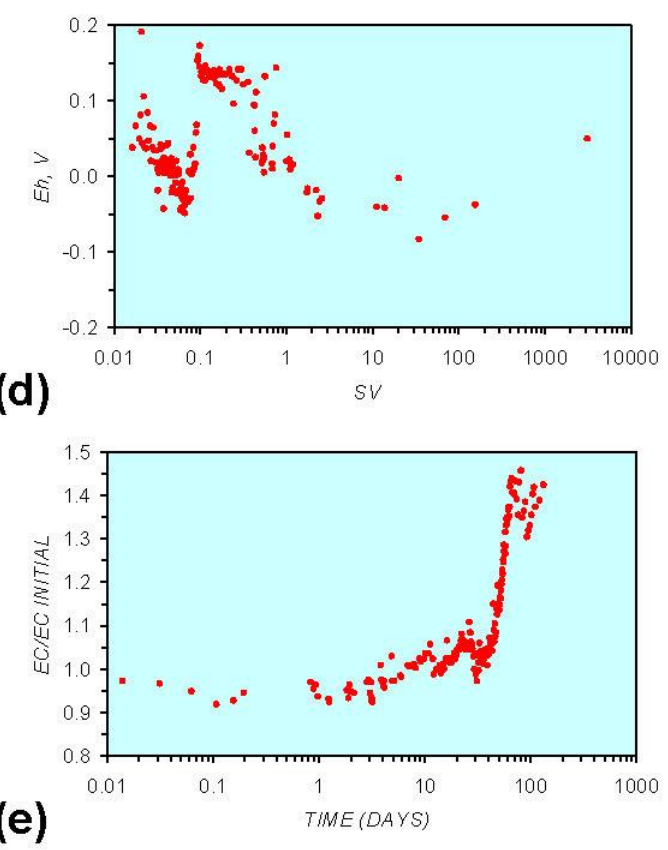
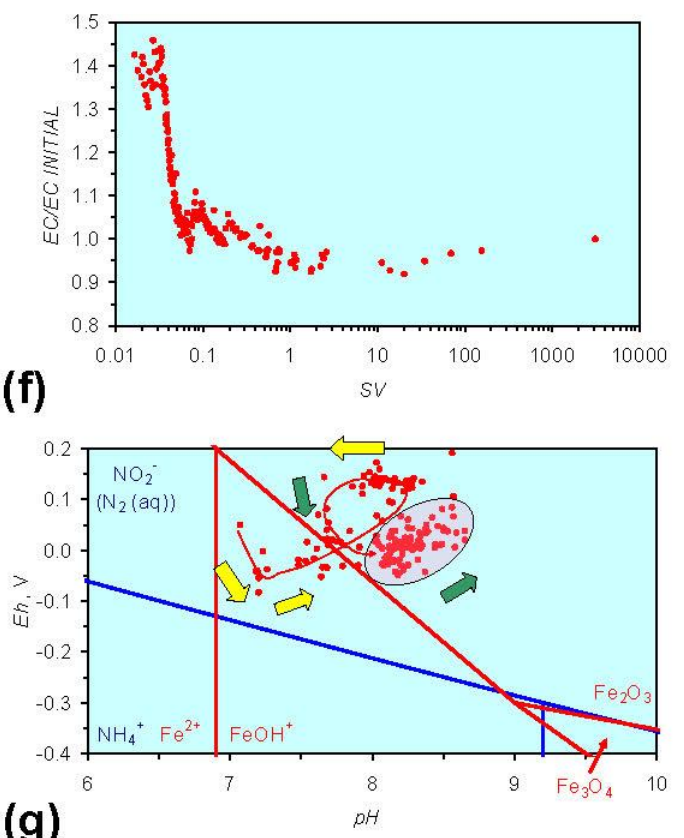

(g)

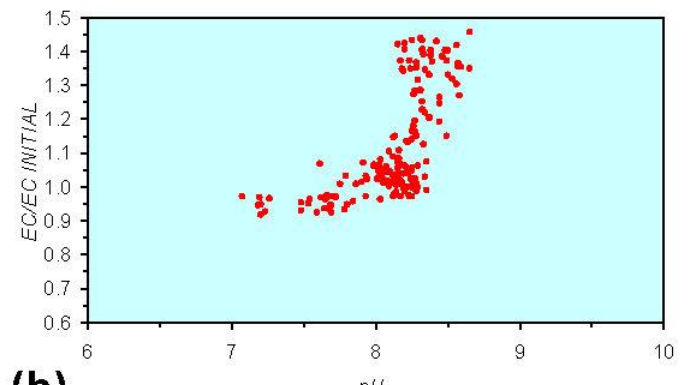

(h)

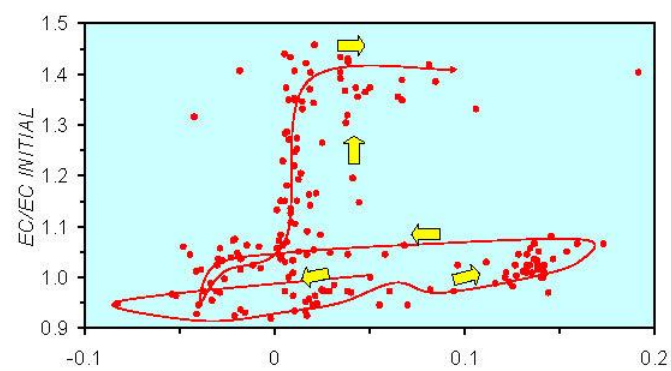

(i)

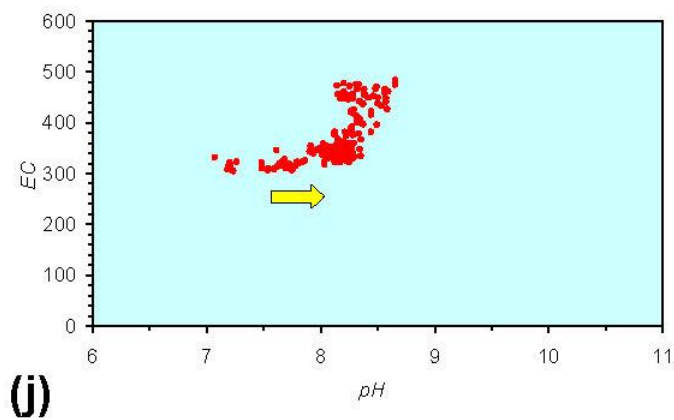


Figure A3. MR3: $\mathrm{n}-\mathrm{Fe}^{0}+\mathrm{n}-\mathrm{Cu}^{0}$, fresh water. (a) $p H$ vs. Time; (b) $p H v s$. SV; (c) $E h v s$. time; (d) Eh vs. SV; (e) EC/EC Initial vs. time; (f) EC/EC Initial vs. SV; (g) Eh vs. pH (SRE ringed); (h) $\mathrm{pH}$ vs. EC/EC Initial; (i) Eh vs. EC/EC Initial; (j) $\mathrm{pH}$ vs. E(C) Arrows indicate decreasing SV and increasing tim(e).

(a)

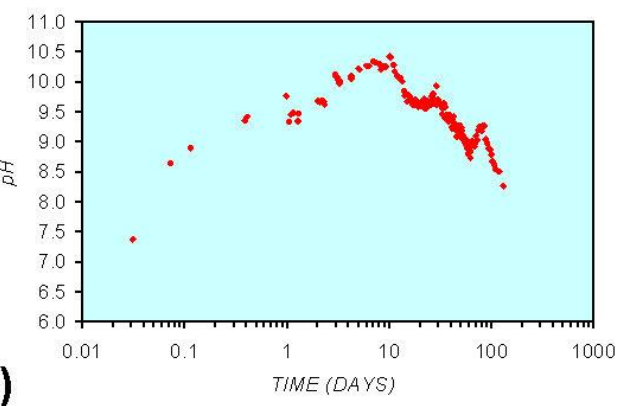

(b)
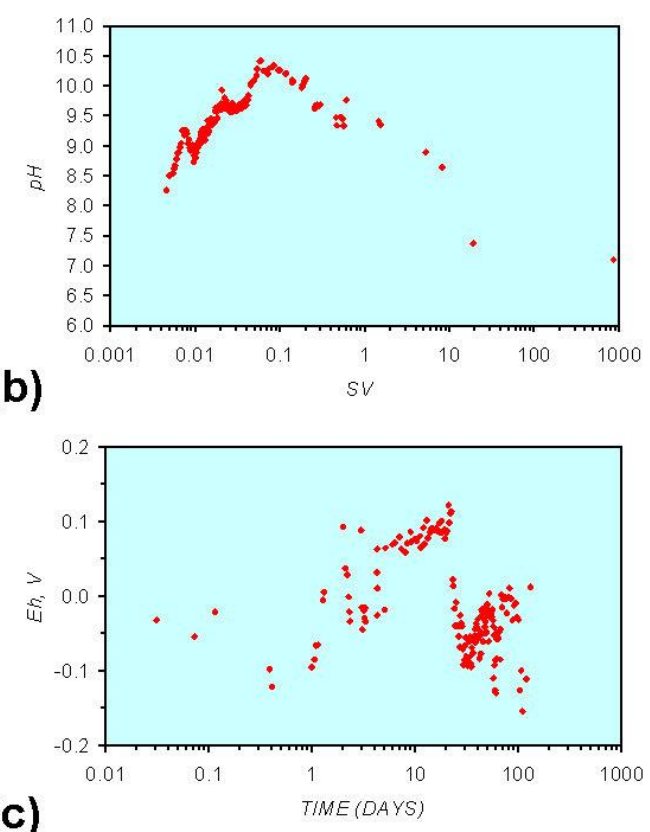

(c)

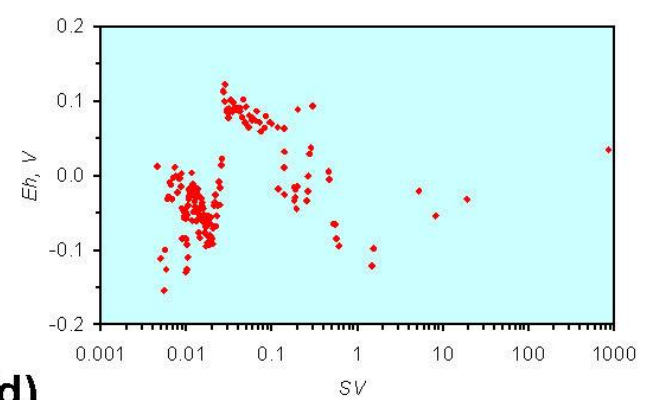

(d)

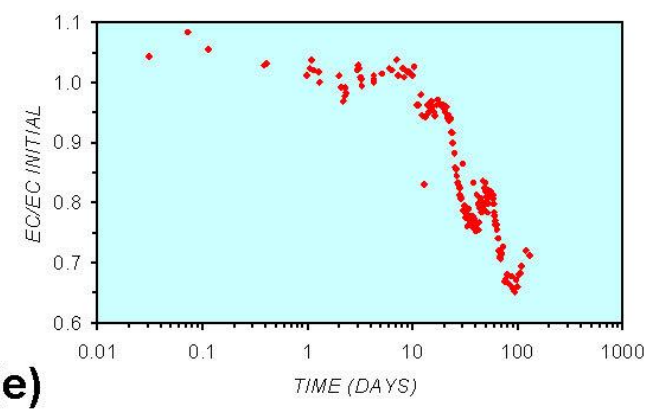

(f)
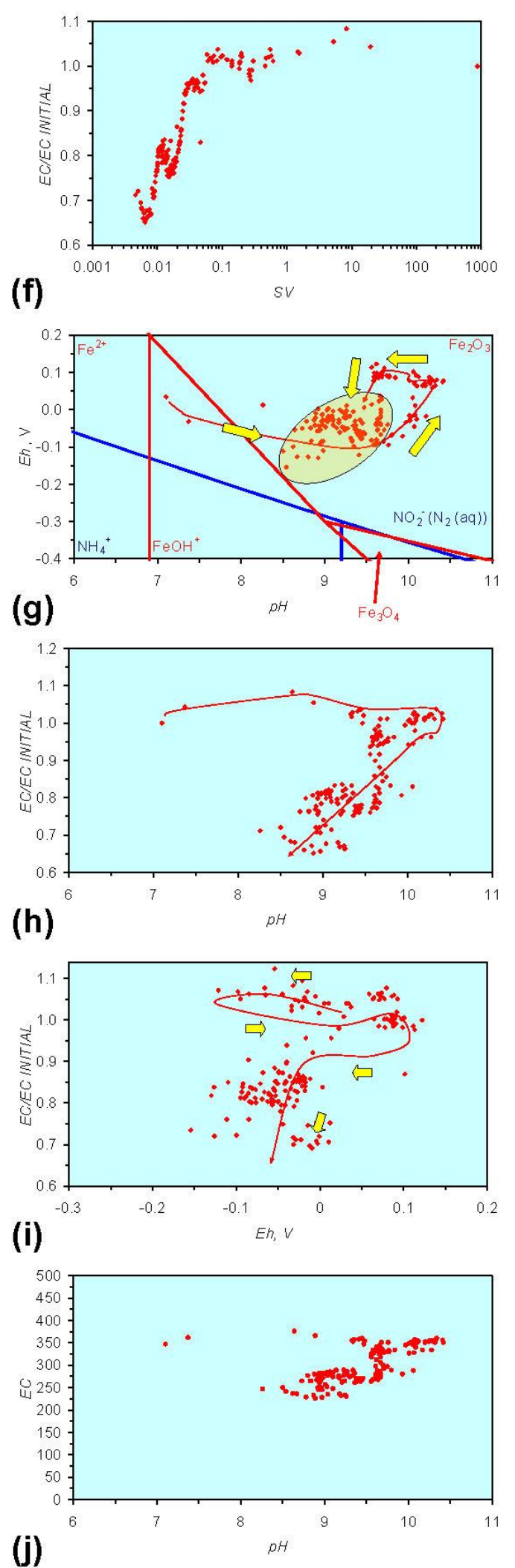
Figure A4. MR4: $\mathrm{n}-\mathrm{Fe}^{0}+\mathrm{n}-\mathrm{Al}^{0}$, fresh water. (a) $p H v s$. Time; (b) $p H v s$. SV; (c) $E h v s$. time; (d) Eh vs. SV; (e) EC/EC Initial vs. time; (f) EC/EC Initial vs. SV; (g) Eh vs. pH (SRE ringed); (h) $\mathrm{pH} v s$. EC/EC Initial; (i) Eh vs. EC/EC Initial; (j) pH vs. E(C) Arrows indicate decreasing SV and increasing tim(e).

(a)
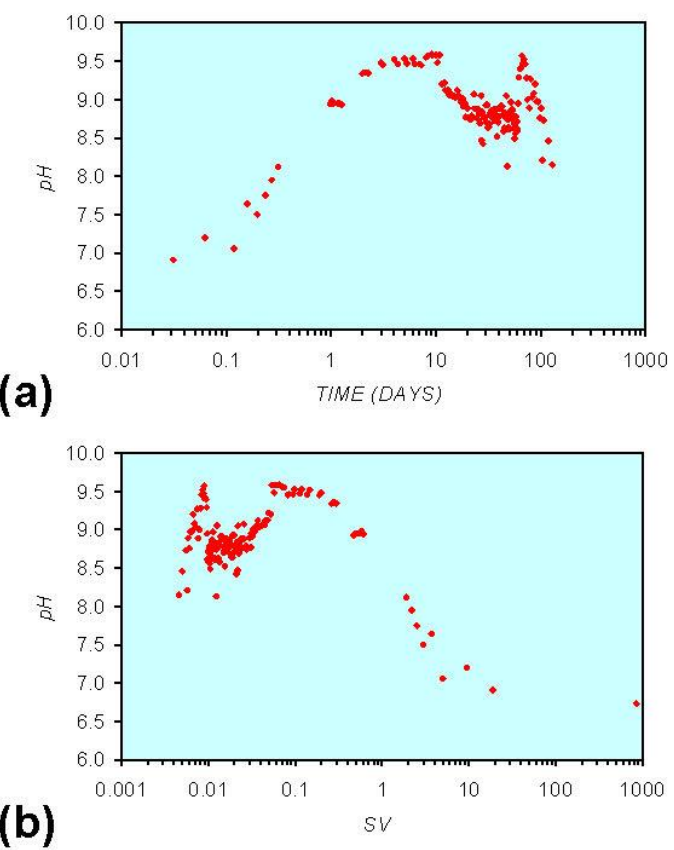

(b)

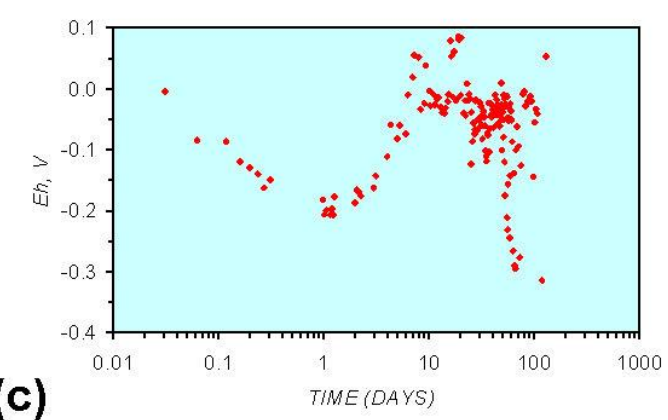

(d)
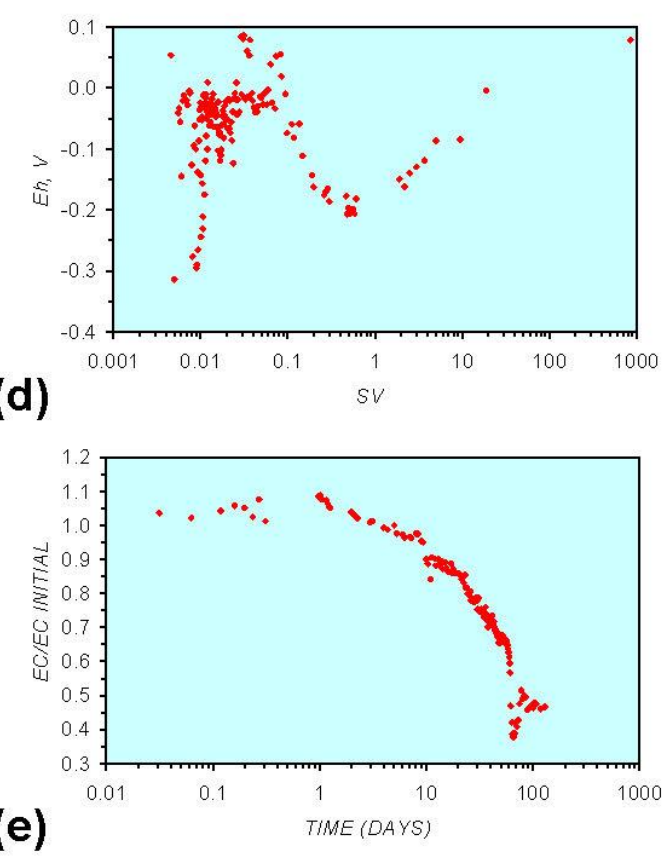
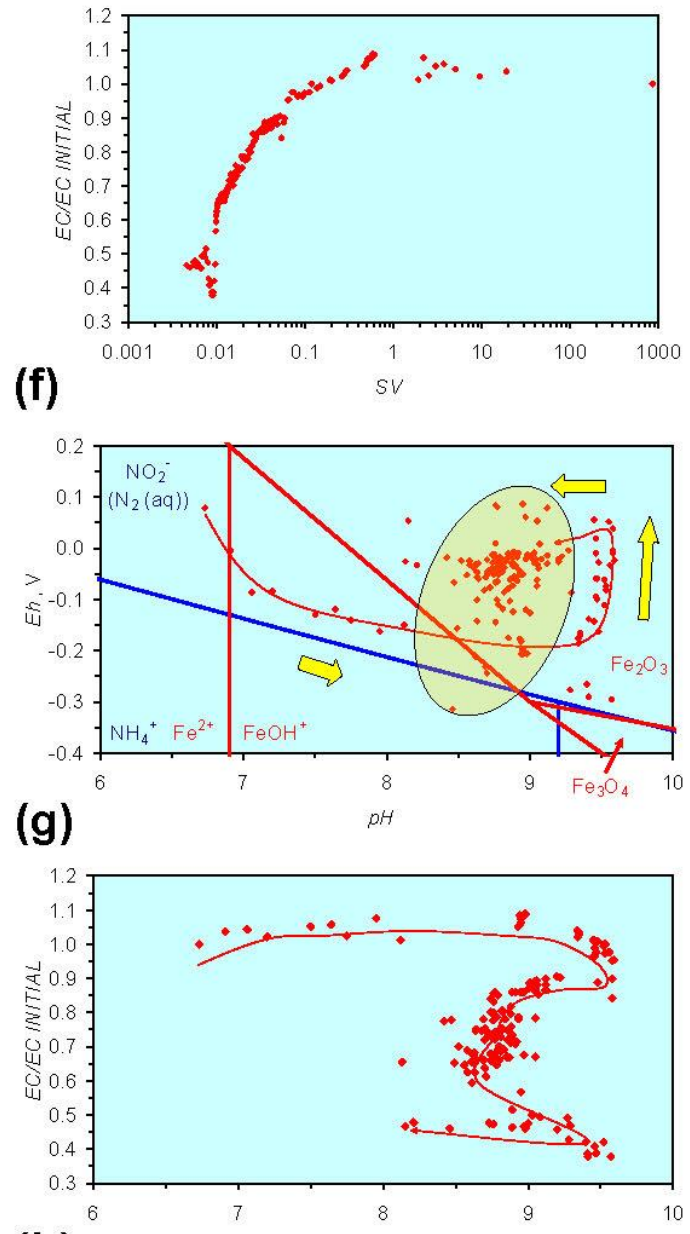

(h)
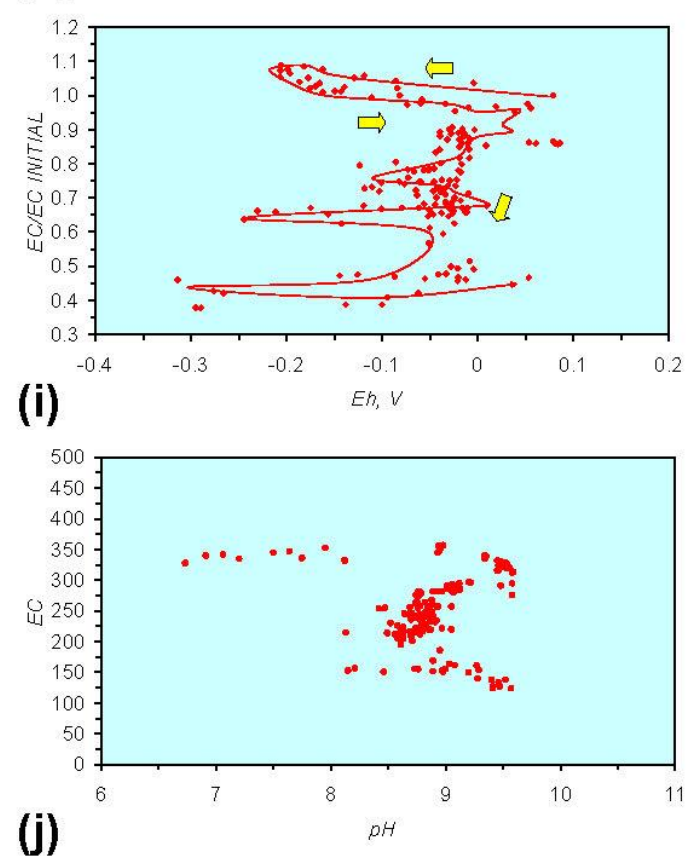
Figure A5. MR5: $\mathrm{n}-\mathrm{Fe}^{0}+\mathrm{n}-\mathrm{Al}^{0}+\mathrm{n}-\mathrm{Cu}^{0}$, fresh water. (a) $p H$ vs. Time; (b) $p H$ vs. SV; (c) Eh vs. time; (d) Eh vs. SV; (e) EC/EC Initial vs. time; (f) EC/EC Initial vs. SV; (g) Eh vs. $\mathrm{pH}$ (SRE ringed); (h) $\mathrm{pH} v s$. EC/EC Initial; (i) Eh $v s$. EC/EC Initial; (j) $\mathrm{pH} v s . \mathrm{E}(\mathrm{C})$ Arrows indicate decreasing SV and increasing tim(e).

(a)
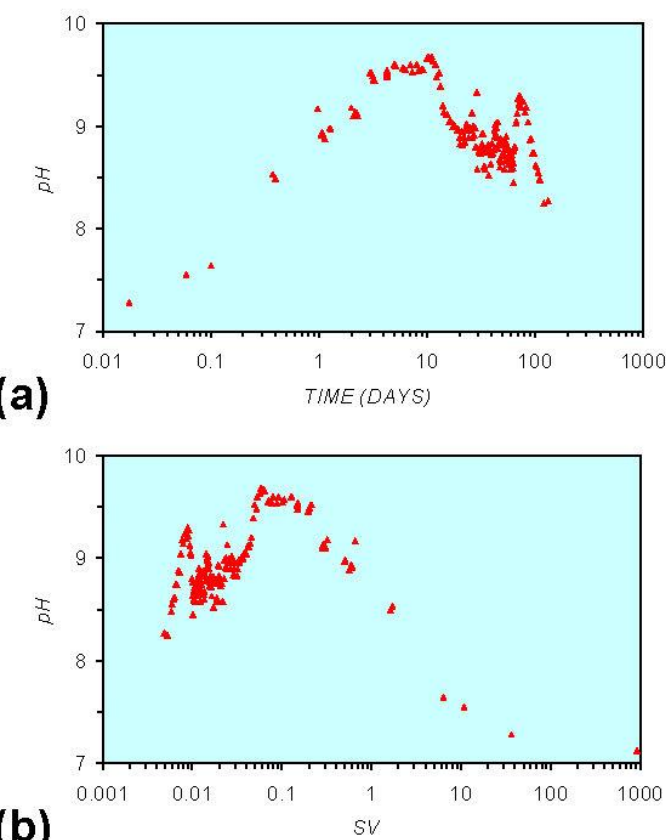

(b)

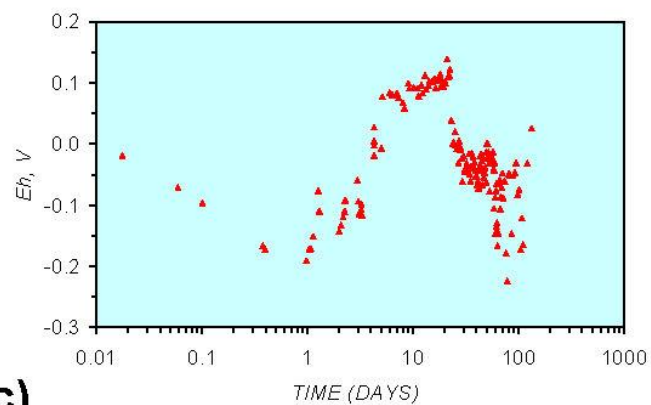

(c)

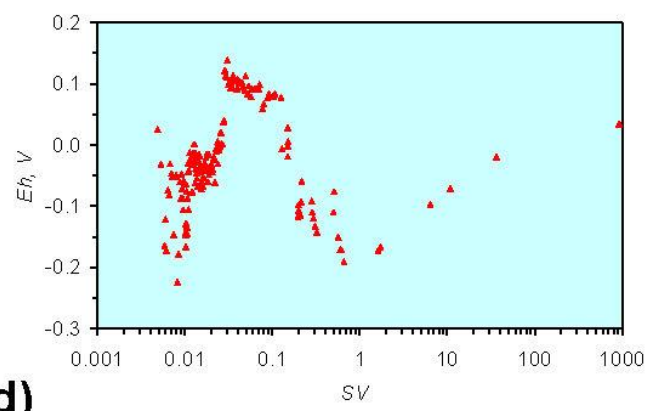

(d)

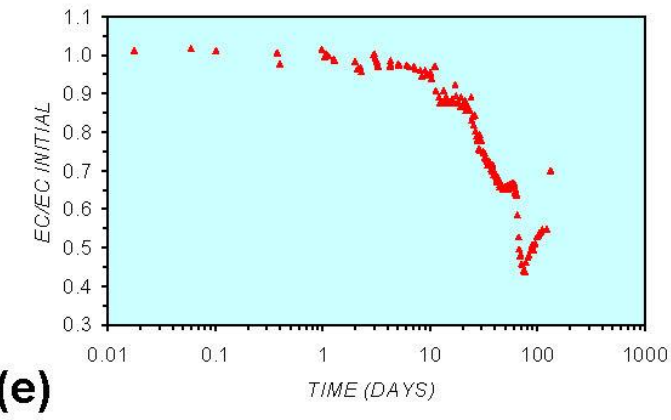

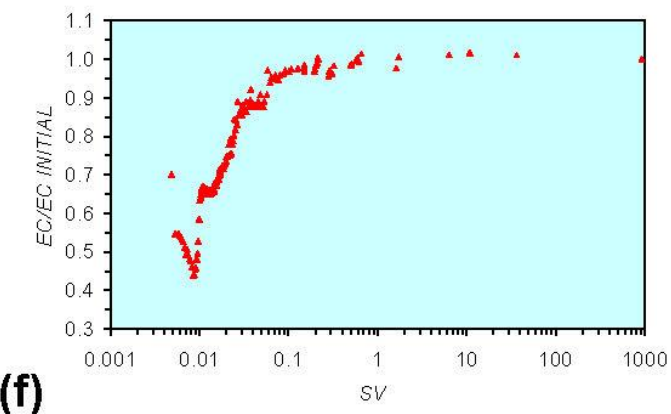
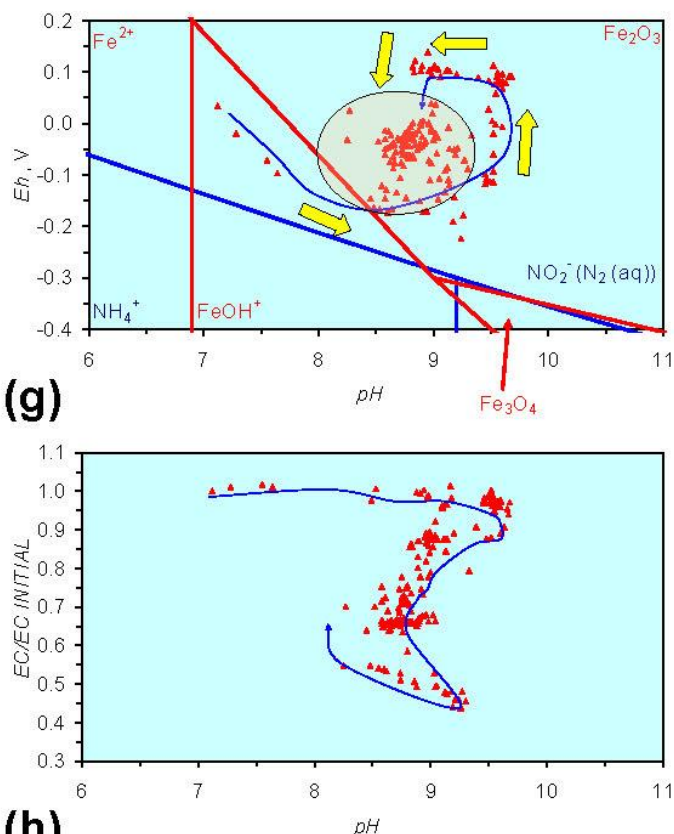

(h)
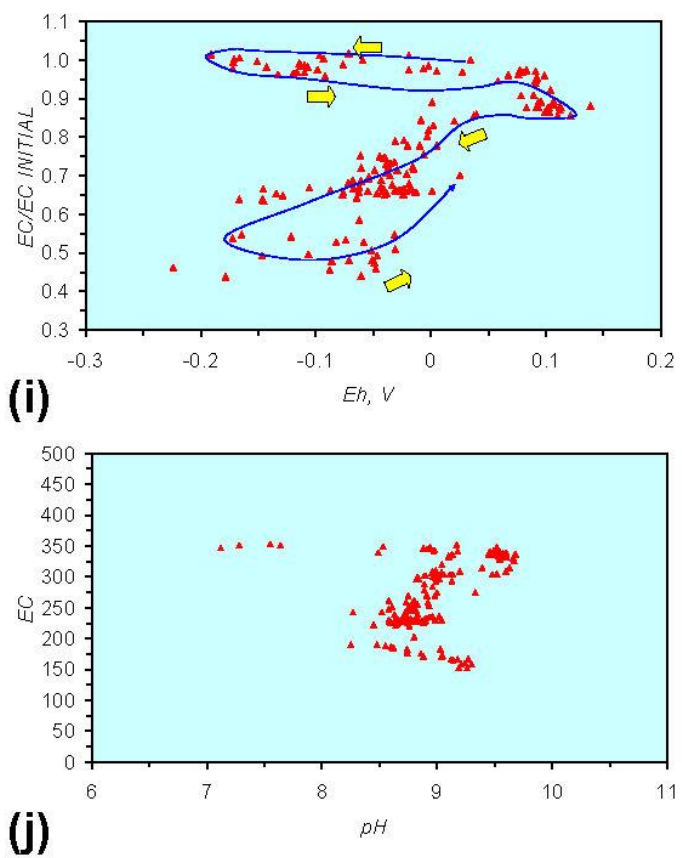
Figure A6. MR6: $\mathrm{n}-\mathrm{Fe}^{0}$, fresh water containing dissolved organic matter. (a) $p H$ vs. Time; (b) $p H$ vs. SV; (c) Eh vs. time; (d) Eh vs. SV; (e) EC/EC Initial vs. time; (f) EC/EC Initial vs. $\mathrm{SV}$; (g) Eh vs. $\mathrm{pH}$ (SRE ringed); (h) $\mathrm{pH}$ vs. EC/EC Initial; (i) Eh vs. EC/EC Initial; (j) $\mathrm{pH} v s$. $\mathrm{E}(\mathrm{C})$ Arrows indicate decreasing $\mathrm{SV}$ and increasing tim(e).

(a)
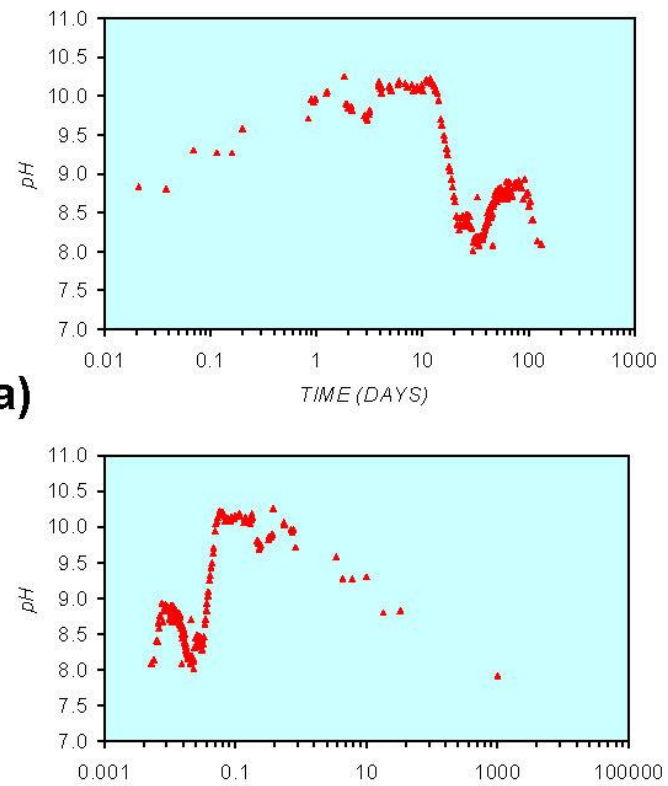

(b)

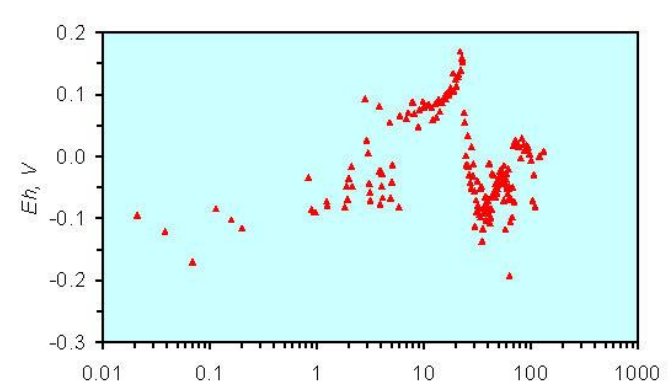

(c)

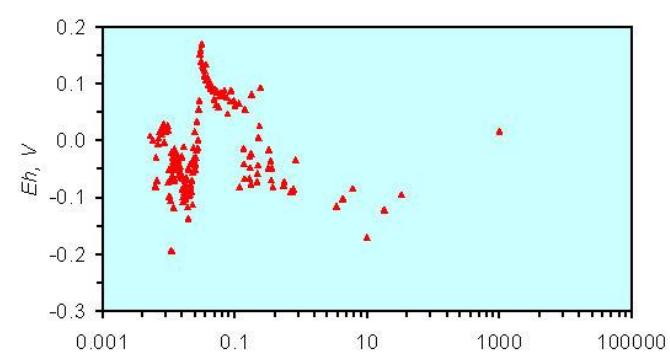

(d)

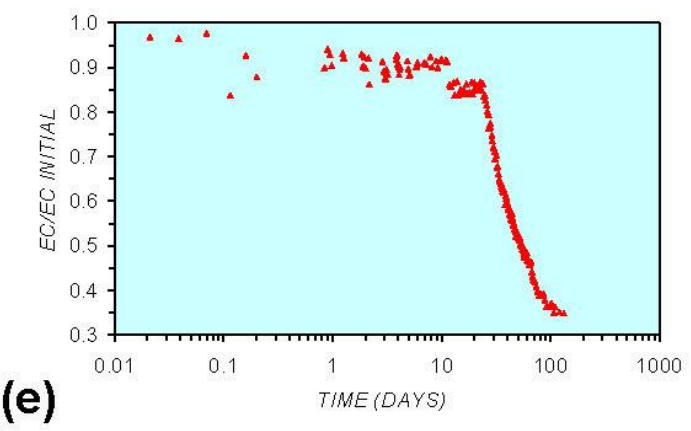

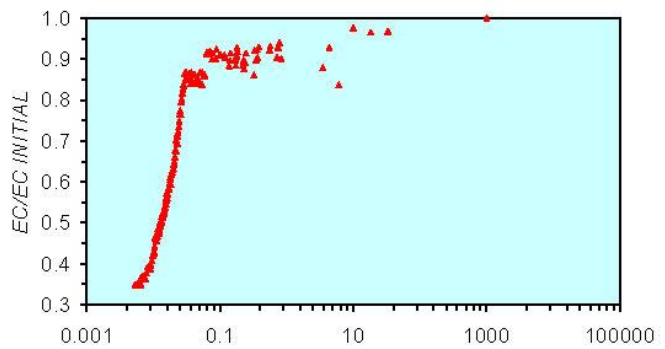

(f)
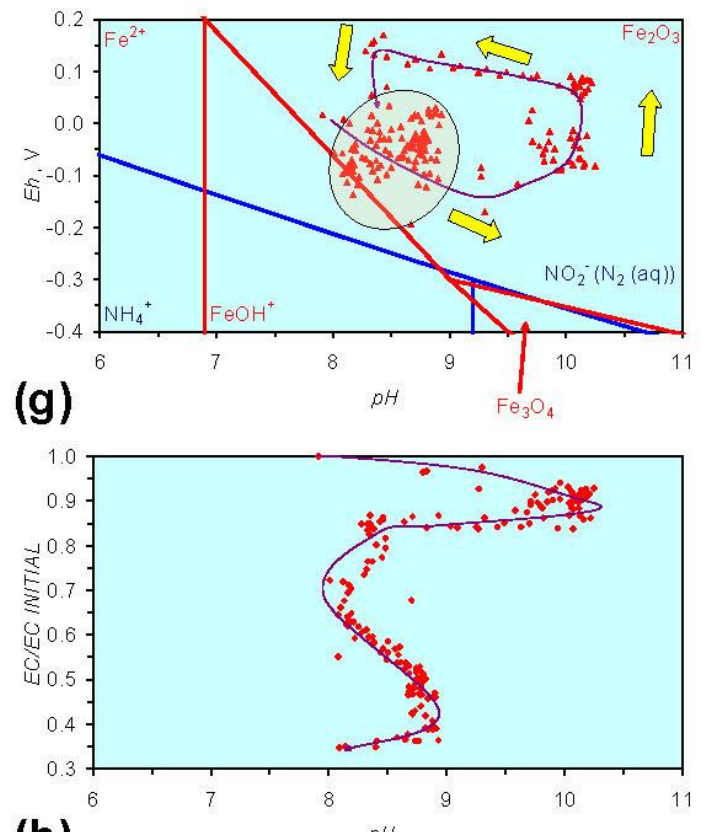

(h)

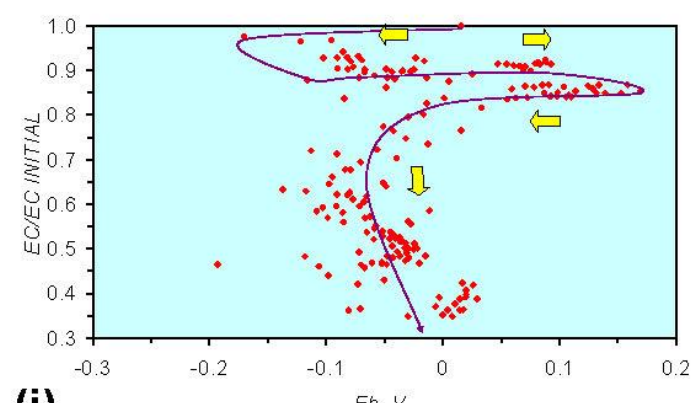

(i)

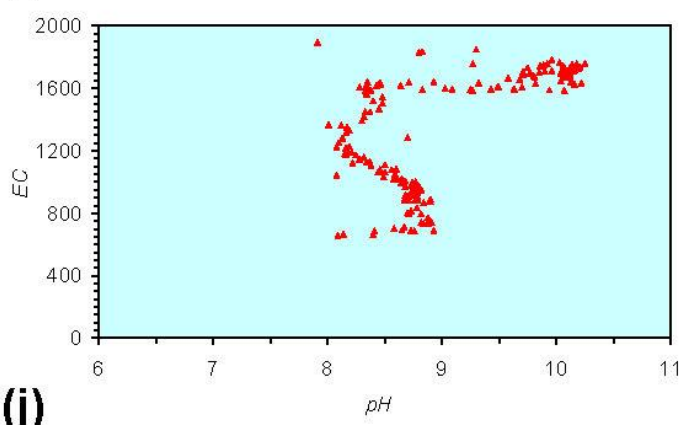


Figure A7. MR7: n-Fe ${ }^{0}$, saline water. (a) $p H$ vs. Time; (b) $p H$ vs. SV; (c) Eh vs. time; (d) Eh vs. SV; (e) EC/EC Initial vs. time; (f) EC/EC Initial vs. SV; (g) Eh vs. pH (SRE ringed); (h) $\mathrm{pH} v s$. EC/EC Initial; (i) Eh vs. EC/EC Initial; (j) $\mathrm{pH} v s . \mathrm{E}(\mathrm{C})$ Arrows indicate decreasing SV and increasing tim(e).

(a)
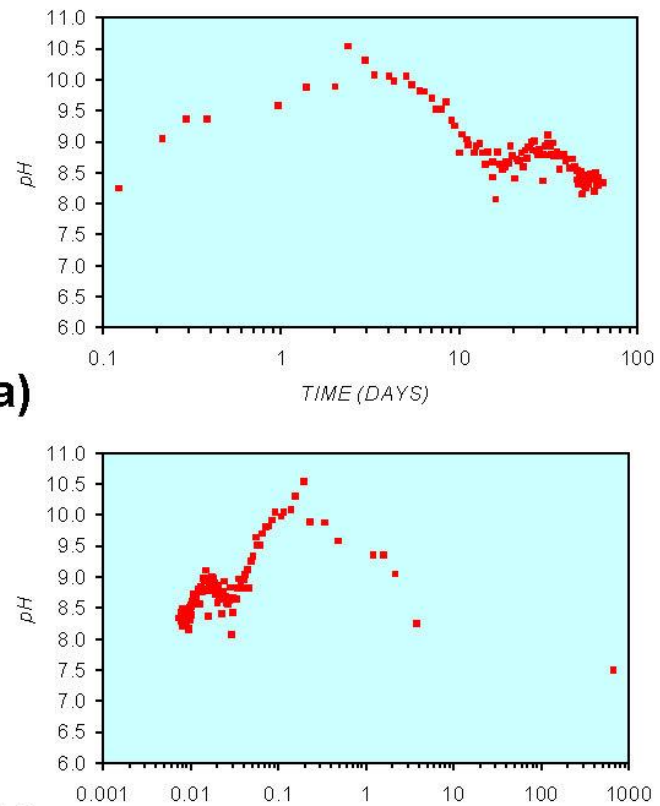

(b)

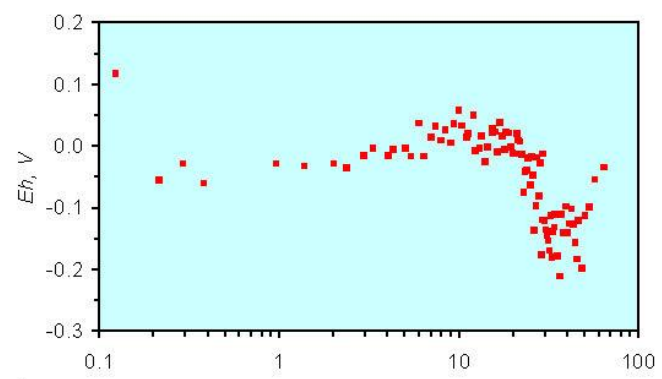

(c)

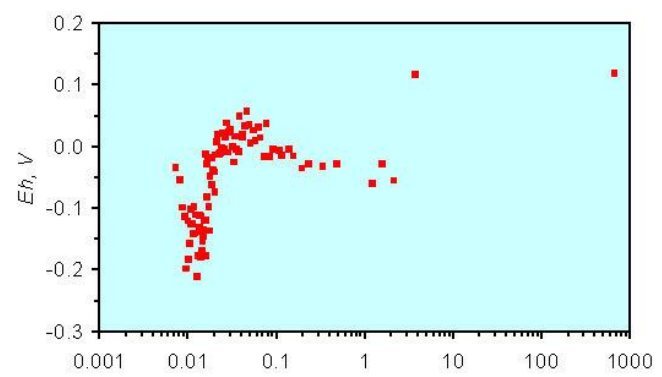

(d)

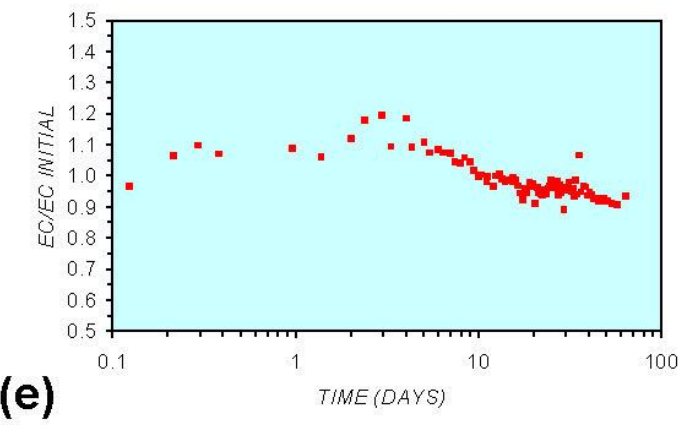

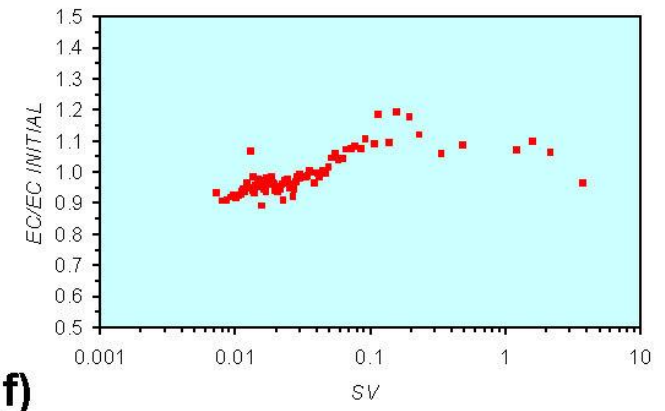
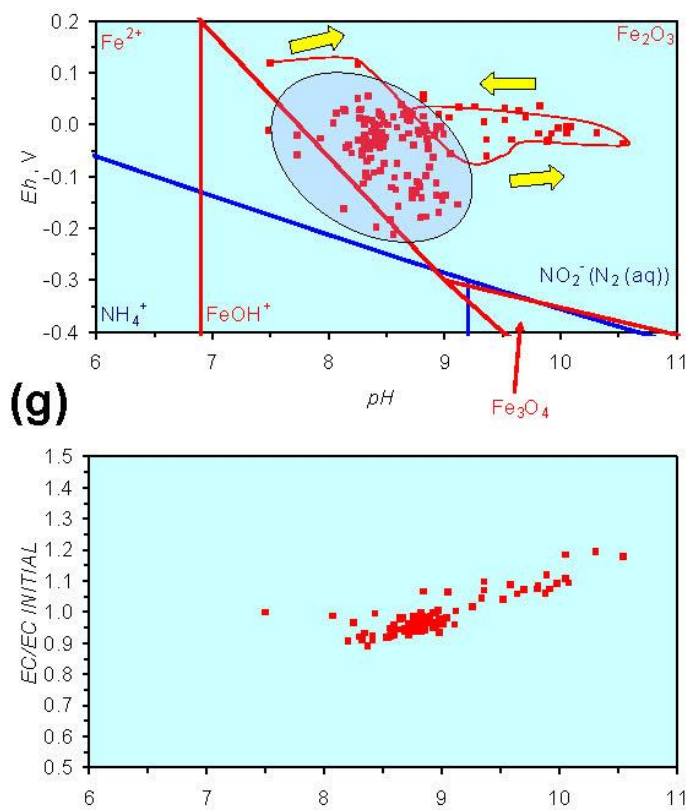

(h)
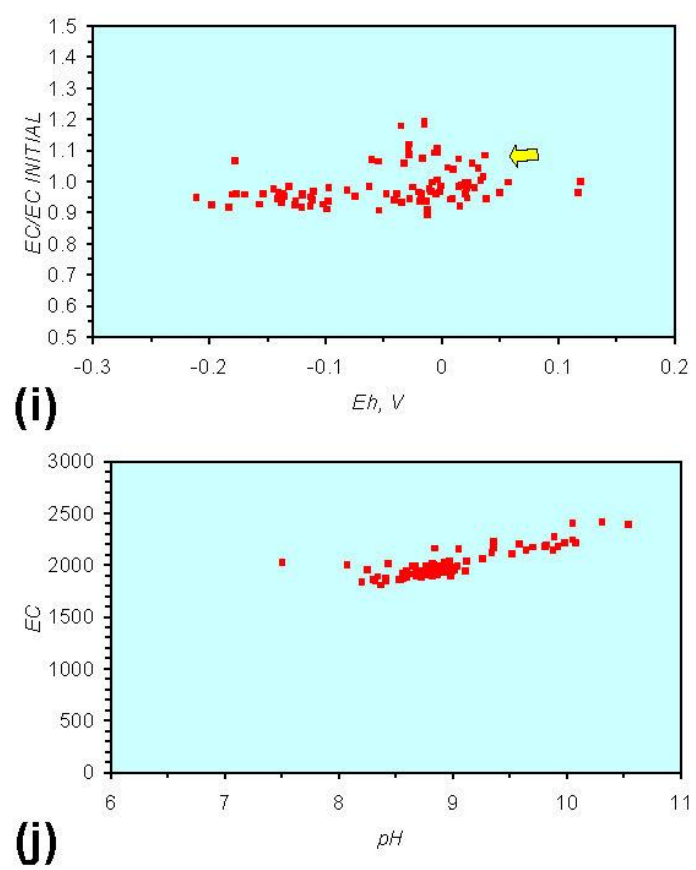
Figure A8. MR8: $\mathrm{n}-\mathrm{Fe}^{0}+\mathrm{n}-\mathrm{Cu}^{0}+\mathrm{n}-\mathrm{Al}^{0}$, saline water. (a) $p H$ vs. Time; (b) $p H$ vs. SV; (c) Eh vs. time; (d) Eh vs. SV; (e) EC/EC Initial vs. time; (f) EC/EC Initial vs. SV; (g) Eh vs. $\mathrm{pH}$ (SRE ringed); (h) $\mathrm{pH} v s$. EC/EC Initial; (i) Eh $v s$. EC/EC Initial; (j) $\mathrm{pH} v s . \mathrm{E}(\mathrm{C})$ Arrows indicate decreasing SV and increasing tim(e).

(a)

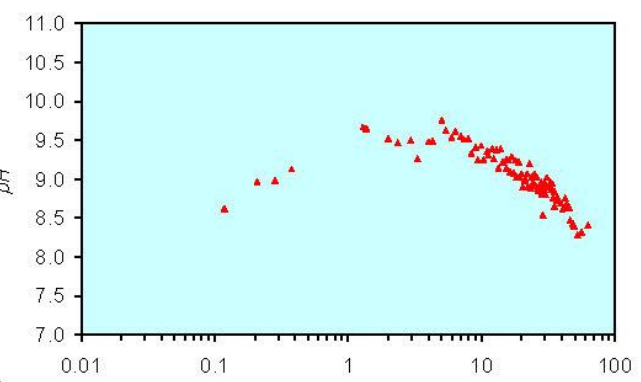

(b)
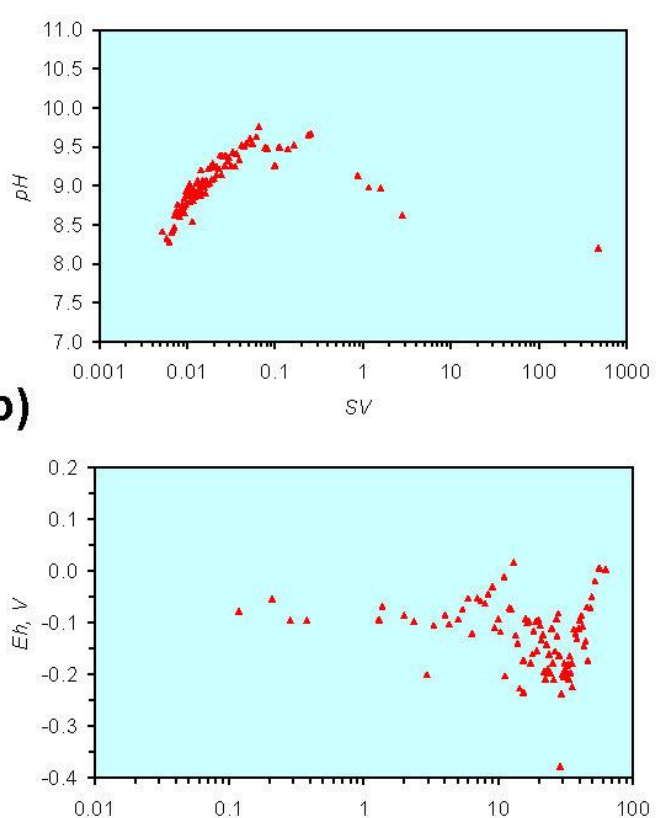

(c)

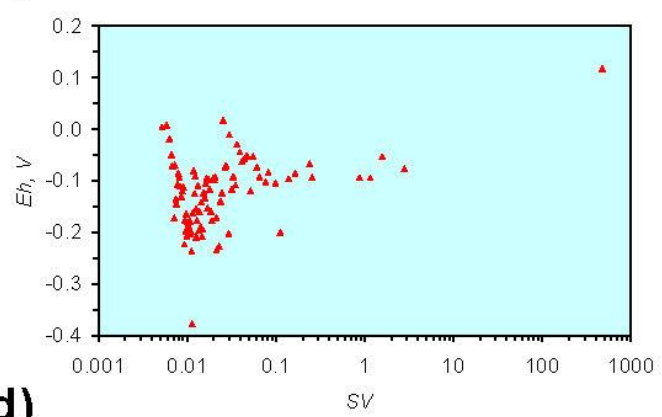

(d)

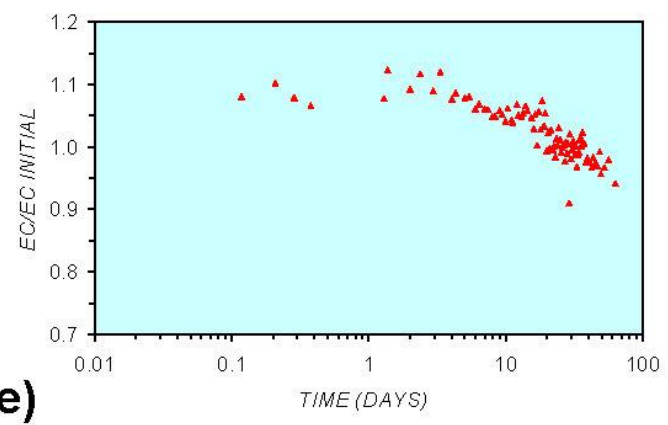

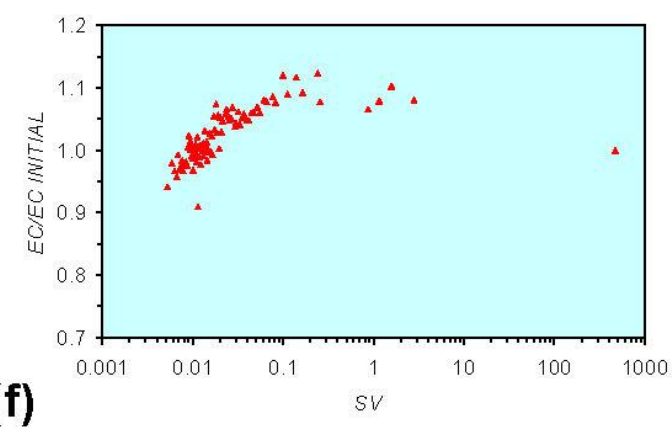
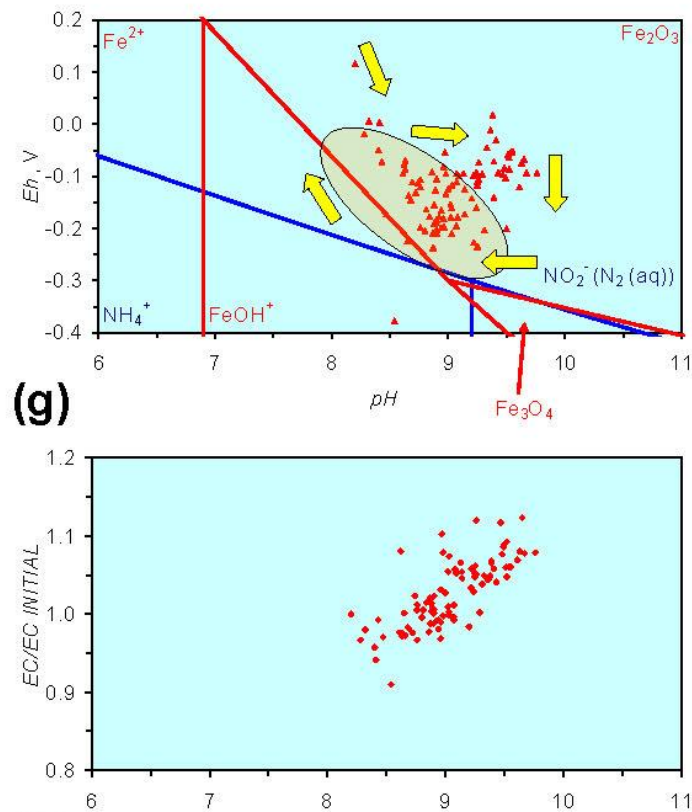

(h)
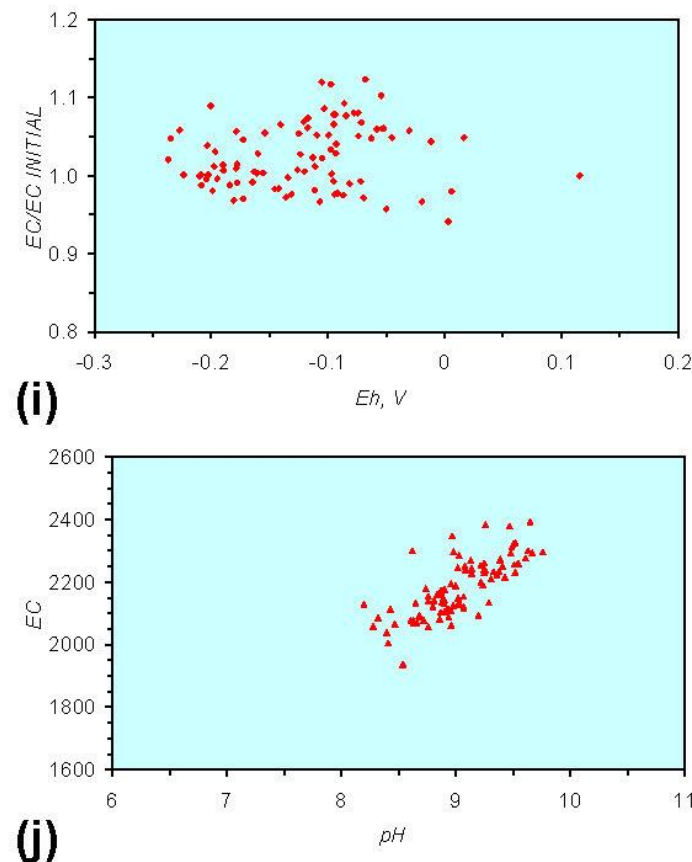
Figure A9. MR9: Ca-montmorillonite, fresh water. (a) $p H$ vs. Time; (b) Eh vs. time; (c) EC/EC Initial vs. time; (d) Eh vs. $\mathrm{pH}$ (SRE ringed); (e) $\mathrm{pH} v s$. EC/EC Initial; (f) Eh vs. EC/EC Initial; (g) pH vs. E(C) Arrows indicate decreasing SV and increasing tim(e).
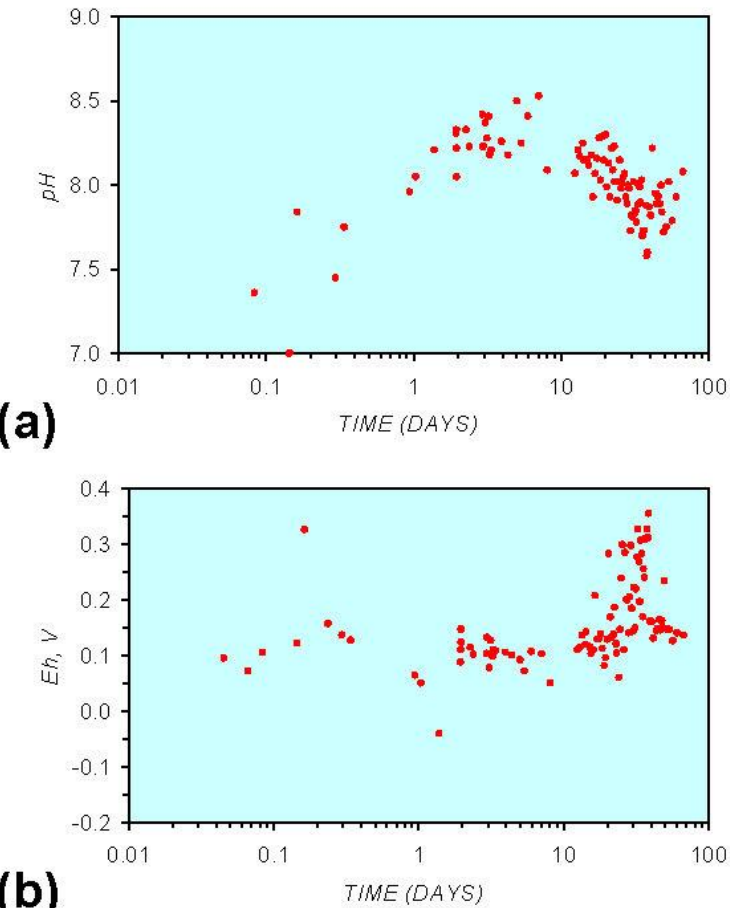

(b)
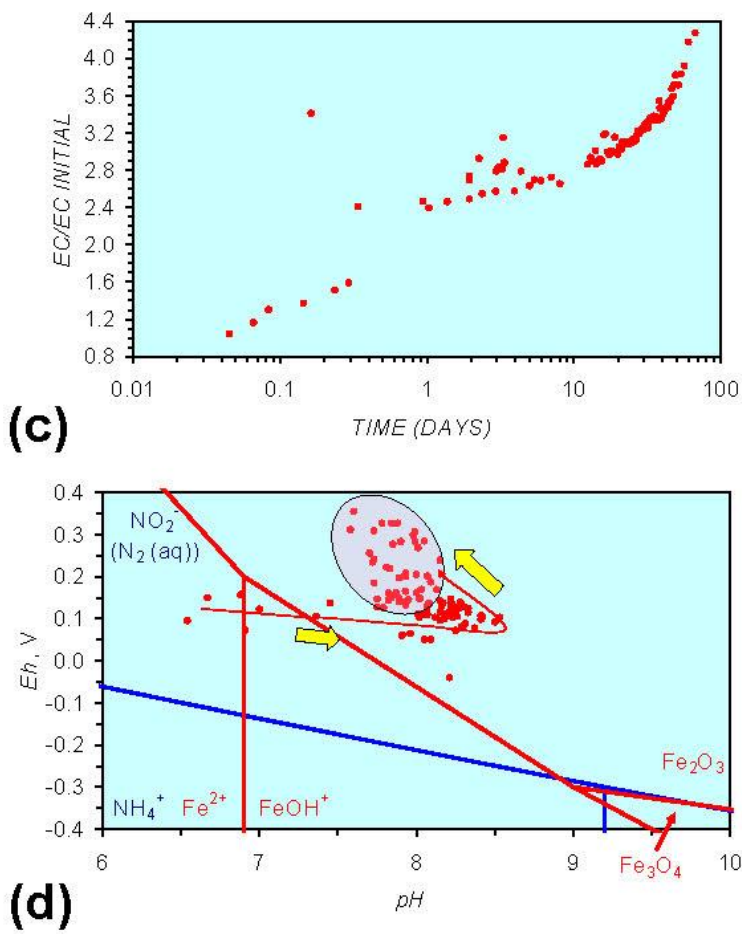

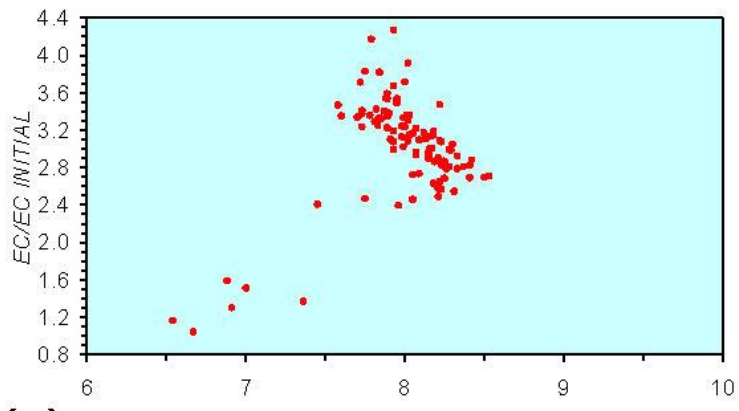

(e)

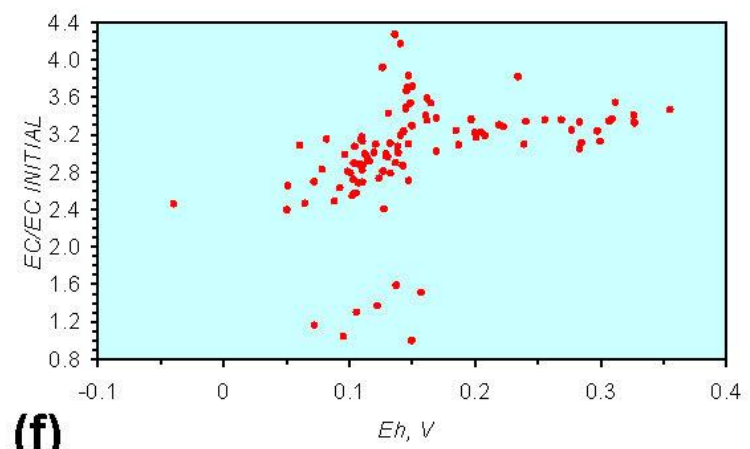

(f)

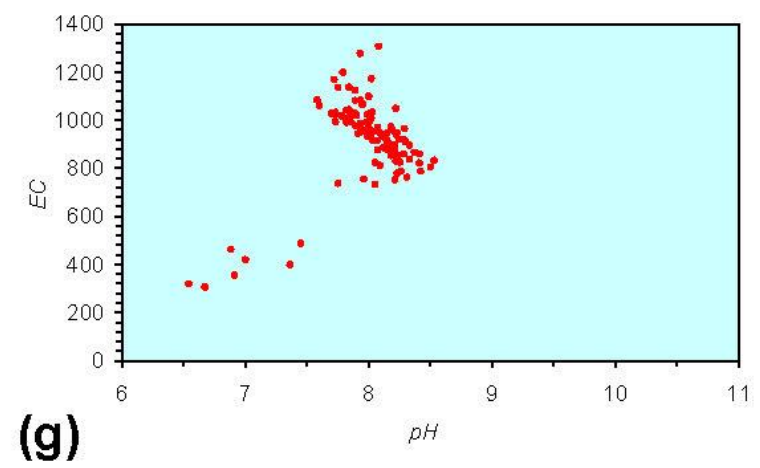


Figure A10. MR10: Ca-montmorillonite $+\mathrm{n}-\mathrm{Fe}^{0}$, fresh water. (a) $p H$ vs. Time; (b) $p H v s$. $\mathrm{SV}$; (c) Eh vs. time; (d) Eh vs. SV; (e) EC/EC Initial vs. time; (f) EC/EC Initial vs. SV; (g) Eh vs. pH (SRE ringed); (h) $\mathrm{pH} v s$. EC/EC Initial; (i) Eh vs. EC/EC Initial; (j) pH vs. $\mathrm{E}(\mathrm{C})$ Arrows indicate decreasing SV and increasing tim(e).

(a)
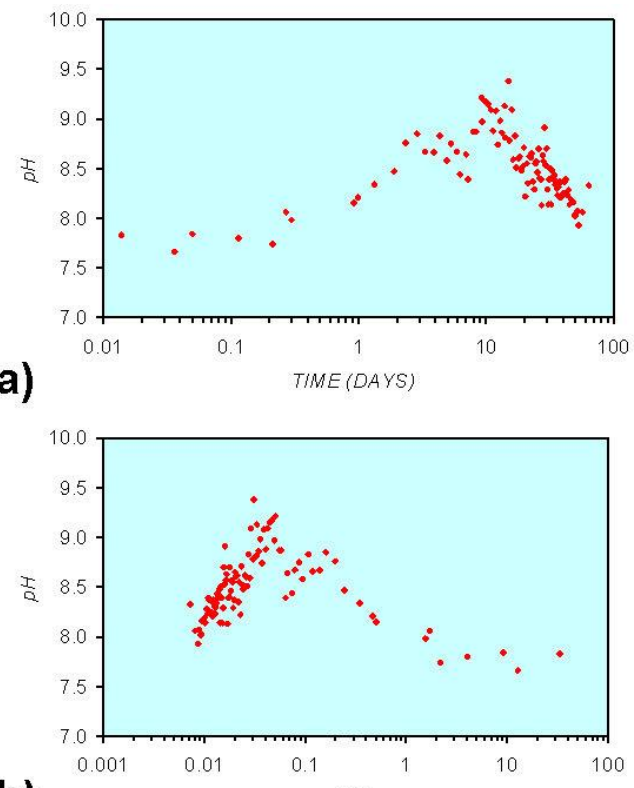

(b)

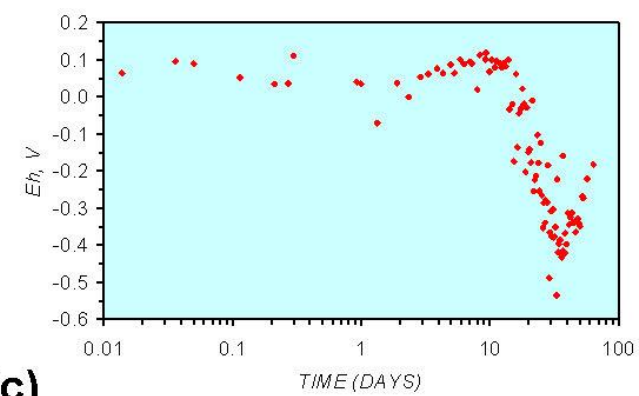

(c)

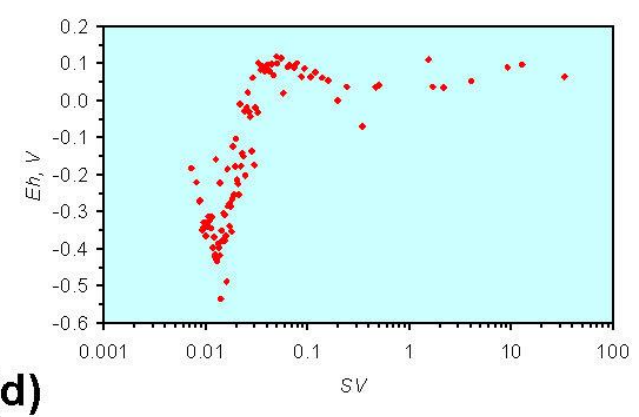

(d)

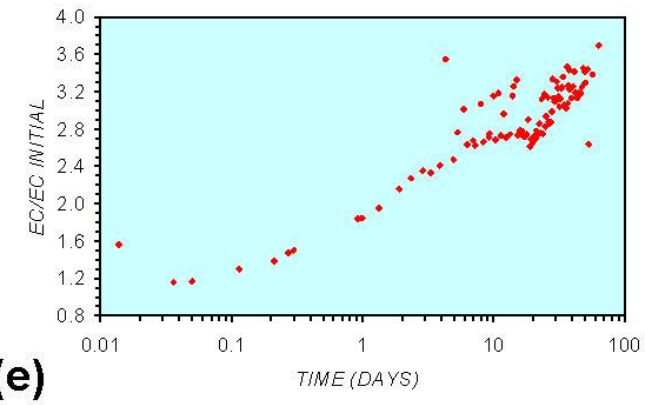

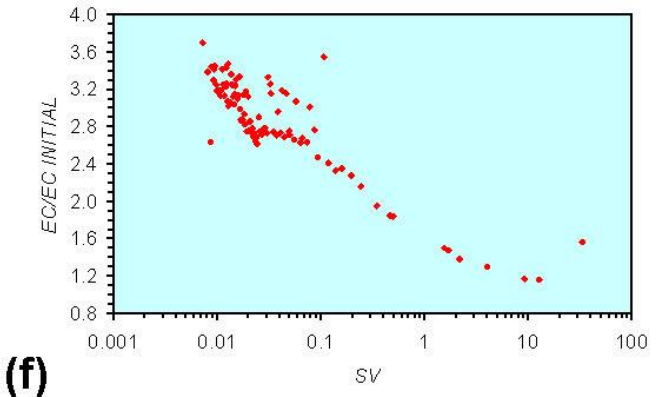

(f)

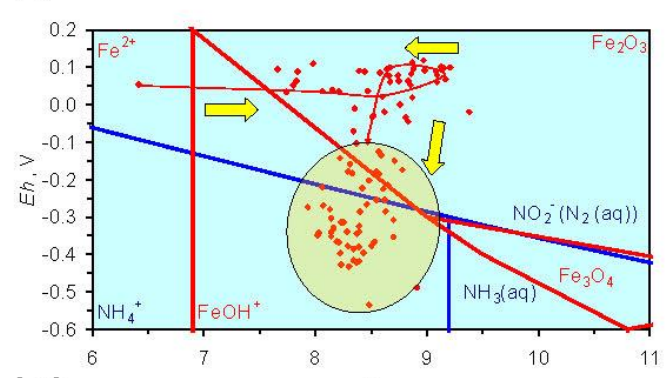

(g)

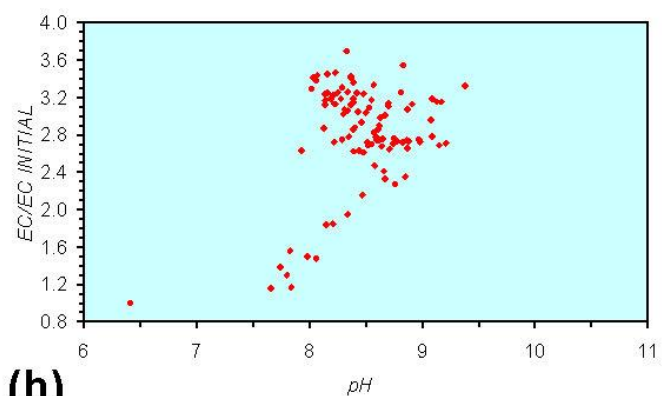

(h)
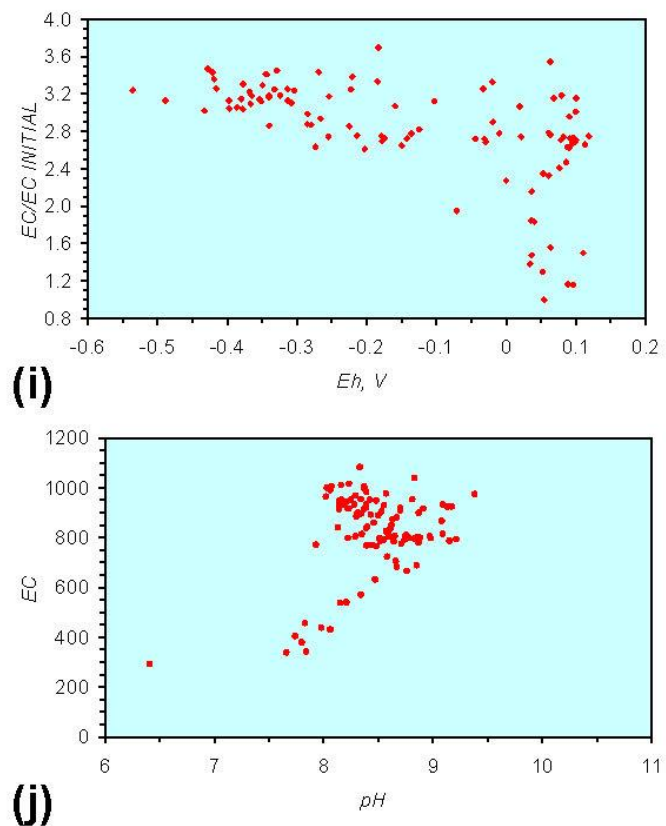
Figure A11. MR11: Ca-montmorillonite $+\mathrm{n}-\mathrm{Fe}^{0}+\mathrm{n}-\mathrm{Cu}^{0}+\mathrm{n}-\mathrm{Al}^{0}$, fresh water. (a) $p H v s$. Time; (b) $p H$ vs. SV; (c) Eh vs. time; (d) Eh vs. SV; (e) EC/EC Initial vs. time; (f) EC/EC Initial vs. SV; (g) Eh vs. $\mathrm{pH}$ (SRE ringed); (h) $\mathrm{pH}$ vs. EC/EC Initial; (i) Eh vs. EC/EC Initial; (j) $\mathrm{pH} v s$. $\mathrm{E}(\mathrm{C})$ Arrows indicate decreasing $\mathrm{SV}$ and increasing tim(e).

(a)
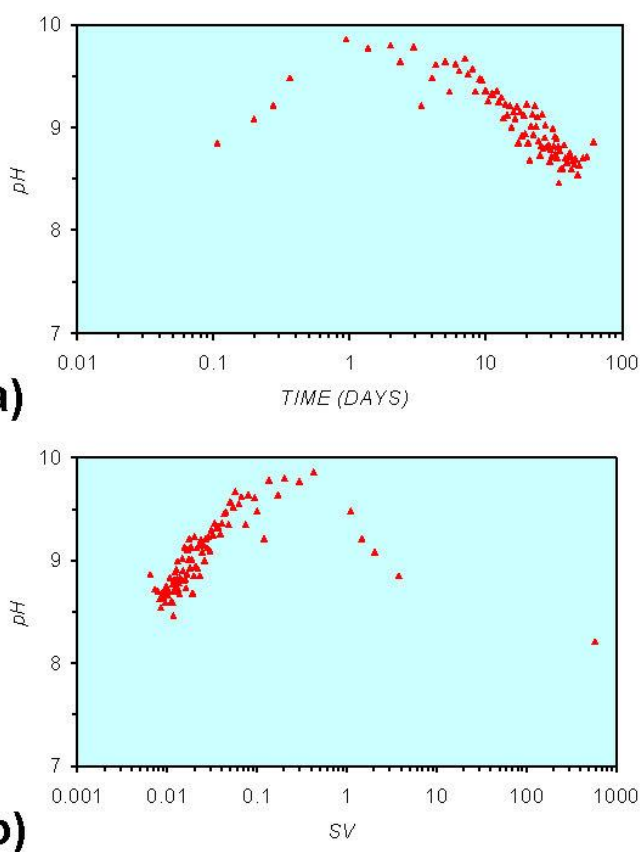

(c)
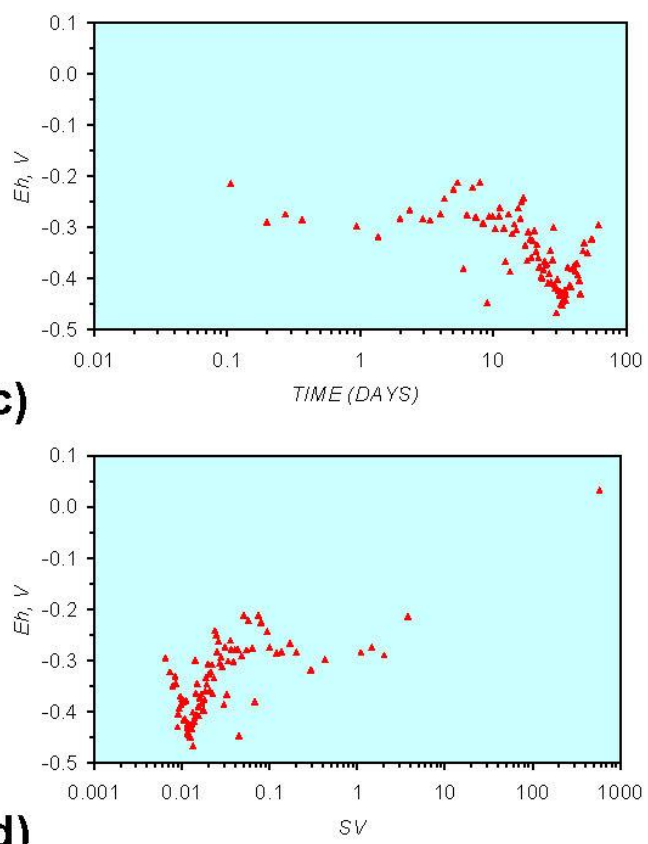

(d)

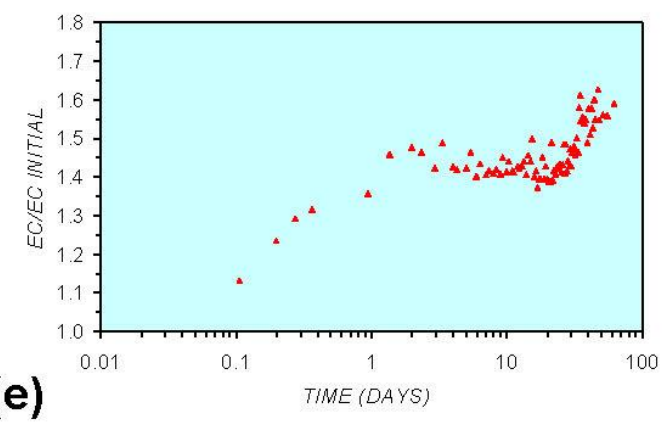

(f)
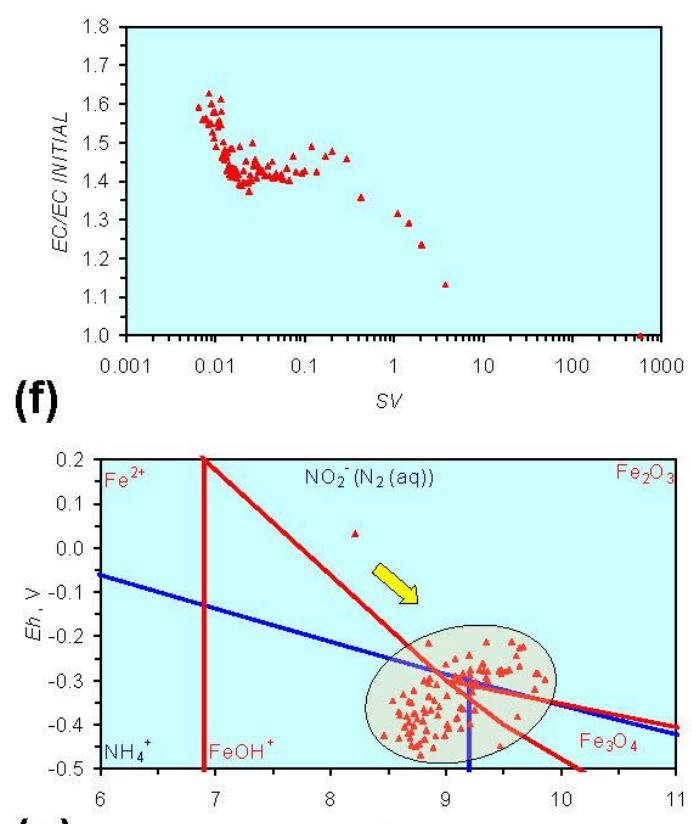

(g)

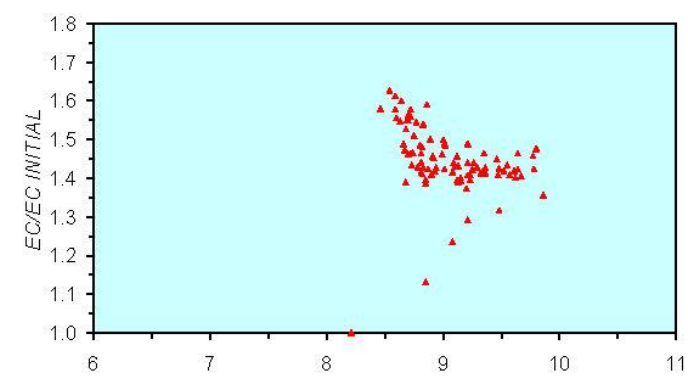

(h)
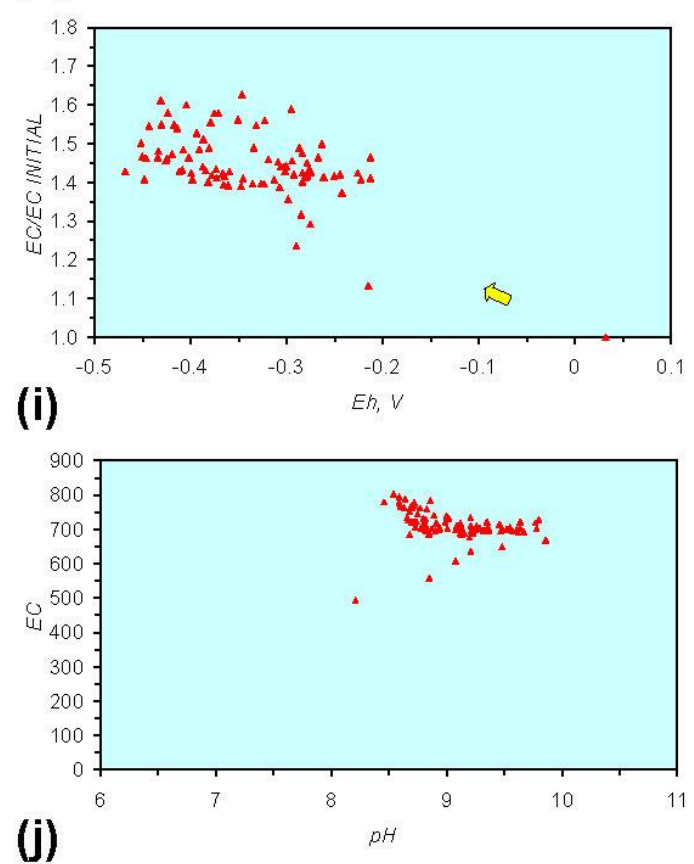
Figure A12. MR12: Ca-montmorillonite, saline water. (a) $p H$ vs. Time; (b) Eh vs. time; (c) EC/EC Initial vs. time; (d) Eh vs. $\mathrm{pH}$ (SRE ringed); (e) $\mathrm{pH} v s$. EC/EC Initial; (f) Eh $v s$. EC/EC Initial; Arrows indicate decreasing SV and increasing tim(e).

(a)
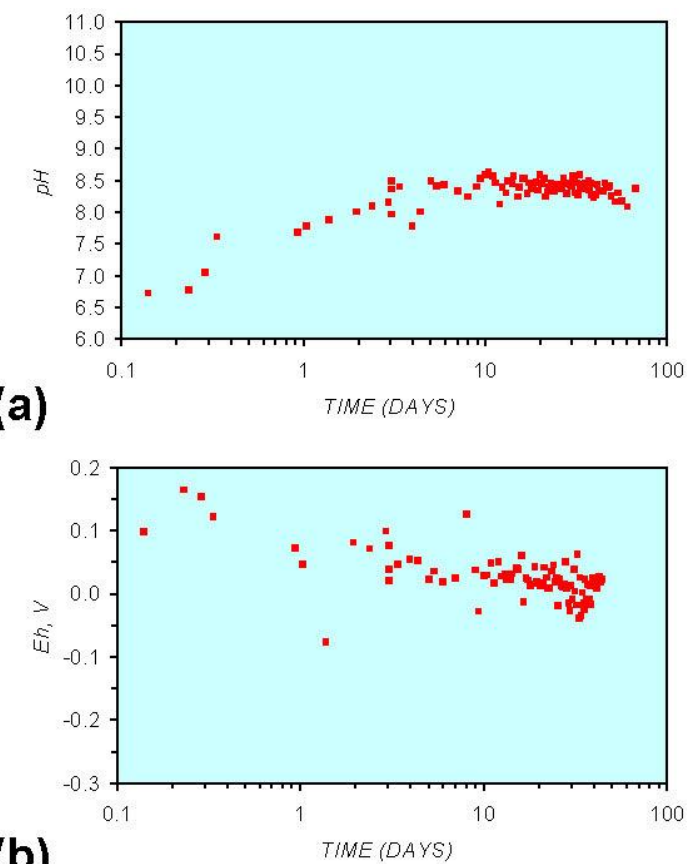

(b)

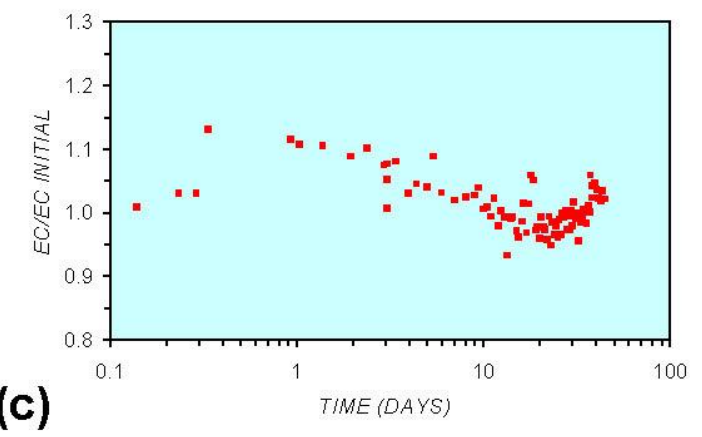

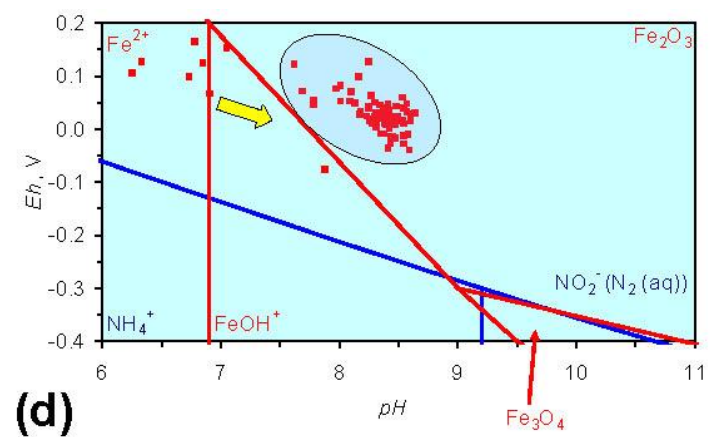

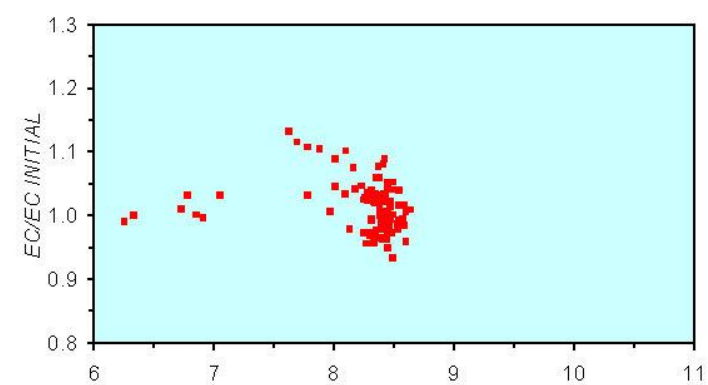

(e)

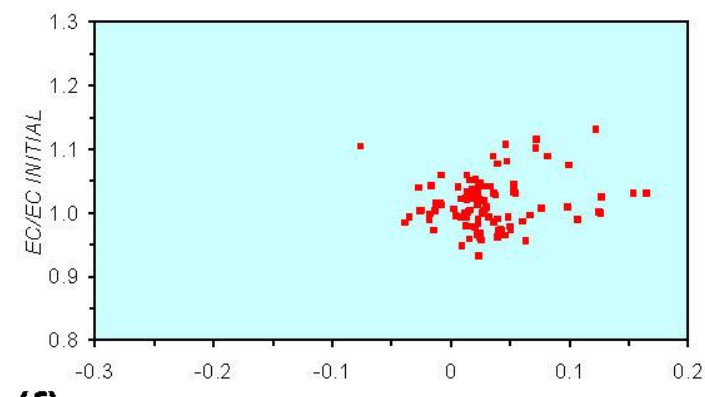

(f) 
Figure A13. MR13: Ca-montmorillonite $+\mathrm{n}-\mathrm{Fe}^{0}$, saline water. (a) $p H v s$. Time; (b) $p H v s$. $\mathrm{SV}$; (c) Eh vs. time; (d) Eh vs. SV; (e) EC/EC Initial vs. time; (f) EC/EC Initial vs. SV; (g) Eh vs. pH (SRE ringed); (h) pH vs. EC/EC Initial; (i) Eh vs. EC/EC Initial; (j) pH vs. $\mathrm{E}(\mathrm{C})$ Arrows indicate decreasing SV and increasing tim(e).

(a)
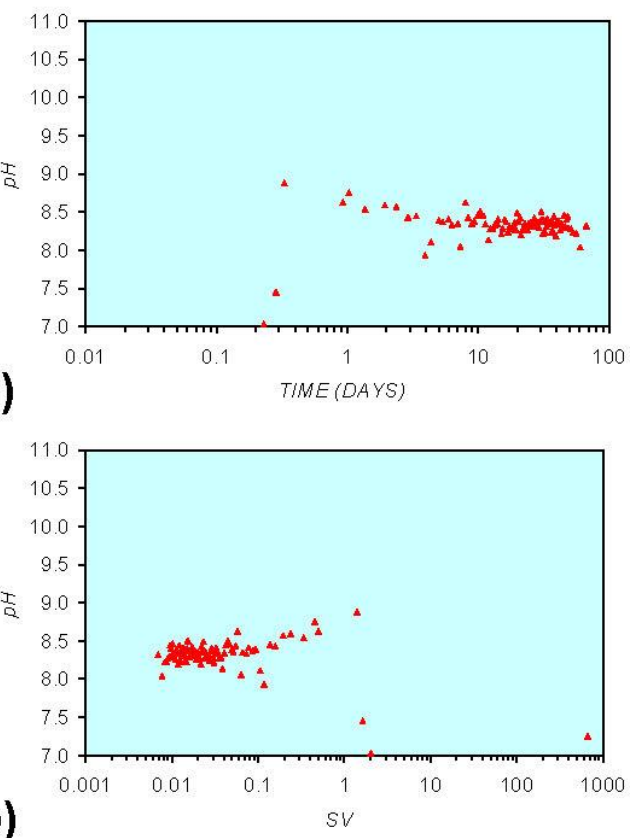

(c)
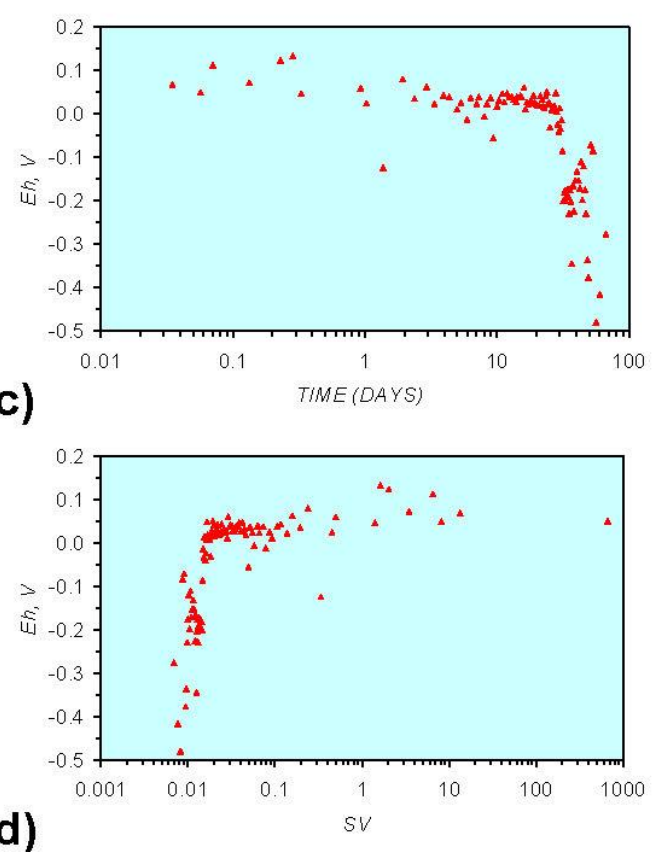

(d)

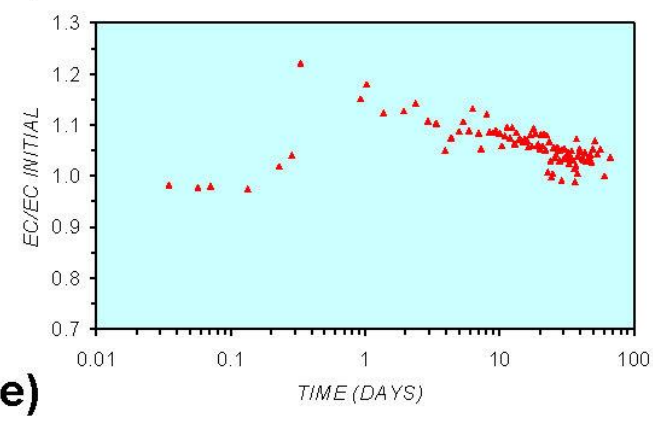

(f)
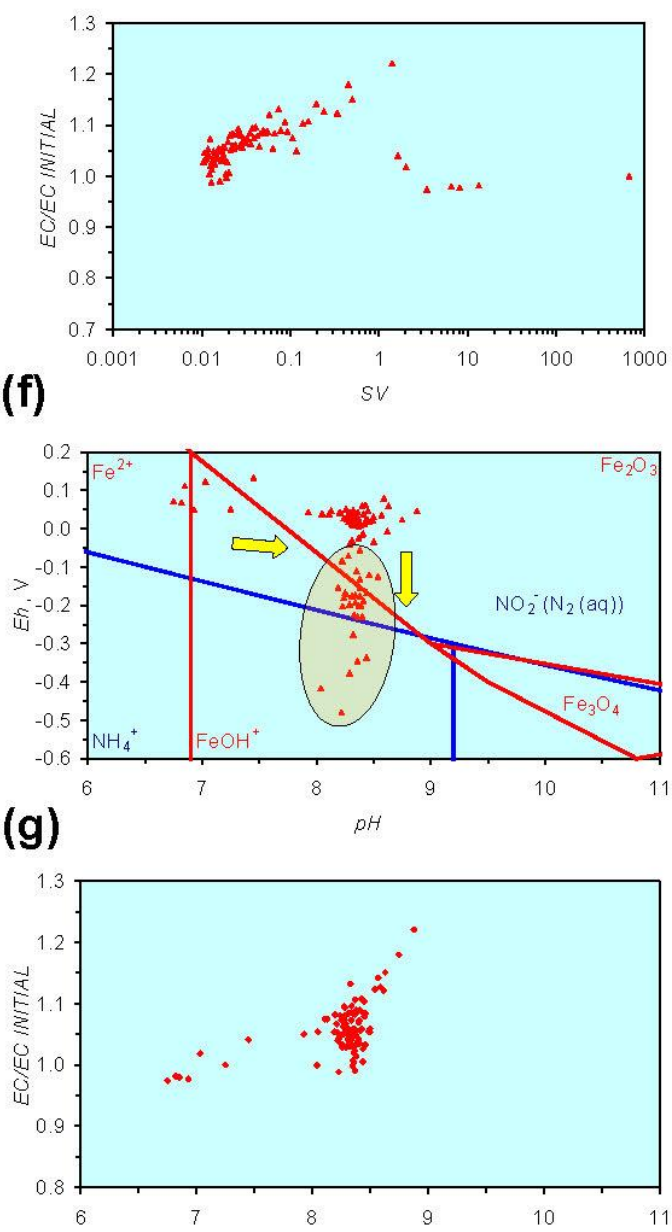

(h)

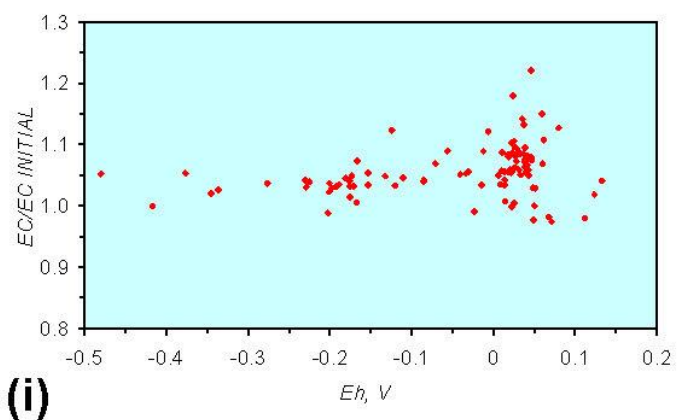

(i)

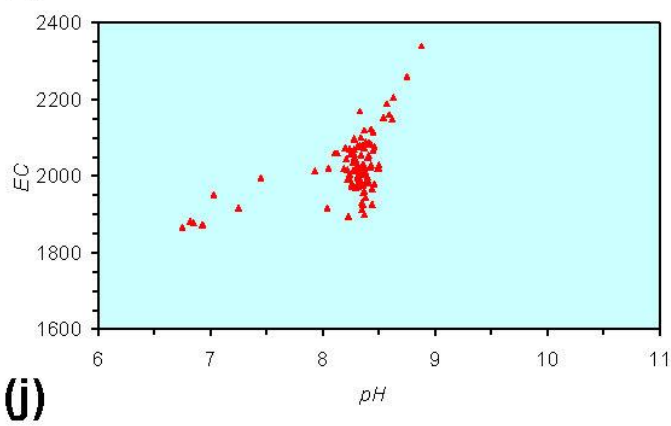


Figure A14. MR14: Ca-montmorillonite $+\mathrm{n}-\mathrm{Fe}^{0}+\mathrm{n}-\mathrm{Cu}^{0}$, saline water. (a) $p H$ vs. Time; (b) $p H$ vs. SV; (c) Eh vs. time; (d) Eh vs. SV; (e) EC/EC Initial vs. time; (f) EC/EC Initial vs. SV; (g) Eh vs. $\mathrm{p}(\mathrm{H})$ The redox trajectory ends in an SRE with a stable $\mathrm{pH}$ and decreasing Eh with time; (h) $\mathrm{pH} v s$. EC/EC Initial; (i) Eh vs. EC/EC Initial; (j) $\mathrm{pH} v s . \mathrm{E}(\mathrm{C})$ Arrows indicate decreasing SV and increasing tim(e).

(a)

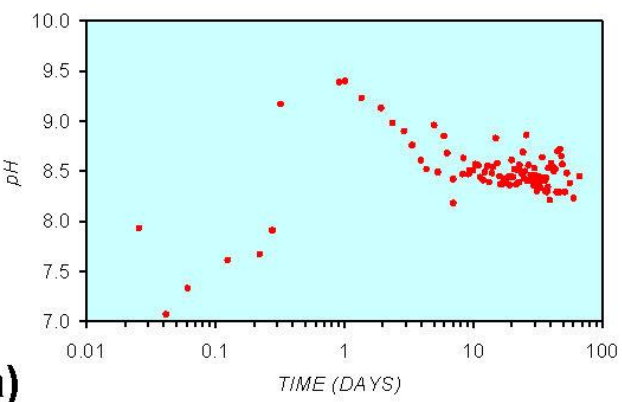

(b)
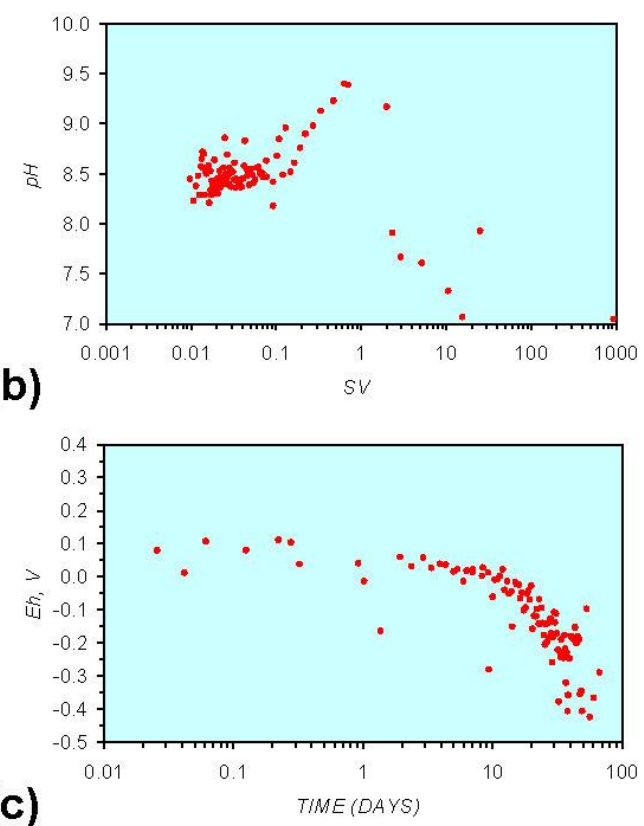

(d)
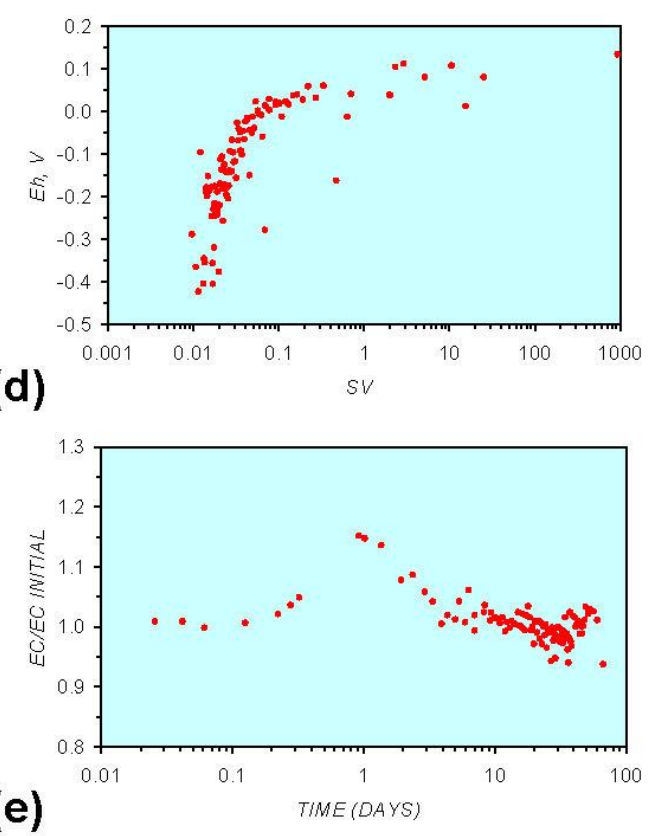
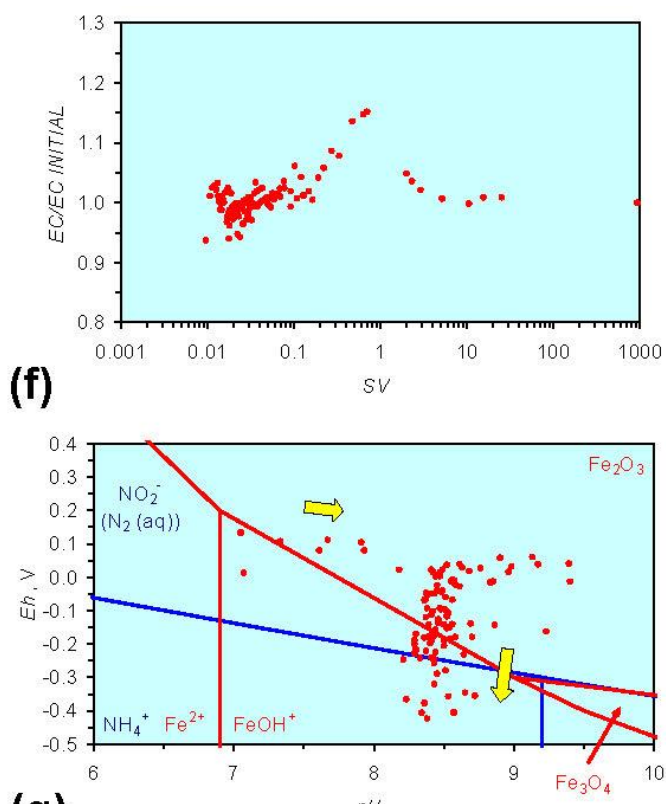

(g)
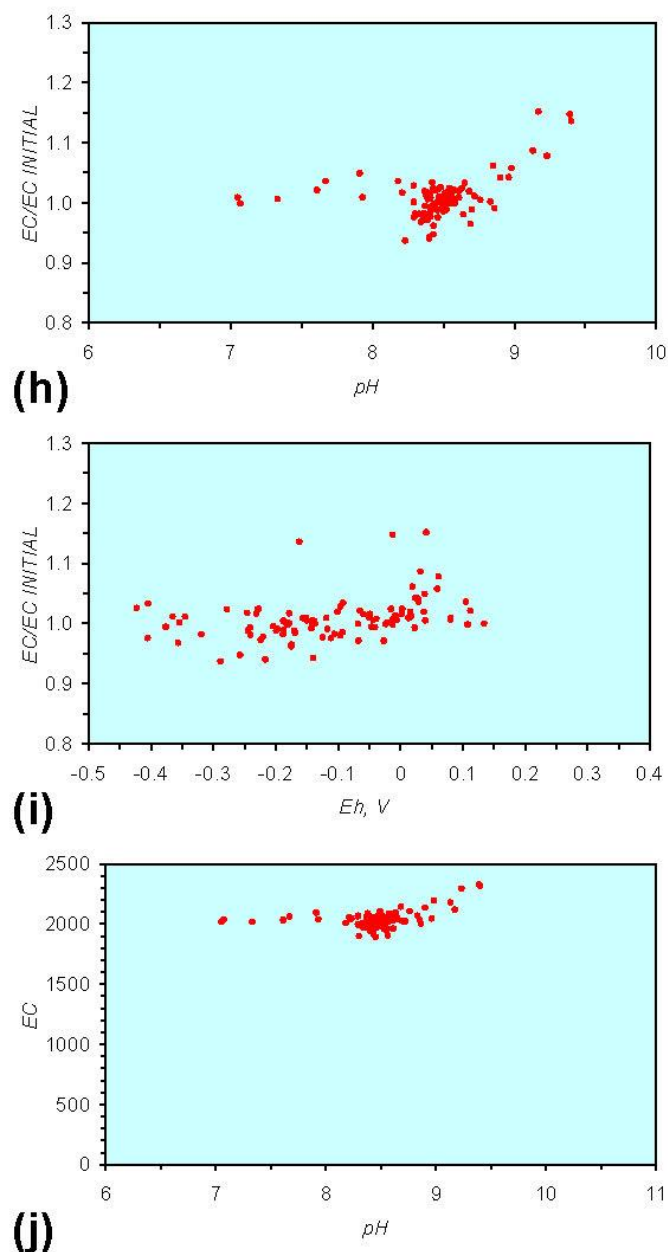
Figure A15. MR15: Ca-montmorillonite $+\mathrm{n}-\mathrm{Fe}^{0}+\mathrm{n}-\mathrm{Al}^{0}$, saline water. (a) $p H$ vs. Time; (b) $p H$ vs. SV; (c) Eh vs. time; (d) Eh vs. SV; (e) EC/EC Initial vs. time; (f) EC/EC Initial vs. SV; (g) Eh vs. pH (SRE ringed); (h) pH vs. EC/EC Initial; (i) Eh vs. EC/EC Initial; (j) $\mathrm{pH} v s . \mathrm{E}(\mathrm{C})$ Arrows indicate decreasing SV and increasing tim(e).

(a)
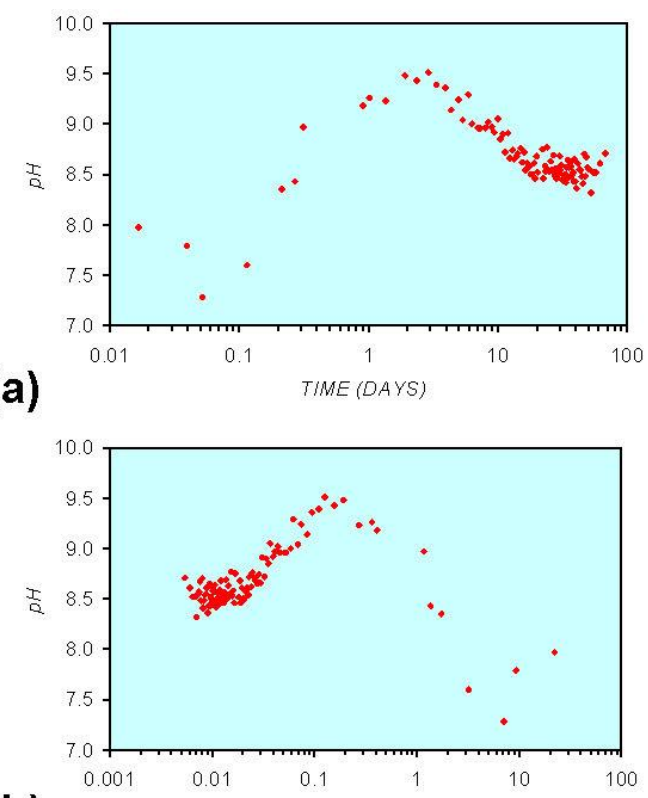

(b)

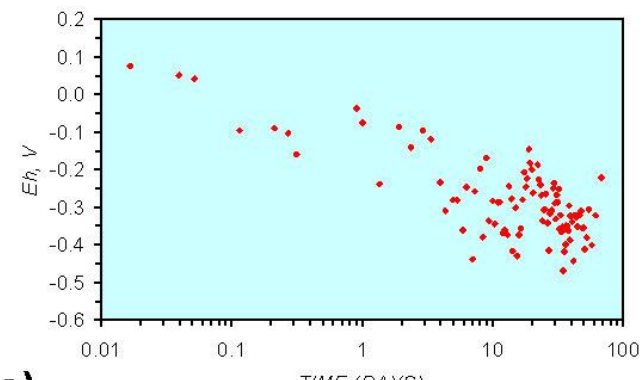

(c)

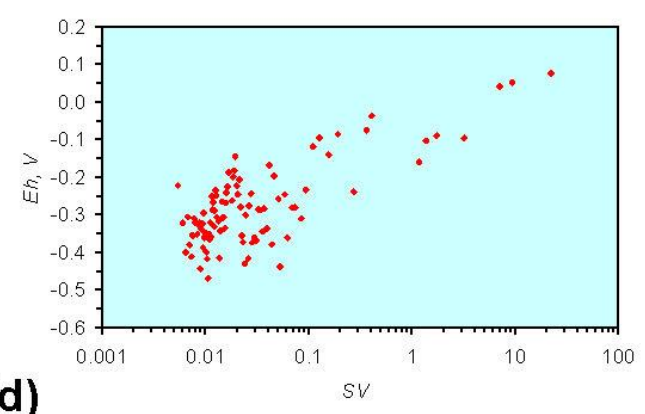

(d)

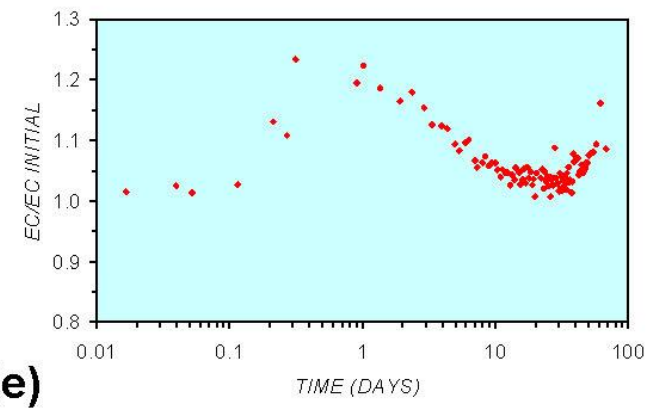

(f)
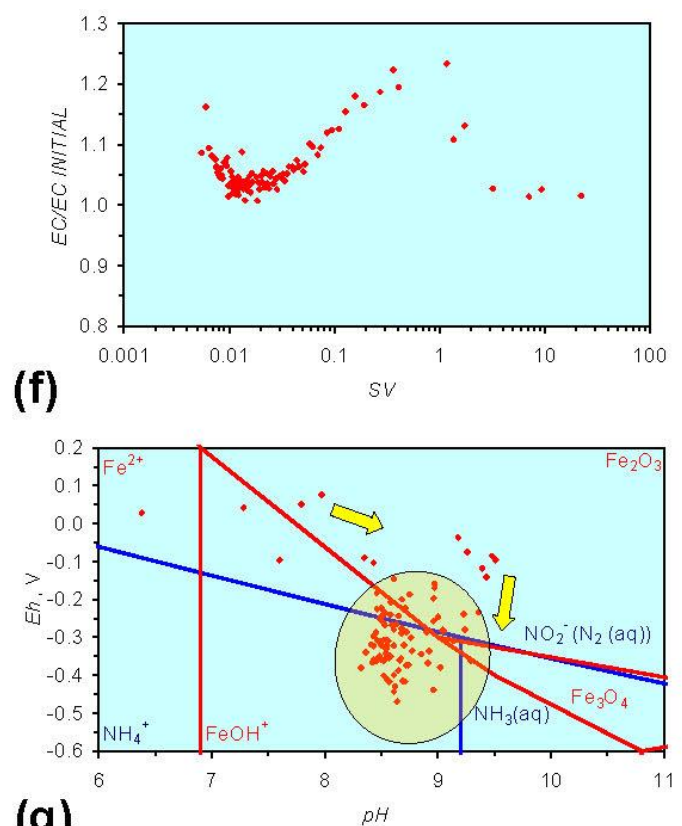

(g)

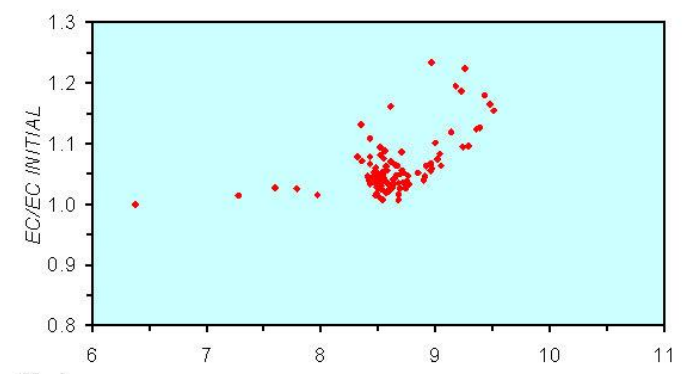

(h)
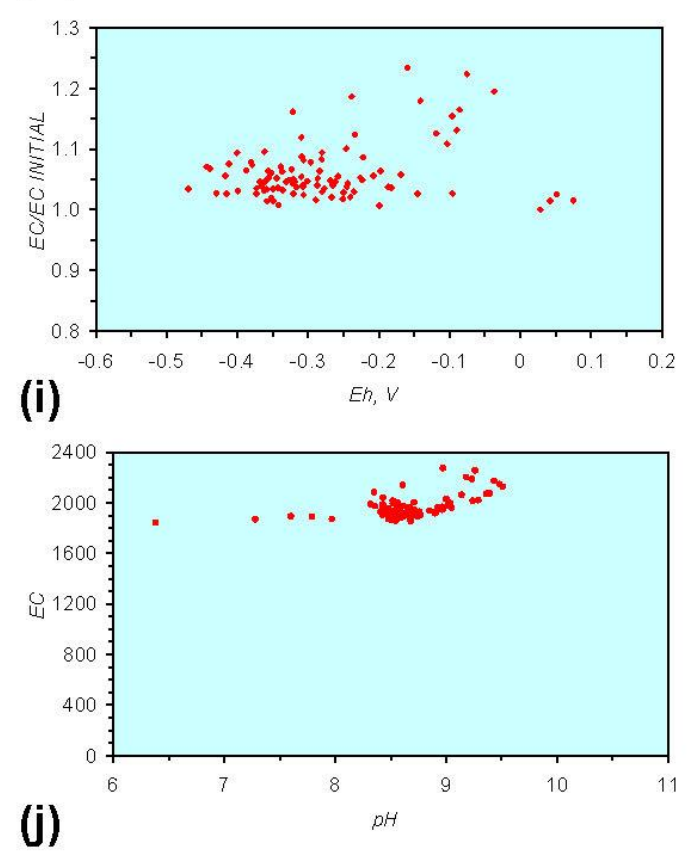
Figure A16. MR11: Ca-montmorillonite $+\mathrm{n}-\mathrm{Fe}^{0}+\mathrm{n}-\mathrm{Cu}^{0}+\mathrm{n}-\mathrm{Al}^{0}$, saline water. (a) $p H v s$. Time; (b) $p H$ vs. SV; (c) Eh vs. time; (d) Eh vs. SV; (e) EC/EC Initial vs. time; (f) EC/EC Initial vs. SV; (g) Eh vs. $\mathrm{pH}$ (SRE ringed); (h) $\mathrm{pH}$ vs. EC/EC Initial; (i) Eh vs. EC/EC Initial; (j) $\mathrm{pH} v s$. $\mathrm{E}(\mathrm{C})$ Arrows indicate decreasing $\mathrm{SV}$ and increasing tim(e).

(a)
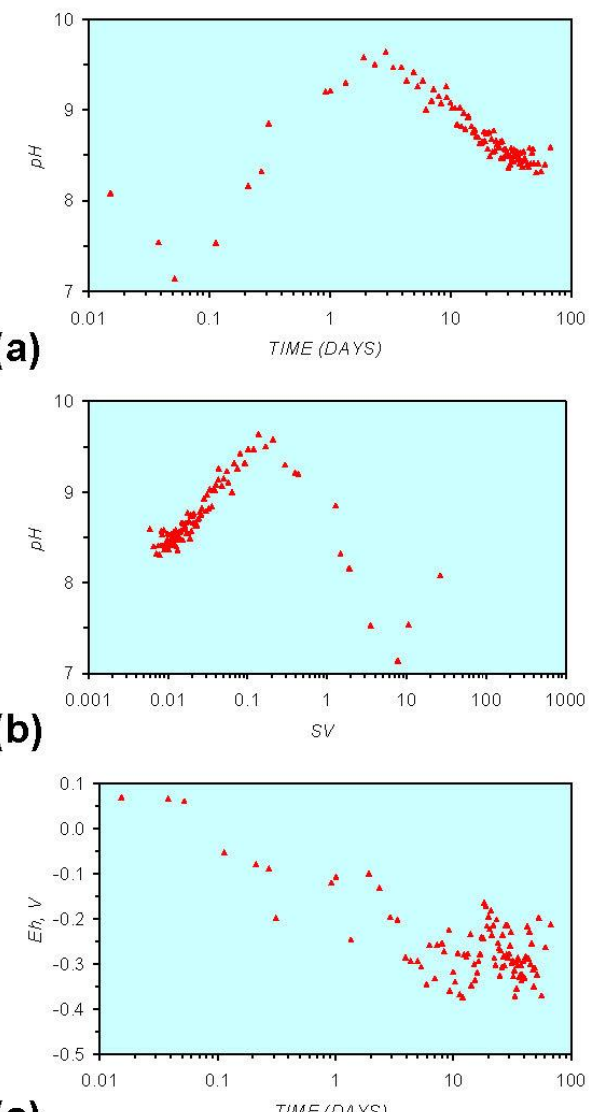

(c)

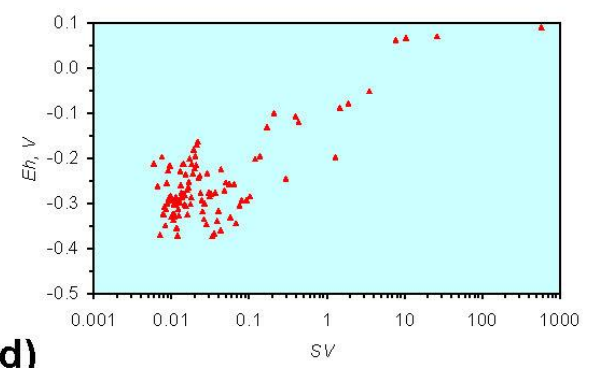

(d)

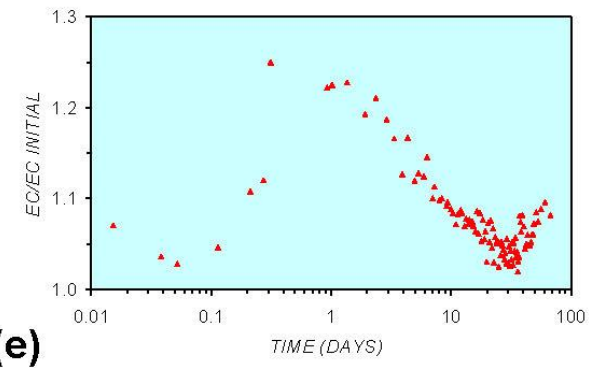

(f)
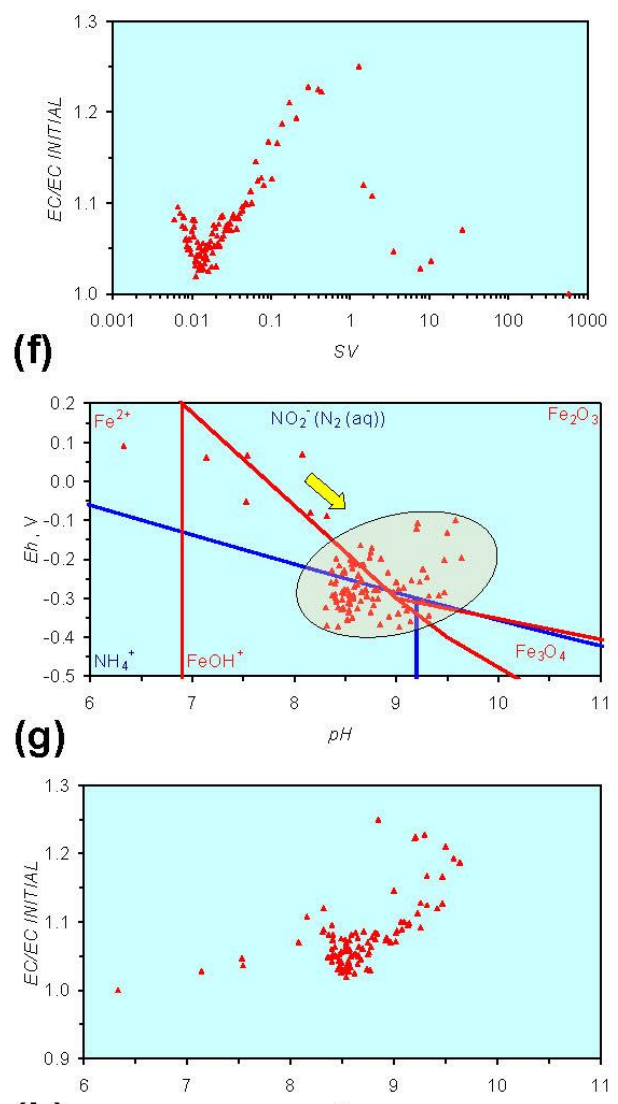

(h)
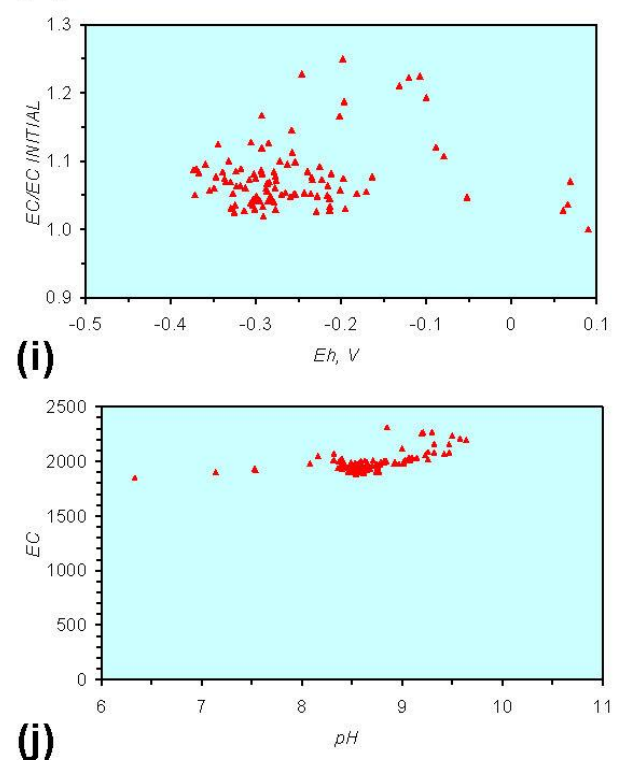

(C) 2011 by the authors; licensee MDPI, Basel, Switzerland. This article is an open access article distributed under the terms and conditions of the Creative Commons Attribution license (http://creativecommons.org/licenses/by/3.0/). 